\title{
TEACHER PREPARATION IMPACTS IN REGARD TO PHYSIOLOGICAL STRESS OF PRESERVICE EDUCATORS WITHIN AGRICULTURAL MECHANICS PROJECT CONSTRUCTION
}

\author{
A Dissertation \\ Presented to \\ The Faculty of the Graduate School \\ At the University of Missouri \\ In Partial Fulfillment \\ Of the Requirements for the Degree \\ Doctor of Philosophy
}

By

JEFFERY J REED

Dr. John Tummons, Co-dissertation Supervisor

Dr. Leon G. Schumacher, Co-dissertation Supervisor

MAY 2021 
The undersigned, appointed by the dean of the Graduate School, have examined the Dissertation entitled

Teacher Preparation Impacts in Regard to Physiological Stress of Preservice Educators within Agricultural Mechanics Project Construction

Presented by Jeffery J. Reed

A candidate for the degree of

Doctor of Philosophy

And hereby certify that, in their opinion, it is worthy of acceptance.

Dr. John Tummons

Dr. Leon G. Schumacher

Dr. Jon C. Simonsen

Dr. Rebecca Mott 


\section{Dedication}

To my wife Andrea and son Jasper. Thank you for your support throughout my journey of higher education. 


\section{Acknowledgment}

Thank you to each of my committee members for urging me to finish and the support along the way on this journey.

Dr. Tummons, thank you for the continual support and the push to get me across the finish line. I will forever be grateful for your guidance and mentorship.

Dr. Schumacher, thank you for the many road trips and "opportunities" to expand my knowledge and try new experiences. 


\section{TABLE OF CONTENTS}

Acknowledgements................................................................. ii

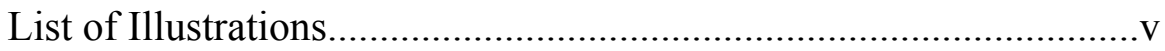

Academic Abstract.........................................................................vi

Chapter

I. INTRODUCTION ........................................................... 1

Introduction................................................................. 1

Theoretical Framework........................................................4

Statement of the Problem...................................................... 7

Purpose of the Study........................................................... 8

Research Questions......................................................... 8

Definition of Terms............................................................11

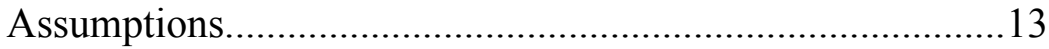

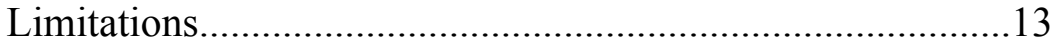

II- REVIEW OF LITERATURE.................................................. 15

Agricultural Education Foundation and Mechanics Preparation...15

Agricultural mechanics provides beneficial education to students however it is a complex task for educators to teach ...16

Agricultural mechanics is viewed as a dangerous portion of agricultural education ...19

Agricultural mechanics education is deficient within teacher preparation programs ...21

Agricultural educators are at a shortage ...24

Agricultural education is stressful and has long term health impacts on educators ...25

Agricultural mechanics teaching and stress ...26

Teacher burnout is attributed to the stress cycle and the resiliency or lack thereof within educators ...27

Stress cycle ...31

Resiliency ...34

Conclusions ...36

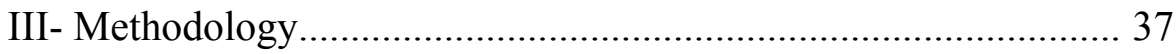

Purpose of the Study...................................................... 37

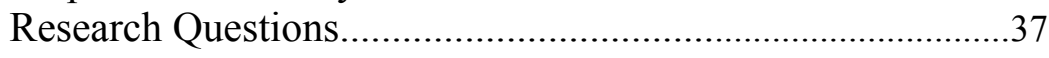

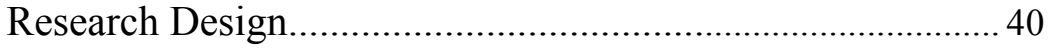

Population and Sample.....................................................42 


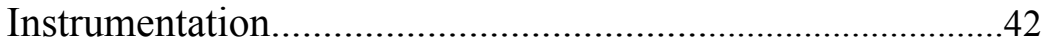

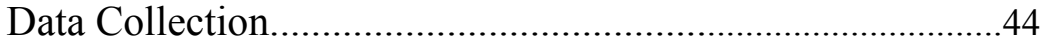

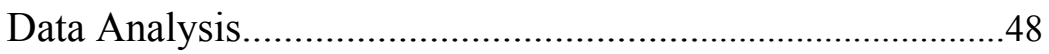

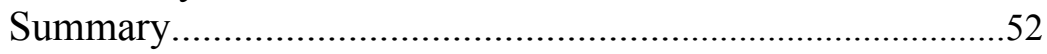

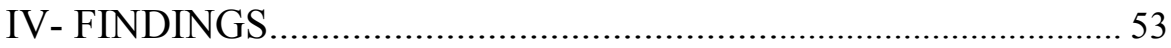

Purpose of the Study.......................................................... 53

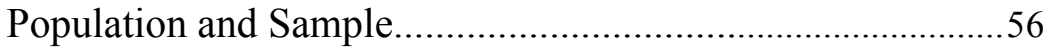

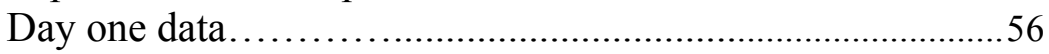

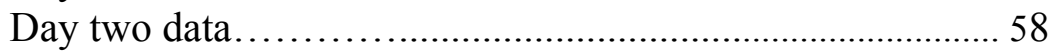

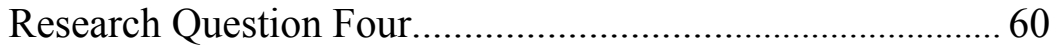

V- Summary, Conclusions, Implications, and Recommendations.... 67

Summary of Inquiry

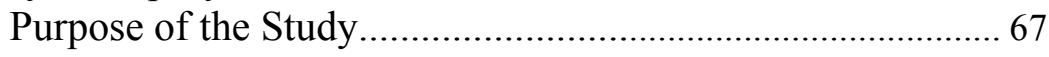

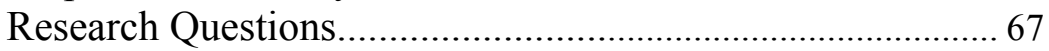

Limitations of the Study..................................................... 70

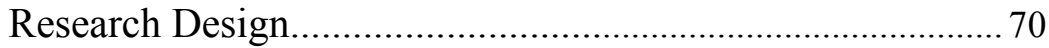

Population and Sample........................................................ 70

Instrumentation............................................................... 72

Data Collection.................................................................... 73

Summary of Findings, Conclusions, and Implications

Research Question One................................................. 77

Research Question Two..................................................... 82

Research Question Three............................................... 84

Research Question Four............................................... 88

Recommendations for Practice...................................................... 94

Recommendations for Future Research....................................... 96

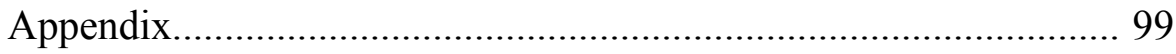

A. Course Syllabus............................................................. 99

B. Project Evaluation Scoring Guide................................. 107

C. Student Evaluation of Teacher Effectiveness Questionnaire..109

D. Participant Journal.................................................. 110

E. Student Consent Form........................................................ 111

F. Recruitment Letter..................................................... 113

G. SAS Outputs......................................................... 114

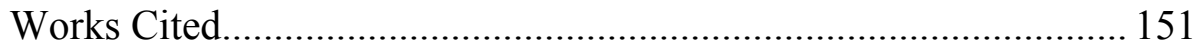

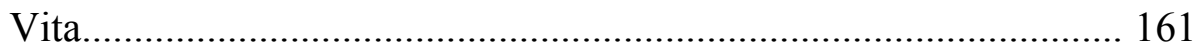

\section{List of Illustrations}


Figure

1.1 Model of Lazarus's Theory of Psychological Stress................ 6

2.1 General model organizational determinants of burnout........... 30

2.2 Model of Lazarus's Theory of Psychological Stress.................. 33

3.1 Research Design........................................................................ 46

Table

4.1 Teacher Heart Rate Information Day 1 ..........................5 56

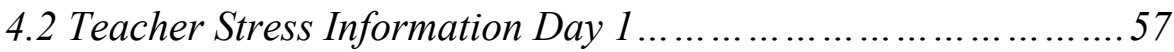

4.3 Teacher Effectiveness Information Day 1 ........................ 57

4.4 Teacher Heart Rate Information Day 2 ..........................58

4.5 Teacher Stress Information Day 2 ............................... 59

4.6 Teacher Effectiveness Information Day 2 .......................... 59

4.7 Analysis of Variance Summary Table for Teaching Delivery.... 60

4.8 Analysis of Variance Summary Table for Learning Environment ...61

4.9 Analysis of Variance Summary Table for Assessment........... 62

4.10 Analysis of Variance Summary Table for Perceived Comfort...62

4.11 Analysis of Variance Summary Table for Heart Rate Low......63

4.12 Analysis of Variance Summary Table for Heart Rate Average. 64

4.13 Analysis of Variance Summary Table for Heart Rate High ..... 64

4.14 Analysis of Variance Summary Table for Stress Response..... 65

4.15 Analysis of Variance Summary Table for Steps................. 65

\section{Teacher Preparation Impacts in Regard to Physiological Stress of}




\title{
Preservice Educators within Agricultural Mechanics Project Construction \\ JEFFERY J REED
}

\author{
Dr. John Tummons, Co-dissertation Supervisor \\ Dr. Leon G. Schumacher, Co-dissertation Supervisor
}

The purpose of this study was to identify how the differences in teacher preparation impact the physiological stress teachers and teaching quality students experience within the agricultural mechanics laboratory setting, specifically when related to project construction. One specific responsibility of agricultural educators is teaching project construction in the agricultural mechanics laboratory. Teachers have reported perceived stress in teaching agricultural mechanics, but no studies to date have measured the physiological stress response when teaching mechanics. For this agricultural mechanics methods course, university instructors enlisted students to serve as teacher for a day to simulate the process of teaching project construction. Researchers utilized a nonequivalent control group design to determine how a treatment of university supervisors modeling the project construction with students before they taught as teacher for day would impact teaching and stress outcomes. The control group did not build the project ahead of time, as has been the practice of the course in the past. The researcher utilized four instruments to measure physiological stress, learning environment, assessment, teaching delivery and perceived comfort of the teacher. The target population for this study was preservice agricultural educators at the University of Missouri. The accessible population consisted of preservice educators for the Fall of 2017 semester $(n=16)$. 
Heart monitor data indicated all teachers were stressed throughout their teaching on day 1 and day 2. Despite their stress, the teachers were effective as rated by their students. The treatment group was less stressed on day 2 than day 1 , indicating the treatment was effective at assisting teachers once the actual project construction began.

The study provides biological evidence supporting the stressful nature of teaching agricultural mechanics. Researchers were able to recreate the stress of agricultural mechanics teaching through a simulated activity. Researchers conclude the treatment of pre-project modeling reduced the stress and increase the teaching performance of preservice teachers by modeling the laboratory activity prior to teaching. 


\section{Chapter I - Introduction}

Agricultural mechanics is one of the most popular agricultural education content areas (Chumbley et al., 2013). Agricultural mechanics is an integral and essential component of the Agricultural education program (Phipps, Osborne, Dyer, \& Ball, 2008), which consists of a three-circle model including classroom education, Supervised Agricultural Experiences (SAE), and FFA (Croom, 2008).

Agricultural mechanics instruction requires a significant investment of time of the agricultural educator. Teachers must manage the laboratory, the equipment, supplies, project construction, skill development, and safety. Shinn (1987) stated that up to two thirds of an educator's time could consist of agricultural mechanics preparation. While Phipps (1980) estimated that one quarter to half of an educator's time is dedicated to teaching agricultural mechanics. Agricultural instructors teach a variety of subjects, including animal science, horticulture, and other complex topics, but agricultural mechanics instruction and lab management often requires additional time and unique knowledge to effectively manage learning.

Agricultural mechanics project construction provides an environment for agricultural educators and students develop skills and create projects through problem solving and project based learning. Blackburn, Robinson, \& Lamm (2014) stated innovative students are able to solve complex problems more completely within agricultural mechanics curriculum. Agricultural mechanics is an area which innovative students are allowed to exercise their innovation and solve complex problems routinely. Agricultural mechanics project construction is a cornerstone of agricultural mechanics 
instruction and is an expectation of many agriculture teachers as a part of the agricultural mechanics laboratory experience.

Agricultural mechanics has been found to provide practical, hands on education also creating a positive educational environment (Johnson, Wardlow, \& Franklin,1997). Hands on activities provide a significantly more effective positive learning environment for agricultural educators, it is important for educators to seize this opportunity when considering their students education attainment.

Agricultural mechanics instruction in the laboratory includes many unique environmental and safety challenges similar to managing a hazardous workplace. Teachers must learn to manage unique factors such as noise and danger, which can reduce the cognitive function of novice students (Miller, 1989). Once these students and educators are faced with these additional stressors, it important for teachers to be able to adequately prepare and adjust to these situations effectively. In addition to sound, educators must be prepared in the event a student may become injured. Saucier \& McKim (2014) deduced that administering first aid was the greatest concern of agricultural mechanics teachers, and compounding feelings of anxiety in the event of an accident.

To prepare teachers to successfully manage an agricultural mechanics laboratory, preservice agricultural education institutions provide specific agricultural education teaching methods course(s) within the content area of agricultural mechanics to address the knowledge and teaching gap. Many preservice students feel underprepared to teach agricultural mechanics and report unique concerns related to agricultural mechanics skills as content (Tummons, Langley, Reed \& Paul, 2016). McKim \& Saucier (2013) stated 
that agricultural mechanics instructors are spending more time per week teaching basic concepts in lab management courses, mostly due to the fact that students receive less training than previous cohorts. This builds upon the level problems educators are facing when researchers such as Rasty, Anderson, \& Paulsen (2017) found that teachers are more effective when the agricultural mechanics educator is exposed more courses over their lifetime.

The limited time focused on agricultural mechanics skill development and methods in the teacher preparation program leaves many preservice teachers feeling ill prepared to serve in the role of agricultural mechanics instructor (Burris, Robinson, \& Terry, 2005). The lack of education which preservice agricultural education teachers receive, the safety concerns of agricultural educators, and the stress associated with each of these factors is cause for concern for agricultural mechanics instructors.

Foster (1986) revealed high levels of anxiety agricultural mechanics educators experience prior to and during the student teaching process. Tummons, Langley, Reed \& Paul (2016) noted that female agricultural mechanics teachers experienced stress while teaching how to use tools that could kill or harm them or students. Thoron, Myers, \& Cody (2008) found educators experienced stress when not receiving the same laboratory settings they had previously experienced. The college laboratory settings were dissimilar than the laboratory settings when teaching in the high school laboratory. Additionally, laboratory settings vary drastically between high schools. For many preservice teachers, agricultural mechanics laboratory instruction is a central and daunting responsibility of their future job for which causes them justifiable stress. 
With deficiency of preparation and the lack of education required to teach this content area, stress becomes a very relevant and valid concern when these educators are expected to teach. Teachers vary in their stress responses, and teacher's response to stress is critical for the long-term retention of teachers (Thieman, Henry, \& Kitchel, 2012). Given a particular stressor, agricultural teachers respond using either a problem-focused or emotion-focused coping strategies; problem-focused strategies build resilience in teachers (Thieman, Henry, \& Kitchel, 2012). Researchers Admiraal, Wubbels, \& Korthagen (2000) worked with preservice educators and found that when teachers employ ineffective ways of coping with stressful encounters with students, this may result in feelings of distress and diminished learning opportunities for students. Johnson \& Wardlow (2017) found mastery experiences such as workshops, in which educators feel a high level of self-efficacy increase their likelihood to effectively teach agricultural mechanics concepts.

\section{Theoretical Framework}

The theoretical model to inform this study is Lazarus's Theory of Psychological Stress. Through the lens of this model, stress is an interface within an individual, the environment which they are currently experiencing, and the demand on an individual's own resources given the current environment (Lazurus, 1991). This model reflects the preservice agricultural educator in the environment of an agricultural mechanics teaching methods course, followed by the stressor event of being required to teach students agricultural mechanics project construction. The model begins with six components, within a two-part appraisal phase. This two part appraisal phase consists of a primary and 
secondary appraisal, trailed by the perception of individual coping ability. For this context, secondary appraisal would be the preservice educator being asked to teach agricultural mechanics project construction. The students focus on their coping, and the future requirement of teaching project construction once they become an agricultural educator. The appraisal process is affected by an individual's personality and their cultural background.

Through this phase two key items are assessed, motivational relevance and motivation congruence (Lazurus, 1991). As the stressor is identified, the individual progresses into a secondary appraisal phase in which the individual determines four components: accountability, problem-focused coping potential, emotion-focused coping potential, and future expectancy. After the appraisal has been processed by an individual, they begin coping in a variety of ways. Some individuals cope and they move forward toward the process of mastering stressors. Some individuals remain within the confines of coping until they attrition out of the event, affecting efficacy for future events. This would students failing to teach/complete their students project construction. Additionally, this would be agricultural educators who move of agricultural education as apart of attrition.

Some respond with problem focused, while others use emotion focused coping skills. Problem focused coping consists of active attempts to alter the problematic relationship; this would be learning a task to the point of stressor removal. In contrast, emotion focused, coping alters the response without changing the activity augments, stress and anxiety, created from the situation without solving the problem. Accountability 
provides an additional escape from the stressor; individuals will reason with the idea that it is not their fault or they do not complete the activity with the stressful event present.

Additionally, the future expectancy of the stressor event plays a role with the individual processing through the potential for future identical stressors to enter their life. A future stressor such as a task or skill that will be required to teach in the future will require them to progress through the threat. In the conceptual model of this study, the participants will know they have a future expectancy, they could blame their accountability on their instructor however they would have to consistently do this creating unwanted attention to their lack of progress.

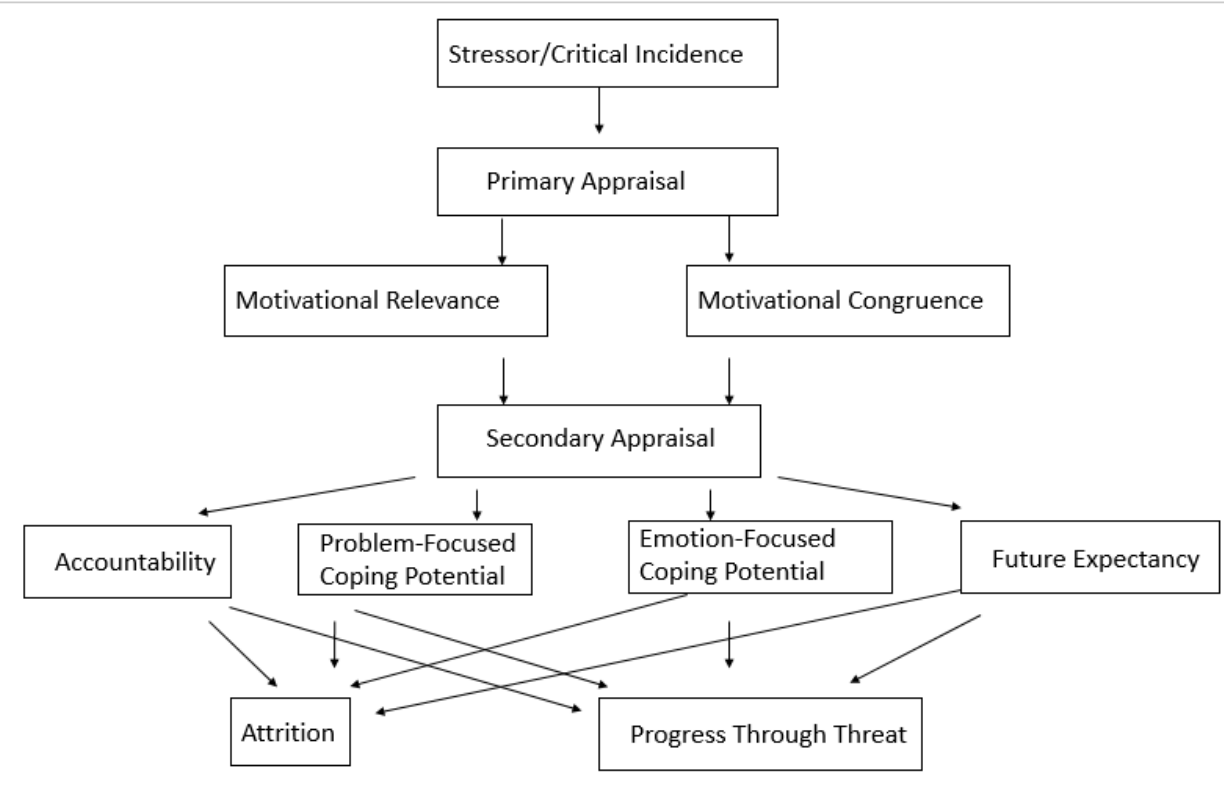

Figure 1.1. Model of Lazarus's Theory of Psychological Stress 


\section{Statement of Problem}

Agricultural mechanics is one of the most popular agricultural education content areas (Chumbley et al., 2013). Agricultural mechanics is a unique learning environment that provides practical and hands on learning (Saucier \& McKim, 2011). Despite these positive factors, agricultural education preservice programs have reduced their agricultural mechanics instruction (Hubert \& Leising, 2000). This reduction in course requirements contributes to the problem of educators to indicating agricultural educators experience stress within the agricultural mechanics educational environment (Tummons, Langley, Reed \& Paul, 2016; Thoron, Myers, \& Cody, 2008; Foster, 1986). Mechanics instructors are expected to teach more with less time, which contributes to teacher stress. Educators prepare for building projects within agricultural mechanics in different ways, this variety of preparation, or lack thereof, effects stress levels within students and teachers. Researchers identified a gap in the literature regarding physiological stress response and teaching quality when managing project construction in the agricultural mechanics laboratory as part of a preservice agricultural mechanics course. Researchers must ask the question: how does a preservice teacher mechanics instructor modeling project construction affect stress levels of teachers and teaching quality for students building projects within an Agricultural Mechanics lab? 


\section{Purpose of the Study}

The purpose of this study was to identify how the differences in teacher preparation impact the physiological stress teachers and teaching quality within the agricultural mechanics laboratory setting, specifically when related to project construction. To address this, several research questions were developed.

\section{Research Questions}

1. What is the measured physiological stress level (heart rate high, heart rate low, stress response and steps) of treatment preservice teachers versus nontreatment preservice teachers?

2. What is the perceived comfort level of treatment preservice teachers' vs nontreatment preservice teachers?

3. What is the perceived teacher effectiveness level (delivery, assessment and learning environment) of treatment preservice teachers' vs non-treatment preservice teachers, from student perspective?

4. To what extent does treatment, days, and interaction of treatment times days explain variation in physiological stress, perceived comfort and teacher effectiveness?

For research question four, the researcher utilized a repeated measures ANOVA to explain variance in treatment, day, and treatment*day interactions 
could be attributed to differences in physiological stress, perceived comfort and teacher effectiveness.

HO1: Differences in treatment, days, and treatment*days does not account for significant $(p>0.05)$ proportions of variance in teaching delivery as perceived by the students.

Ha1: Differences in treatment, days, and treatment *days accounts for a significant $(p<0.05)$ proportion of variance in teaching delivery as perceived by the students.

HO2: Differences in treatment, days, and treatment*days does not account for significant $(p>0.05)$ proportions of variance in learning environment as perceived by the students.

Ha2: Differences in treatment, days, and treatment *days accounts for a significant $(p<0.05)$ proportion of variance in learning environment as perceived by the students.

HO3: Differences in treatment, days, and treatment*days does not account for significant $(p>0.05)$ proportions of variance in assessment as perceived by the students.

Ha3: Differences in treatment, days, and treatment *days accounts for a significant $(p<0.05)$ proportion of variance in assessment as perceived by the students.

HO4: Differences in treatment, days, and treatment*days does not account for significant $(p>0.05)$ proportions of variance in perceived comfort as perceived by the teacher. 
Ha4: Differences in treatment, days, and treatment *days accounts for a significant $(p<0.05)$ proportion of variance in perceived comfort as perceived by the teacher.

HO5: Differences in treatment, days, and treatment*days does not account for significant $(p>0.05)$ proportions of variance in heart rate low of the teacher. Ha5: Differences in treatment, days, and treatment *days accounts for a significant $(p<0.05)$ proportion of variance in heart rate low of the teacher. HO6: Differences in treatment, days, and treatment*days does not account for significant $(p>0.05)$ proportions of variance in heart rate average of the teacher.

Ha6: Differences in treatment, days, and treatment *days accounts for a significant $(p<0.05)$ proportion of variance in heart rate average of the teacher.

HO7: Differences in treatment, days, and treatment*days does not account for significant $(p>0.05)$ proportions of variance in heart rate high of the teacher. Ha7: Differences in treatment, days, and treatment *days accounts for a significant $(p<0.05)$ proportion of variance in heart rate high of the teacher. HO8: Differences in treatment, days, and treatment*days does not account for significant $(p>0.05)$ proportions of variance in stress response of the teacher. Ha8: Differences in treatment, days, and treatment *days accounts for a significant $(p<0.05)$ proportion of variance in stress response of the teacher. HO9: Differences in treatment, days, and treatment*days does not account for significant $(p>0.05)$ proportions of variance in steps of the teacher. 
Ha9: Differences in treatment, days, and treatment *days accounts for a significant $(p<0.05)$ proportion of variance in steps of the teacher.

\section{Definition of Terms}

The following definition of terms were developed to provide clarity for the reader. Each of the terms below are utilized throughout the dissertation.

Agricultural Education: the systematic instruction in agricultural and natural resources at the elementary, middle school, secondary, postsecondary or adult levels for the purpose of preparing people for the entry or advancement in agricultural occupations or professions, job creation and entrepreneurship, and agricultural literacy (Phipps, 2008). Agricultural Mechanics: the selection, operation, maintenance, servicing, selling, and use of power units, machinery, equipment, structures, and utilities used in agriculture (Herren, 2010).

Heart Rate Variability (HRV): beat-to-beat variations in heart rate, measured through electrocardiogram (ECG) readings. Characterized by several different frequency bands: Very Low Frequency (VLF), Low Frequency (LF), and High Frequency (HF). VLF is not used for this study due to a lack of accuracy in readings of five minutes or less. LF readings are indicative of sympathetic nervous system activation. HF readings indicate an activation of the parasympathetic nervous system (McCraty \& Atkinson, 1996).

Prepared teacher: teachers whom have built a specific project previously through guided instruction prior to them teaching their students how to build a specific project. 
Preservice Teacher: for this study, is a student enrolled in a teacher preparation program and satisfactorily meeting the benchmarks for each appropriate stage in the program. This term is used to describe students through graduation and certification.

Perception: the way you notice or understand something using one of your senses (Merriam-Webster, 2001).

Treatment Teacher: teachers whom have built a specific project previously through guided instruction prior to them teaching their students how to build a specific project. Resilience: "the capacity to adjust to adverse conditions to increase one"s competence, achieve school goals, and remain committed to teaching" (Thieman, et al., 2012, p. 83). Strategic and Metacognitive Thinking:

Stress Response: refers to the chain of events that take place on a physiological level within the human body upon detection of a threat (Sapolsky, 2004b).

Stressors (Critical Incidences): refers to an interaction or event during the microteaching lesson where an emotional response was triggered within the participant, as indicated by heart rate variability readings and researcher observations of behavioral changes. This is not always a negative or dramatic event, simply one that has significance to the individual (Kain, 2007).

Teacher Effectiveness: teacher's ability to utilize experience to enable them to better prepare students and parents for more positive responses (Peterson, Wahlquist, \& Bone, 2000)

Non-Treatment Teacher: teachers whom have not built a specific project previously through guided instruction prior to them teaching their students how to build a specific project. 


\section{Basic Assumptions}

For this study, the following assumptions were made.

1. The responses were honest in truthful to the best of their ability with their responses.

2. The HRV was not manipulated by the students or teachers throughout the study.

3. Stress is experienced within the confines of the study within the context of preservice educators within an agricultural mechanics laboratory.

\section{Limitations of the Study}

The following were identified as limitation to the study:

1. This study used time and place sampling of an intact group of preservice educators. Therefore caution should be taken when interpreting the results of this study beyond the confines of preservice teachers within an agricultural mechanics course in Missouri.

2. Preservice teachers shared their perceptions as a part of the study, however researchers did not conduct observations within the confines of the study and cannot verify absolute accuracy of those perceptions.

3. Data collection was limited to preservice agricultural education majors at the University of Missouri. 
4. The participants were $75 \%$ female, and $25 \%$ male. $100 \%$ of the participants were Caucasian. 


\section{Chapter II - Review of Literature}

The key priority for this document was to synthesize the research related to agricultural mechanics within agricultural education and the challenge this creates for educators, stress and how individuals manage stress, and resiliency. Within the synthesis I sought to identify deficiencies, common themes and common methods utilized within this area. The majority of agricultural mechanics educational research has been conducted through primarily descriptive and survey research. The majority of this research has focused on competencies, teacher needs, safety, mathematics, and career development events.

\section{Agricultural Education Foundation and Mechanics Preparation}

Agricultural education has a dynamic structure which includes three key components, a supervised agricultural experience, FFA and a classroom/laboratory instruction component (Croom, 2008). The classroom experience includes laboratory instruction, this laboratory instruction for an agricultural educator, sometimes involves agricultural mechanics which requires a significant amount of preparation by the agricultural educators. Shinn (1987), once stated that this preparation could consist as much as one third to two thirds of instruction for an agricultural educator. Similar studies have also stated the increased time allocation an agricultural mechanics course requires such as Phipps (1980) estimated $25-40 \%$ of time was allocated to agricultural mechanics instruction. Johnson \& Schumacher (1989) found agricultural educators spend approximately $60 \%$ of their time on agricultural mechanics instruction preparation. 
Agricultural educators face a challenge of balancing the three interconnected components of the agricultural education model, however research indicates a significant amount of time for this model is spent on agricultural mechanics alone.

\section{Agricultural mechanics provides beneficial education to students; However, mechanics is a complex task for educators to teach}

Agricultural mechanics instruction is often a dynamic environment to manage, as instructors must develop and deliver curriculum to develop occupational skills, safety behaviors and problem solving. Laboratory teaching also provides an active, engaged environment where scientific inquiry can occur, elevating student's motivation and interest (Osborne \& Dyer, 2000). Phipps, Osborne, Dyer, \& Ball (2008) surmised agricultural mechanics is an essential element to an agricultural education program. Agricultural mechanics provides unique opportunities for learning and the development of students, Agnew \& Shinn (1990) found students learn best with various techniques, determined by the level and types of information being asked of them. A tremendous amount of content knowledge is required to teach the differing concepts within the realm of agricultural mechanics Pate, Warnick, \& Meyers (2012) found forty-nine skills described by experienced teachers required to teach welding. This high number of skills

for a beginning teacher to recall suggesting mechanics skills are complex and challenging for novices. With this high number of skills, it is important to focus on areas which students can recall and educate more effectively. This aligns with the findings of Saucier \& Krysher (2014) where students believed personal importance or value of a skill 
determines an individual's own willingness to teach that skill within agricultural mechanics. Additionally, Wells, Perry, Anderson, Shultz, \& Paulsen (2013) asserted prior experience increases ones motivation to increase their knowledge if they had a successful experience the first time, creating an urgency that agricultural mechanics must be taught effectively and successfully at the high school level. Achievement of students within the confines of agricultural mechanics could provide a partial explanation of some educators experiencing stressors while others are able to progress through coursework without stressors occurring. Johnson (1991) sought out students competing in a state agricultural mechanics contest and found students with more previous agricultural mechanics experiences consistently achieve better scores on agricultural mechanics contest.

Preservice agricultural mechanics curriculum is scaffolded into various activities as apart of their preparation for students teaching, Schumacher \& Johnson (1990) found the student teaching experience reinforces the agricultural mechanics teaching experience within specific competencies within agricultural mechanics, suggesting student teaching is an essential part of the preservice preparation in agricultural mechanics.

The stressors experienced within agricultural mechanics are also experienced within the welding industry, Lincoln Electric has sought to address stress through the development of their virtual welding machine. Stone, McLaurin, Zhong, \& Watts (2013) found using virtual reality welding machines offered an effective way to teach agricultural mechanics skills and successfully lower stress. The physical and cognitive effects of virtual welding additionally were increased and allowed welders to progress at a faster pace than those students trained through traditional welding training, (Stone, Watts, \& Zhong, 2011; Stone, Watts, Zhong, \& Wei 2011) However, virtual welding 
technology is expensive, and the utilization of these instruments within the high school classroom is the unit being cost prohibitive. The welding industry, which includes competences included within the agricultural education curriculum, values agricultural mechanics education and its evolution. From basic skill development through large project construction, as demonstrated by James F Lincoln foundation awards and through the Lincoln Electrics development of the virtual welding machine.

Agricultural mechanics in regards to its future importance is not deemed as important through the lens of future value, as found by Foster, Bell, \& Erskine (1995). Agricultural mechanics is viewed by agricultural educators, principals and superintendents in differing views in regard to the future importance. Additionally, Blackburn, Robinson, \& Lamm (2014) stated innovative students are able to solve complex problems more completely within agricultural mechanics. Agricultural mechanics is an area which the innovative students are allowed to exercise their innovation and solve complex problems routinely within the confines of the agricultural mechanics content area. Agricultural mechanics students have been found to achieve higher levels of educational attainment, for example, Brzozowski (1988) found agricultural science 1 and 2 students achieved a significantly higher score on content knowledge exam if they were enrolled in agricultural mechanics courses. Grubb \& Lazerson (2005) encouraged a shift from occupational education to higher order thinking integration into specific skills such as problems solving and communication through the lens of career and technical education courses such as agricultural mechanics to develop the skills of the twenty-first century. Significant factors within agricultural mechanics in regard to the practical, hands out education that occurs have been found as positive 
educational environment, Johnson, Wardlow, \& Franklin (1997) hands on activities provide a significantly more effective positive learning environment for agricultural educators, it is important for educators to seize this opportunity when considering their students education attainment. Opportunities for lowering stress and anxiety do exist as, Johnson \& Wardlow (2017) found mastery experiences such as workshops, in which educators feel a high level of self-efficacy increase their likelihood to teach agricultural mechanics concepts more effectively. Foster, Bell, \& Erskine (1995). Anderson, Velez, \& Anderson (2014) found safety training of agricultural education preservice teachers to be vital to the safe and effective operation of agricultural mechanics laboratories. Johnson, Schumacher, \& Stewart (1990) recommended for laboratory management within agricultural mechanics laboratory, to include timely and relevant instruction. While some researchers have found agricultural mechanics education to be deficient in the areas of skill development, knowledge of competencies, and required coursework, others have found sometimes the educators possess the knowledge, but do not implement proper practices. According to Schlautman \& Silletto (1992), agricultural education teachers do not utilize lab management to the degree which they know to be safe and proper.

\section{Agricultural mechanics is viewed as a dangerous portion of agricultural education}

While agricultural educators face compounding stressors from a variety of sources, it is important to note the additional potential for stressors when educators are subjected to educating students in potentially dangerous situations such as the agricultural mechanics laboratory. Miller (1989) found the agricultural mechanics laboratories 
provide unique environments with compounding factors such as noise, which reduce the cognitive function of students. Once these students and educators are faced with these additional stressors, it important for teachers to be able to adequately prepare and adjust to these situations effectively. Woodford, Lawrence, Bartrug, Center, \& Virginia (1993) also found the noise levels within agricultural mechanics labs add additional safety concerns such as hearing loss to students. These additional factors cause more concern and preparation for the agricultural mechanics instructor. In addition to sound, educators must be prepared in the event a student may become injured, Saucier \& McKim (2014) deduced administering first aid was the greatest concern for agricultural mechanics teachers, and compounding feelings of anxiety should an accident occur. When proper training is not provided, this leaves educators at not only an increased level of anxiety, but also an increased level of liability for student safety. Saucier, Vincent, \& Anderson (2011), indicate beginning educators within agricultural mechanics do not know how to properly assess the safety of devices or situations within a laboratory setting. This is an area which is concerning, because these educators who cannot differentiate between the safe and unsafe can potentially insert students into an unsafe situation. While some educators have expressed concerns for the agricultural mechanics laboratory it is important to discuss the very real fears some of these educators are facing, Female preservice educators indicated a potential responsibility for safety to the point of life and death decision making (Tummons, Langley, Reed \& Paul, 2016). While some educators have very specific concerns within the agricultural mechanics laboratory, Shoulders \& Myers (2012) observed teacher views of agricultural mechanics barriers vary by teacher, facility, location and student population. This could be due to the variety of settings the 
agricultural mechanics laboratory occurs, since no two laboratories are the same.

\section{Agricultural mechanics education is deficient within teacher preparation programs}

Agricultural educators are typically prepared as educators through a series of content courses such as agricultural mechanics, horticulture, leadership and animal science. Throughout the past 20 years, agricultural educators have indicated deficient instruction within agricultural mechanics nationwide. Burris, Robinson, \& Terry (2005) discussed the preparation of pre-service agricultural educators within the confines of agricultural mechanics and described these students as possibly not being adequately prepared within the agricultural mechanics content area. McKim \& Saucier (2013) reported teachers within the past twenty years are teaching more agricultural mechanics courses, spending more time on agricultural mechanics courses per week, however the educators are receiving less education in agricultural mechanics at their preservice institutions. Safety education was recommended by Perry, Williams, \& Anderson (2012) for teachers to further their education on safety related items within agricultural mechanics. Additionally, Saucier, Terry, \& Schumacher (2009) recommend for agricultural mechanics teachers receive additional mechanics training and specifically safety in mechanics training. Agricultural educators are often required to perform tasks which may not be asked of a traditional educator. Additional tasks required of an agricultural mechanics educator provide additional barriers, such as the maintenance and repair of malfunctioning laboratory equipment which Saucier \& McKim (2011) found student teachers were in need of professional development regarding, along with the areas of laboratory management, and administering first aid. Not only are teacher 
preparation faculty required to teach specific skills, they must be able to teach skills at the level which would allow them to be successful educators. Preservice agricultural education students must demonstrate the skills they have been taught, and additionally demonstrate how to teach, repair, maintain, and adjust this machinery in a safe manner. Saucier, McKim, \& Tummons (2012) believed teaching agricultural mechanics should be assessed within the preservice teacher program to equip teachers for better performance of skills. Saucier, McKim, Terry, \& Schumacher (2014) found lab management training is needed for educators to improve the safety of their laboratories. The needs of preservice educators are dynamic and complex. Edwards \& Briers (1998) found educators struggled with balancing of personal and professional roles, additionally educators expressed the need for additional instruction regarding learning environments and how to manage those environments. Hubert \& Leising (2000) found an average of only 6 hours of college level courses are required by agricultural education programs for teacher certification. Recently Rasty, Anderson, \& Paulsen (2017) asserted, the more courses students are exposed to over a lifetime, the more important those students view those courses in the future and increase the likelihood of those students teaching their students these skills. This is a direct link between an individual's preparation of coursework and efficacy to teach those courses. The lower hours required within agricultural mechanics courses can potentially be the only exposure preservice educators receive to the competencies they will be teaching.

McCubbins, Anderson, Paulsen, \& Wells (2016) studied agricultural mechanics instructors, the instructors reported not having the appropriate tools to teach agricultural mechanics. However, a large portion of these tools are available for free through state and 
federal grants, which could indicate a lack of understanding concepts which agricultural educators are teaching.

Some researchers have recommended ways to lower these stressors through additional educational development. Dyer \& Andresen (1999) recommend identifying which laboratory activities cause the greatest hazard toward students and teachers, and develop teacher identification of safety and achievement relationships. While professional development preferences vary by educational setting, Garton and Chung (1996) found agricultural mechanics as one of the skill areas perceived to need to be developed more. Universities must be purposeful when planning the agricultural mechanics coursework for preservice educators, Lawver, Barton, Akers, Smith, \& Fraze (2004) found educators expressed complications with agricultural mechanics coursework when not allowed to the curriculum they will be required to align with for teacher certification.

Educators have additionally sought out professional development in the area of laboratory safety and feel this is the best avenue to approach this topic, Saucier, Vincent, \& Anderson (2014). McKim, \& Saucier (2011) found agriculture teachers were in need of agricultural mechanics laboratory management in-service education in the areas of: first aid, correcting hazardous laboratory conditions, and general laboratory safety. Additionally, Johnson \& Schumacher (1989) reported safety is the leading concern for agricultural educators. Within a laboratory/mechanics setting this concern is compounded. Researchers strive to create a more innovative approach for educators to teach skills which may be deemed as dangerous, Stringham \& Swan (2012) asserted the integration of modeling to teach agricultural mechanics skills which could be dangerous, 
burdensome or costly could be the solution. Agricultural mechanics teachers currently utilize this in some form, for example AC electric demonstration boards are widely adopted teaching aids created through modeling. Agricultural educators would like for our students to embrace and learn all aspects of the agricultural mechanics realm we also must accept the balance between lab safety and achievement of educational goals.

\section{Agricultural educators are at a shortage}

Agricultural educational instructors are leaving the profession at concerning levels, and levels of attrition are steadily increasing (Boone, \& Boone, 2010). Researchers have well documented the concerns of experienced educators teaching agricultural mechanics, which could be driving teachers from the field. Preservice teachers indicate a high level of uncertainty within agricultural mechanics which could entice them to not enter the field. As the attrition rates of these educators continues to rise, agricultural educator shortage is developing to a level of epidemic proportions (Foster, Lawver, \& Smith, 2014; Kantrovich, 2007). While agricultural education is a focus of research for those with a vested interest, teacher attrition is not limited to just agriculture. Morris (2006) found teacher retention is not only an agricultural education problem, it is a teacher problem and a career tech teacher problem. Ingersoll \& Smith (2003) argue the increasing student enrollments and increasing numbers of teachers reaching retirement age are leading to a perilous time within education, where educators are being rushed into the teaching field. Agricultural mechanics being one of these fields placing less experienced teachers within them, which have increased safety concerns or 
decrease laboratory utilization. It is important to note the career and technical education teachers such as agricultural educators encourage and train their students to enter career fields, these fields are a likely recruiter for these educators along with their students. Myers, Dyer, \& Washburn (2005) found that beginning agricultural educators are not entering the field which they trained for, creating issues with replenishing the already understaffed agricultural education field.

\section{Agricultural education is stressful and has long term health impacts on educators Agricultural Education Stress}

Agricultural education has been found in multiple studies to be a stressful endeavor for educators. Straquadine (1990) found agricultural educators are at risk of overwork to the point of receiving negative effects comparable to an addiction. It is no surprise to individuals who have ever taught agricultural education this is the case, agricultural education is a very rewarding experience but creates health concerns for educators. Torres, Lambert, \& Tummons (2012) found time management as a repeating factor of stress within agricultural educators, additionally once the agricultural educator position novelty wears off, stress is believed to increase rapidly. There are some contrasting views however, Torres, Lawver, \& Lambert (2009) found stress is not seen at all times during the agricultural education teacher evolution.

Considering the perceived stress these educators are facing, it is not surprising these educators often jeopardize their own health for their positions. Lee (1990) described 
agricultural educators as attending school even when emotional or psychosomatic conditions jeopardize their health. These agricultural educators consistently perform under continuous stresses, strains and health issues in order to achieve and educate their students. Sorensen \& McKim (2014) found agricultural educators' work life balance to be disproportionate. Again, revealing the dedication agricultural educators possess in order to educate their students, which comes at a cost, often leading to attrition and contributions to the teacher shortage.

\section{Agricultural mechanics teaching and stress}

Edwards, \& Briers (1998) found educators reported needing more instruction on learning environments and how to manage them, specifically agricultural mechanics. Baker, Thoron, Myers, \& Cody (2008) revealed laboratory instruction is vital, however educators do not have all of the same laboratory resources/setup so prescribe methods of instruction become difficult adding stress to beginning educators. Adding to the agricultural mechanics dynamic, Dillingham, Ramirez, \& Amsden (1993) found females experience less stress when other females are present within the agricultural mechanics environment, however there is a lack of females within the agricultural mechanics setting, Johnson (1991). Adding to the issues are finding from Tummons, Langley, Reed \& Paul (2016) female preservice teachers are severely stressed when working within the agricultural mechanics laboratory. Fletcher \& Miller (1995) researched the safety perceptions of agricultural mechanics instructors and found an increased potential for accidents and /or hazards cause increased stress within the agricultural mechanics 
laboratory. Increasing the needs for instruction and development for these educators within the confines of agricultural mechanics. Foster (1986) found educators experienced high anxiety within agricultural mechanics education prior to and during student teaching.

\section{Teacher burnout is attributed to the stress cycle and the resiliency or lack thereof within educators}

Compounding variables within agricultural mechanics education such as lacking education, safety concerns, experience levels, and laboratory management have complicated the dynamic currently occurring within agricultural education and the shortage of teachers. Additionally, the dynamic and potential dangerous environment of the agricultural mechanics laboratory considerations must be made when considering the compounded effects and teacher burnout and stress. The level of stress and impact on the future of agricultural education is a topic which must be researched further to reveal the specific stressors educators are facing in an effort to increase retention and educational effectiveness. Alarming results such as, Bennett, Iverson, Rohs, Langone, \& Edwards (2002) work with stress and teacher turnover, $14.5 \%$ if teachers within this study at high risk of leaving the ag teaching community.

Admiral, Wubbels, \& Korthagen (2000) worked with preservice educators and found that when teachers employ ineffective ways of coping with stressful encounters with pupils, this may result in feelings of distress and diminished learning opportunities for pupils. In the agricultural mechanics environment, we see this specific idea repeated, educators are constantly being distressed in the environment and are diminishing the 
learning which their students are receiving. Anderson (2010) found educators possessed an uncertainty regarding ability to relate content knowledge as well as relevant personal experiences to students which caused additional stress. A significant amount of work has indicated early service educators are at risk of not entering the profession, leaving the profession of agricultural education researchers such as Brunetti (2001) revealed teacher burnout is not only an early career problem, long term service teachers are being pushed to the point of breaking through confounding variables of resources, facilities, class sizes, etc. signifying this is a much large issue than just improving our early career educators, who have different needs than their experienced predecessors. Byrne (1998) found teachers required a significant amount of support in order to process through the stressors of beginning the career of education, they are hungry for support and must be provided a variety of options for this support mechanism to occur. Differing views on approaches to decreasing teacher burnout have been explored, Carmona, Buunk, Peiro, Rodriguez, \& Bravo (2006) works with teachers found teachers with high view of self over peers were less likely to burnout. Viewing education as a competition with other teachers made them less likely to burnout if they viewed themselves as better educators. Teachers who directly addressed their own view for improvement also were decreased in their likelihood to burnout. Bringing forth the idea which a large portion of the educator is self-owned and educators must work toward self-improvement and motivation to improve their own self-worth. From the works of Chenevey, Ewing, \& Whittington (2008) we know stress may diminish job satisfaction which we know as agricultural educators and those working with agricultural mechanics are constantly feeling stressed, and elevated anxiety levels. Educators self-reflection can also be skewed, Evers, Tomic, \& Brouwers 
(2004) found teachers view themselves in a more positive way than their students in regards to burnout, it could be possible to utilize students as predictors in teacher burnout due to complexity of teacher viewed repercussions of response to burnout questions. Additional work in the area of stress and burnout has been conducted in industry as well, Hobfoll \& Shirom (1993) found stress and burnout is not necessarily a teacher problem but a workplace problem. Some researchers such as Howard \& Johnson (2004) have found stress research, could be addressed more effectively by looking at educator stress from the viewpoint of areas where teachers are exceling and describes their effective strategies for coping as opposed to the common view of what is wrong. Leiter (1991) provided a general model for organizational determinants of burnout, when applied to the agricultural mechanics education issue currently being experienced by educators, there are areas which preservice educators may intervene to better enable these educators to be successful. Should preservice educators possess knowledge of the stressor levels educators are facing with specific items such as teaching students the usage of agricultural mechanics skills, these items could be organized in a manner which balanced the educators stress level to a more manageable level. 


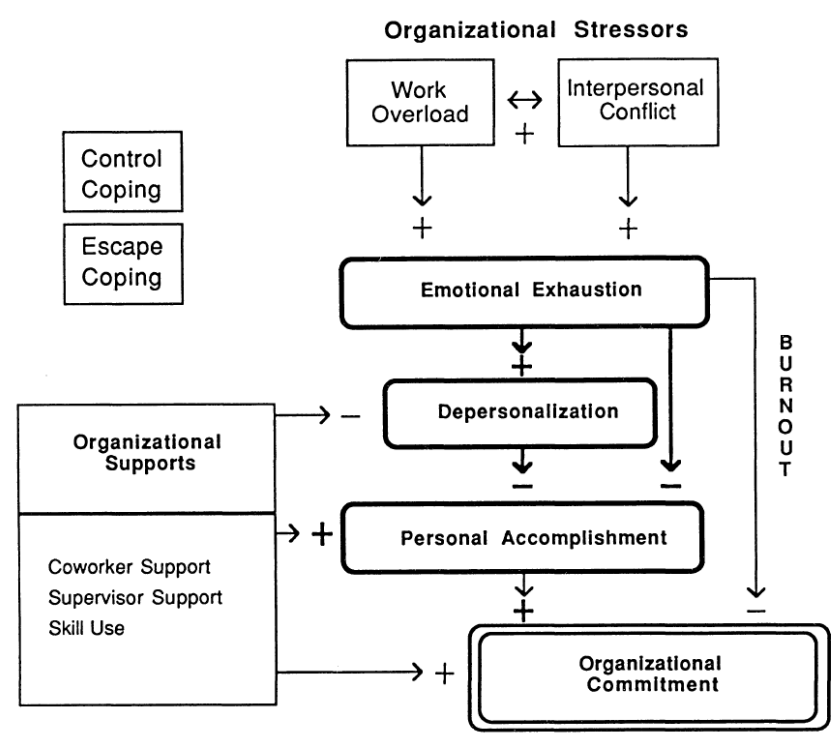

Figure 2.1 General model organizational determinants of burnout

Maslach (1982) has indicated occupational stressors are an indication of burnout through the use of tools such as the one developed by Maslach, Jackson, \& Leiter (1996). This burnout assessment tool is recommended to assess the levels at which individuals are experiencing stressors in an effort to measure their potential for burnout. Stress and teacher turnover are almost synonymous within agricultural education research, Newcomb, Betts, \& Cano (1987). Social credibility and job security were found by Vandenberghe \& Huberman (1999) to increase the potential for teacher burnout and the challenging social context agricultural educators are exposed to within communities. Agricultural mechanics environmental factors can complicate education concerns attributed to burnout, Virnich, Wissing, Wirsching, Schaarschmidt, Bauer, Stamm, \& Mueller (2006) found destructive and aggressive behavior of students is high cause for stress in teachers. The agricultural mechanics laboratory can increase this concern due to the items readily available for increased destruction. Agricultural mechanics has provided 
specific results in regards to educators leaving the agricultural education field, educators felt dissatisfied with working with this content when leaving the field, Walker, Garton, \& Kitchel (2004).

\section{Stress cycle}

Stress has repeatedly been found within agricultural mechanics instructors. As noted above, stress contributes to long term negative impact on mental and physical health, through the stress cycle and the recovery from stressful events. Stress is the idea that a threat to an individual's well-being to include creates a negative experience Kyciacou (2001). Current research indicates the agricultural mechanics laboratory has become this negative experience for some educators.

Heart rate variability has been determined to be a reliable and valid measure to assed actual physiological stress (Delaney \& Brodie, 2000). These researchers reported that as stress is experienced over time, consistently past two-three weeks, stress becomes chronic stress and has negative effectives over time. Chronic stress leads to increased potentials for illness and disease. Researchers have consistently stated stress must be researched in a more sophisticated manner, as opposed to survey research design, the shift should include a shift to theory-based investigations that test causal models of teacher stress and health Guglielmi \& Tatrow (1998). Researchers such as Kyriacou (2000) have found teaching to be one of the most stressful professions, however researchers have designed methods to pre-empt stress, within a range of direct action and palliative coping strategies and methods successful schools do to minimize stress of 
educators. Additional recommendations made by Kyriacou (2003) include, exploring specific sources of stress within education to include (i) monitoring the extent to which particular educational reforms are generating high levels of teacher stress; (ii) exploring why some teachers are able to successfully negotiate periods of career reappraisal and retain a positive commitment to the work, whilst others are not; (iii) clarifying the nature of the stress process in term of two types of triggers' one based on excessive demands and the other based on a concern with self-image; (iv) assessing the effectiveness of particular intervention strategies to reduce teacher stress; (v) exploring the impact of teacher-pupil interaction and classroom climate on teacher stress. Early work of Lazarus \& Folkman (1984) provided insight on how to assess stress, determining it is very contextual, based in prior experiences and their success or failure. As his work continued the development of Lazarus's Theory of Psychological Stress which provides insight to teacher appraisals of their own stressors. Once an educator identifies the stressor the will attempt to master, tolerate, or reduce the demands of the stressor (Lazarus, 1991). If an educator cannot process through the stressors or reduce the stressor demand this could likely result in attrition from the position which causes the stressor. 


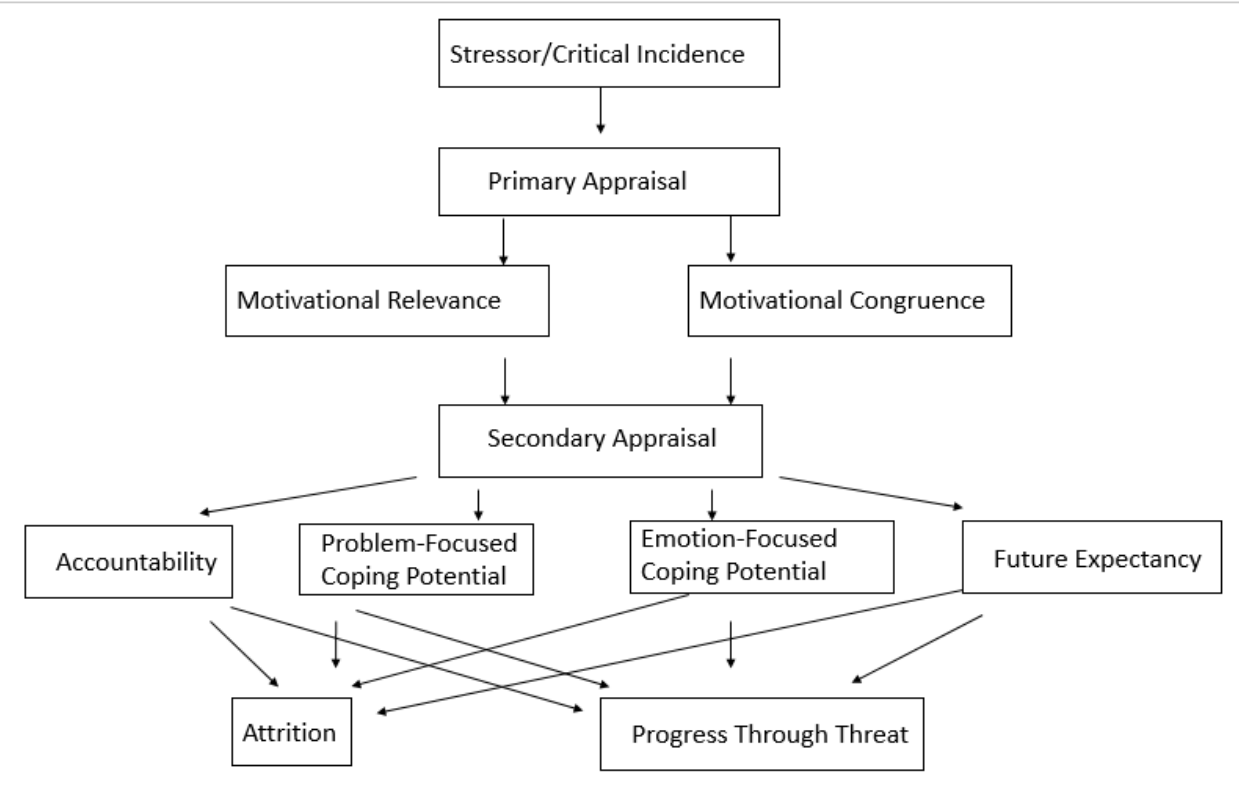

Figure 2.2 Model of Lazarus's Theory of Psychological Stress

The stress process includes the initiation of a stressful event known as stressors, once experienced the body will initiate a response to the stressor, this response can be measured through heart rate variability (McCraty, Atkinson, Tiller, Rein, \& Watkins, 1995). Montgomery \& Rupp (2005) found the strongest educator stressors were negatively oriented responses to educational situations and the teacher's ability to cope with those responses. Olpin \& Hesson (2010) argue the existence of good stress and bad stress, however other researchers argue that stress compounds and creates overwhelmingly negative impact longitudinally (Sapolsky, 1994). 


\section{Resiliency}

Resilience provides an explanation and tool to work through issues agricultural educators are facing. Gu \& Day (2007) found early, mid and late teacher resilience to be an effective tool to work through stress. Croom (2003) found teachers experience emotional exhaustion at all levels of agricultural education, however they possess a number of coping factors to increase their resiliency and process through challenges. Teacher resiliency has been found to determine their ability to persevere through obstacles they must address in order to continue down their path of education in spite of these adversities (Bandura, 1997; Luthans, Youssef, \& Avolio, 2007; Masten, 2001; Reivich \& Shatte, 2002; Thieman, Henry, \& Kitchel, 2012). The resiliency development of students can also be developed by their teachers through relationships, competence, skills, ownership, accomplishment, and humor are significant factors which can increase teacher retention (Bobek, 2002). Brunetti (2006) found students, professional and personal satisfaction, and support from administrators, colleagues and the organization of the school were factors in resiliency of mid-late service educators. Castro, Kelly \& Shih (2010) believed preservice agricultural educator training should promote problem-solving through teaching case studies, guiding pre-service and beginning teachers through action research oriented projects, and encouraging more advanced methods of problem-solving. Further, teacher educators can also facilitate discussion about school as a workplace, exploring professionalism and ways to manage co-workers and parents. Teacher educators may foster peer-support groups by creating cohorts in teacher education and creating beginning teacher support teams within the school. Finally and most importantly, 
teacher educators and school leaders must provide an atmosphere that allows novice teachers to feel safe when they seek advice, guidance, and support. Tait (2008) found early career educators were less able to manage complex situations when resiliency was not present, as an early career educator. Thieman, Henry, \& Kitchel (2012) introduced the idea of resiliency to agricultural education. They described the relationships existing between coping, resiliency, stress and teacher burnout, all of which are current issues facing agricultural education and specifically agricultural mechanics educators. The also asserted the resiliency new teachers should possess in order to survive and thrive.

\section{Conclusions}

Agricultural education is a profession characterized by high stress and high demands resulting from scope of work beyond the normal school day and a broad range of content knowledge and skill required to address a full agricultural education program curriculum. There is a high need for workers skilled in agricultural mechanics, and the high school agriculture program is the premier form of exposure for future employees while they are in junior high and high school. Agricultural mechanics laboratory safety in high schools is of high concern for those in agricultural education, career and technical education and industry. Agricultural teacher educators across the country have observed

an increasing trend of preservice teachers lacking skills, resiliency and showing increased amounts of stress within the area of agricultural mechanics. What specific skills/tools are these educators experiencing stressors? This need for novel and cutting-edge approaches should be explored to observe and measure preservice teacher development and stress in 
addition to in-service teacher stress. Specifically, what level of stress are these educators experiencing while they are conducting specific lessons at varying levels of experience? Integrating traditional research methods such as biological monitors would allow for objective analysis to be conducted in an effort to further explore the stresses which agricultural mechanics educators face. Measures of educator stress typically involve selfreport questionnaires, which have not been useful in effectively lowering teacher stress attrition or been proven as accurate reflections of physiological stress. Researchers such as Jarczok, Jarczok, Mauss, Koenig, Li, Herr, \& Thayer (2013) argue perceived stress has not been adequately examined in contrast to measured physiological stress with teachers, which current research recommendations are based upon. Additionally, King, Rucker, \& Duncan (2013) utilized a model to identify specific stressors within agricultural education specifically related to FFA and CDE preparation. They asserted this methodology can allow educators to address specific stressors and concerns for agricultural educators in an effort to minimize these stressful situations. This type of methodology is the direction agricultural education research must evolve into, we know teachers are at a shortage, stressed and agricultural mechanics has been repeatedly been identified as a significant source or this stress. If we can identify, mitigate and level the stresses educators are experiencing we would be addresses the needs of agricultural educators. It is essential to agricultural industry that agricultural educators be proficient, comfortable, and safe in providing instruction in the agricultural mechanics laboratory. 


\section{Chapter III: Methodology}

\section{Purpose of the Study}

The purpose of this study was to identify how the differences in teacher preparation impact the physiological stress and teaching quality within the agricultural mechanics laboratory setting, specifically when related to project construction. To address this, several research questions were developed.

1. What is the measured physiological stress level (heart rate high, heart rate low, stress response and steps) of treatment preservice teachers versus nontreatment preservice teachers?

2. What is the perceived comfort level of treatment preservice teachers' vs nontreatment preservice teachers?

3. What is the perceived teacher effectiveness level (delivery, assessment and learning environment) of treatment preservice teachers' vs non-treatment preservice teachers, from student perspective?

4. To what extent does treatment, days, and interaction of treatment times days explain variation in physiological stress, perceived comfort and teacher effectiveness? 
HO1: Differences in treatment, days, and treatment*days does not account for significant $(p>0.05)$ proportions of variance in teaching delivery as perceived by the students.

Ha1: Differences in treatment, days, and treatment *days accounts for a significant $(p<0.05)$ proportion of variance in teaching delivery as perceived by the students.

HO2: Differences in treatment, days, and treatment*days does not account for significant $(p>0.05)$ proportions of variance in learning environment as perceived by the students.

Ha2: Differences in treatment, days, and treatment *days accounts for a significant $(p<0.05)$ proportion of variance in learning environment as perceived by the students.

HO3: Differences in treatment, days, and treatment*days does not account for significant $(p>0.05)$ proportions of variance in assessment as perceived by the students.

Ha3: Differences in treatment, days, and treatment *days accounts for a significant $(p<0.05)$ proportion of variance in assessment as perceived by the students.

HO4: Differences in treatment, days, and treatment*days does not account for significant $(p>0.05)$ proportions of variance in perceived comfort as perceived by the students. 
Ha4: Differences in treatment, days, and treatment *days accounts for a significant $(p<0.05)$ proportion of variance in perceived comfort as perceived by the students.

HO5: Differences in treatment, days, and treatment*days does not account for significant $(p>0.05)$ proportions of variance in heart rate low as perceived by the students.

Ha5: Differences in treatment, days, and treatment *days accounts for a significant $(p<0.05)$ proportion of variance in heart rate low as perceived by the students.

HO6: Differences in treatment, days, and treatment*days does not account for significant $(p>0.05)$ proportions of variance in heart rate average as perceived by the students.

Ha6: Differences in treatment, days, and treatment *days accounts for a significant $(p<0.05)$ proportion of variance in heart rate average as perceived by the students.

HO7: Differences in treatment, days, and treatment*days does not account for significant $(p>0.05)$ proportions of variance in heart rate high as perceived by the students.

Ha7: Differences in treatment, days, and treatment *days accounts for a significant $(p<0.05)$ proportion of variance in heart rate high as perceived by the students. 
HO8: Differences in treatment, days, and treatment*days does not account for significant $(p>0.05)$ proportions of variance in stress response as perceived by the students.

Ha8: Differences in treatment, days, and treatment *days accounts for a significant $(p<0.05)$ proportion of variance in stress response as perceived by the students.

HO9: Differences in treatment, days, and treatment*days does not account for significant $(p>0.05)$ proportions of variance in steps as perceived by the students.

Ha9: Differences in treatment, days, and treatment *days accounts for a significant $(p<0.05)$ proportion of variance in steps as perceived by the students.

\section{Research design}

This study utilized quasi-experimental design research methods, utilizing nonequivalent control group design (Campbell \& Stanley, 1966). This process involves a treatment and a control group. However the groups are within predefined groups which are not controlled by the design of the researcher; therefore, random selection was not possible. Groups constitute naturally occurring groups, such as those in predesigned groups, such as classrooms. The assignment of the treatment is assumed to be random, however under the researcher's control (Cambell \& Stanley, 1966). These methods can 
be assumed to control for main effects, such as history, testing and instrumentation validity issues (Campbell \& Stanley, 1966).

This purposive sampling design was utilized, because true randomization could not be accomplished, due to the course being required as within the agricultural education teacher option required course at the University of Missouri. Sample size will be a limitation to this study, consisting of 16 participants, the researcher acknowledges the limitations of the findings to application with only this sample.

\section{Variables}

This study consisted of one predictor (independent) variable: teacher preparation.

Additionally, the study consisted of three outcome (dependent) variables for this study: (1) physiological stress of preservice teachers and (2) teacher comfort level, and (3) teacher perceived effectiveness.

The predictor variable, treatment of preservice teachers, was modified teacher instruction on specific project construction techniques within an agricultural education, teacher preparation program. The course itself was an agricultural mechanics teaching methods course designed to prepare preservice educators to teach students project construction while teaching in the agricultural mechanics laboratory. Each student within the course serves as "teacher for a day" during this time the "teacher" is responsible for all course content, just as they were the assigned teacher for the course. For this inquiry, treatment teachers were provided additional training about how to build and teach a specific project to their students before serving as teacher for a day (when they taught 
project construction to their peers). The non-treatment preservice teachers received no additional instruction while they were building the projects with their students. All preservice teachers received information at the same time in regard to the day each project they would be teaching. The participants all had the same access to the bill of materials, facilities, tools and building plan for the projects. University instructors were present throughout the duration of the teaching time with both the treatment and control groups. The University instructors however did not add in the teaching, project construction, etc. they did however provide the materials for the projects.

\section{Population}

The target population for this study was preservice agricultural educators at the University of Missouri. The accessible population consisted of preservice educators (soon to be student teaching) for the Fall of 2017 semester ( $\mathrm{n}=16$ ).

Subsequent to Institutional Review Board (IRB) guidelines, participants were recruited via an initial recruitment letter. As participants indicated an interest to be part of the study, an IRB approved consent letter was distributed to participants. Both letters explained potential risk associated with the study, the research project, and participants for this project.

\section{Instrumentation}

This study utilized four instruments to gather information from the preservice agricultural educators- ambulatory heart rate monitors, pre-class questionnaires, post- 
teaching reflection questionnaires, and project grading rubrics. Physiological stress data was collected using Firstbeat ambulatory heart rate monitors, similar to those worn by athletes. The device connects directly to the skin via two chest electrodes and the data were downloaded periodically throughout the study into analytic software via USB for data analysis. Participants placed the monitors on themselves prior to the agricultural teaching methods course beginning each course meeting time and removed them once the course was completed each day. Participants wore the devices the previous semester and several weeks prior to the data being collected to acclimate the participants with the monitors and to gather baseline data. The monitors measured HRV and movement via accelerometer within the device. These devices have been shown to measure physiological stress, stress response, stress recovery, respiration and motion (McCraty \& Atkinson, 1996).

The second instrument (Appendix D) was a daily journal. This questionnaire was given to all participants at the beginning of each class period and included questions regarding their perceived comfort, measured on a six-point scale: $0=$ Very Low, 1, 23=Moderate, 4, \& 5=Very High and provided background information for monitor data accuracy. Information was in regard to caffeine, alcohol and drug intake was documented within this journal. This data informed the Firstbeat data, and certified Firstbeat consultants removed some data due to answer placed on the second instrument in regard to substance usage particularly to reduce stress.

The third instrument (Appendix C) measured teacher perceived effectiveness from the students' perspective. Teacher perceived effectiveness was measured utilizing a paper and pencil instrument (Peterson, Wahlquist, \& Bone, 2000) previously developed 
for a similar population with a Cronbach's alpha value of 0.91 and test-retest correlation of 0.96 (Peterson, Wahlquist, \& Bone, 2000). The scale consists of 12 items on a 5-point Likert type scale: $1=$ Strongly Disagree, $2=$ Disagree, $3=$ Neutral, \& 4=Agree, $5=$ Strongly Agree. Face and content validity were established by a panel of four experts in agricultural mechanics education. The instrument was field tested prior to the study on 16 similar preservice teachers enrolled in an agricultural mechanics teaching method course at Tarleton State University. The instruments yielded Cronbachs's alphas reliability coeffecients of 0.87 and test-retest correlation of 0.92 .

The fourth instrument was a project construction rubric, each project was scored utilizing the same educational expert and rubric (Appendix B) throughout the course for project quality scoring at the completion of each project. The rubric scores for each project were compared to the treatment and control groups to determine if any significant differences exist.

\section{Data collection procedures}

Data were collected from participants in person during their preservice preparation course in the Fall of 2017. Participants were in the final year of teacher preparation coursework at a Midwest land-grant university (they would soon student teach and then graduate). The sixteen participants agreed to participant in the study by signing an IRB approved consent form after responding to the recruitment letter distributed to students within the course. Participants were assured of their 
confidentiality, data storage security and potential risks via these documents as required by IRB.

The agricultural mechanics teaching methods course was designed to teach preservice teachers how to manage an agricultural mechanics laboratory, construct projects effectively, and safely after they had become agricultural educators. The course scaffolds students from initial knowledge and skills of materials and tool use, then micro teaching of individual tools and their uses, then concludes with student built projects. Students also serve in the role of "teacher for the day" on a rotational schedule throughout the course. This allows for the students to gain the depth of knowledge required prior to the construction of their projects. The course syllabus can be seen within Appendix A.

On the first day of the course, 16 preservice educators were given notification of their date of instruction, the type of project they would construct, and the number of students they will be instructing. The 16 participants were randomly placed into four groups for each of the four projects they would construct within the confines of the agricultural mechanics teaching methods course. Although the sampling was randomized through placement of groups, the sampling was purposive in nature. Participants each assumed the role of teacher for one project, leaving them with three students in their group. Once the project was completed, the "teacher" of the previous project rotated to a student role and another group member assumed the teacher role for the next project. This system allowed all sixteen participants to assume the role of the teacher for one project. This method alleviated any one participant from increasing their comfort level teaching any of the projects. The rotational schedule is shown in Figure 3.1 below. 

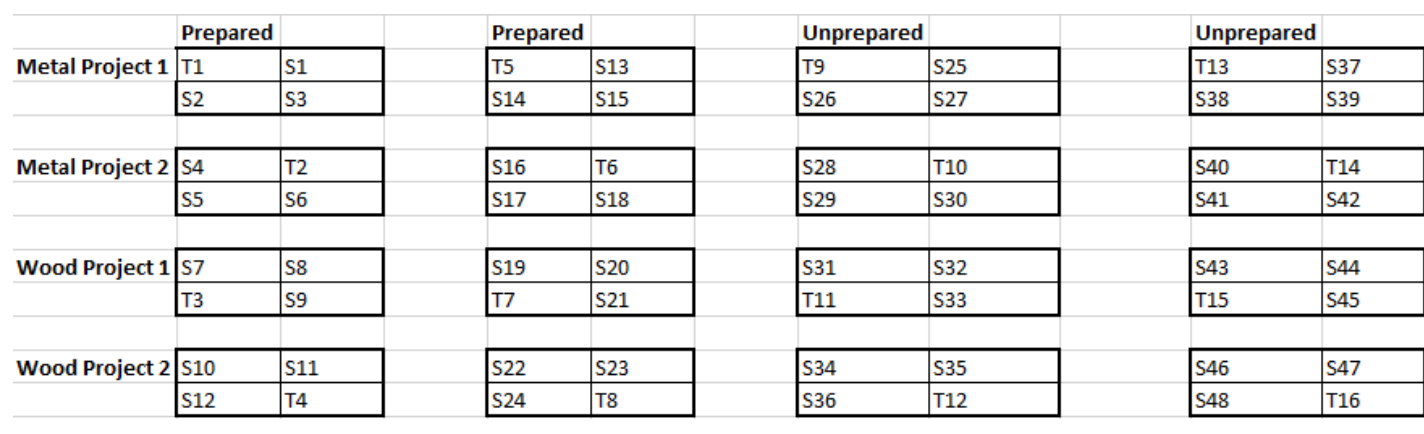

\begin{tabular}{|l|l|}
\hline S16 & T6 \\
\hline S17 & S18 \\
\hline
\end{tabular}

\begin{tabular}{|l|l|}
\hline S28 & T10 \\
\hline S29 & S30 \\
\hline
\end{tabular}

\begin{tabular}{|l|l|}
\hline S40 & T14 \\
\hline S41 & S42 \\
\hline
\end{tabular}

\begin{tabular}{|l|l|}
\hline S19 & S20 \\
\hline T7 & S21 \\
\hline
\end{tabular}

\begin{tabular}{|l|l|}
\hline S31 & S32 \\
\hline T11 & S33 \\
\hline
\end{tabular}

\begin{tabular}{|l|l|}
\hline S43 & S44 \\
\hline T15 & S45 \\
\hline
\end{tabular}

\begin{tabular}{|l|l|}
\hline S22 & S23 \\
\hline S24 & T8 \\
\hline
\end{tabular}

\begin{tabular}{|l|l|}
\hline S34 & S35 \\
\hline S36 & T12 \\
\hline
\end{tabular}

\begin{tabular}{|l|l|}
\hline S46 & S47 \\
\hline S48 & T16 \\
\hline
\end{tabular}

Figure 3.1 Research Design

A total of four groups existed within the rotational schedule. This design was chosen to allow each participant to assume the role of the teacher for one project. The participants were randomly assigned to their groups and remained as an intact group throughout the study. The four groups were divided into two treatment groups and two control groups.

The treatment and control groups had access to all of the same resources for the projects to be constructed. The participants were only allowed to utilize the provided bill of materials and construction plans during their project construction.

The control groups were defined by the following: (1) the control group did not receive any outside assistance prior to the completion of their projects, (2) the control group participants within the teacher role, received the same guidance during the construction of the projects as the treatment group within the confines of the course meeting time, and (3) the control group did not receive any guidance outside of class meeting time regarding their project.

The treatment groups were defined by the following: (1) received guidance ahead of time for the project where they would assume the teacher role, (2) guidance consisted 
of the participant building the project they taught ahead of their teaching time with the University instructor for the course, (3) the participant completed the project achieving a grade of $95 \%$ or better on their first attempt, prior to teaching their students.

All participants (both preservice teachers and students) began wearing ambulatory heart rate monitors at the beginning of the course each day two weeks prior to the first data being collected to acclimate participants to the wearing monitors and to gather baseline data. Participants had additionally worn the monitors in the previous spring semester for acclimation to the monitors. During the study, participants wore the monitors daily within the course (8:00am-10:30am) and took them off each day at the conclusion of the course (10:30am). In addition to wearing the monitors, participants completed instrument 2 (Appendix D) which was used to record their perceived comfort and provided background information for monitor data accuracy.

At the conclusion of course meeting time each day, participants within the role of student for that day completed instrument 3 (Appendix C) to measure the perceived effectiveness of their teacher (Peterson, Wahlquist, \& Bone, 2000).

Participant characteristics were controlled for by utilizing purposive random assignment to groups and assignment to treatment, providing detailed instruction prior to project construction to 8 of the groups. Plans, materials, and tool availability were the same for all groups. Groups were separated into two different labs to avoid cross contamination during the project construction process. This isolation allowed for groups to work on their own without interference or influence from other groups. Despite isolation design, researchers acknowledge spill over (or discussion after class between the students) was a potential threat to the study. 
Each project was scored utilizing the same educational expert and rubric, instrument 4 (Appendix B) throughout the course for project quality at the completion of each project. The rubric scores for each project were compared to the treatment and control groups to determine if any significant differences existed.

\section{Data analysis}

Data were analyzed using the Statistical Analysis Software (SAS) for Windows. Research question one:

1. What is the measured physiological stress level (heart rate high, heart rate low, stress response and steps) of treatment preservice teachers versus nontreatment preservice teachers?

Research question one was answered from the perspective of the treatment and non-treatment preservice teacher. The data were interval in nature; construct summated mean scores, median, mode, variance, standard deviation, and range were reported for preservice teachers within questions one.

\section{$\underline{\text { Research question two: }}$}

2. What is the perceived teacher perceived effectiveness level of treatment preservice teachers' vs non-treatment preservice teachers?

Research question two was answered from the perspective of the treatment preservice teacher. The data were interval in nature; construct summated mean scores, median, mode, variance, standard deviation, and range were reported for preservice teachers within questions two. Teacher perceived effectiveness 
were measured utilizing an instrument (Peterson, Wahlquist, \& Bone, 2000) previous developed for a similar population. Pilot tests were conducted on a similar population of preservice agricultural education students and found to be reliable and valid.

\section{Research question three:}

3. What is the perceived teacher effectiveness level (delivery, assessment and learning environment) of treatment preservice teachers' vs non-treatment preservice teachers, from student perspective?

Research question three was answered from the perspective of the prepared preservice teacher. The data were interval in nature; construct summated mean scores, median, mode, variance, standard deviation, and range were reported for preservice teachers within questions three.

Research question four:

4. To what extent does treatment, days, and interaction of treatment times days explain variation in physiological stress, perceived comfort and teacher effectiveness?

For research question four, the researcher utilized a repeated measures ANOVA to explain variance in treatment, day, and treatment*day interactions could be attributed to differences in physiological stress, perceived comfort and teacher effectiveness.

HO1: Differences in treatment, days, and treatment*days does not account for significant $(p>0.05)$ proportions of variance in teaching delivery as perceived by the students. 
Ha1: Differences in treatment, days, and treatment *days accounts for a significant $(p<0.05)$ proportion of variance in teaching delivery as perceived by the students.

HO2: Differences in treatment, days, and treatment*days does not account for significant $(p>0.05)$ proportions of variance in learning environment as perceived by the students.

Ha2: Differences in treatment, days, and treatment *days accounts for a significant $(p<0.05)$ proportion of variance in learning environment as perceived by the students.

HO3: Differences in treatment, days, and treatment*days does not account for significant $(p>0.05)$ proportions of variance in assessment as perceived by the students.

Ha3: Differences in treatment, days, and treatment *days accounts for a significant $(p<0.05)$ proportion of variance in assessment as perceived by the students.

HO4: Differences in treatment, days, and treatment*days does not account for significant $(p>0.05)$ proportions of variance in perceived comfort as perceived by the teacher.

Ha4: Differences in treatment, days, and treatment *days accounts for a significant $(p<0.05)$ proportion of variance in perceived comfort as perceived by the teacher.

HO5: Differences in treatment, days, and treatment*days does not account for significant $(p>0.05)$ proportions of variance in heart rate low of the teacher. 
Ha5: Differences in treatment, days, and treatment *days accounts for a significant $(p<0.05)$ proportion of variance in heart rate low of the teacher.

HO6: Differences in treatment, days, and treatment*days does not account for significant $(p>0.05)$ proportions of variance in heart rate average of the teacher.

Ha6: Differences in treatment, days, and treatment *days accounts for a significant $(p<0.05)$ proportion of variance in heart rate average of the teacher.

HO7: Differences in treatment, days, and treatment*days does not account for significant $(p>0.05)$ proportions of variance in heart rate high of the teacher. Ha7: Differences in treatment, days, and treatment * days accounts for a significant $(p<0.05)$ proportion of variance in heart rate high of the teacher. HO8: Differences in treatment, days, and treatment*days does not account for significant $(p>0.05)$ proportions of variance in stress response of the teacher. Ha8: Differences in treatment, days, and treatment *days accounts for a significant $(p<0.05)$ proportion of variance in stress response of the teacher. HO9: Differences in treatment, days, and treatment*days does not account for significant $(p>0.05)$ proportions of variance in steps of the teacher.

Ha9: Differences in treatment, days, and treatment * days accounts for a significant $(p<0.05)$ proportion of variance in steps of the teacher. 
Field (2009) identified assumptions when utilizing one way repeated measures ANOVA statistical analysis. The first assumption is the dependent variable is continuous, the researcher verified this to be true.

Assumption two, independent variables should consist of at least 2 categorical variables, the researcher verified this to be true (Field, 2013).

Assumption three, data maintains absence of outliers, outliers were removed from the data set. Researcher utilization of histograms (See Appendix G) allowed for removal of outliers with data.

Assumption four, the distribution of the dependent variable in the two or more related groups should be approximately normally distributed. A Shapiro-Wilk test of normality was utilized, the data were normally distributed (Field, 2013).

Assumption five, sphericity of data was not measured because researchers utilized a repeated measures variable (days) with only two levels, therefore sphericty is met (Field, 2009).

\section{Summary}

A one way repeated measures ANOVA was conducted to compare the effect of teacher preparation on physiological stress on students, physiological stress on preservice teachers, teacher perceived effectiveness, and teacher perceived comfort. 


\section{CHAPTER IV}

\section{FINDINGS}

\section{Purpose of the Study}

The purpose of this study was to identify how the differences in teacher preparation impact the physiological stress preservice teachers experience within the agricultural mechanics laboratory setting, specifically when related to project construction. To address this, several objectives were developed.

\section{Research Questions}

1. What is the measured physiological stress level (heart rate high, heart rate low, stress response and steps) of treatment preservice teachers versus nontreatment preservice teachers?

2. What is the perceived comfort level of treatment preservice teachers' vs nontreatment preservice teachers?

3. What is the perceived teacher effectiveness level (delivery, assessment and learning environment) of treatment preservice teachers' vs non-treatment preservice teachers, from student perspective?

4. To what extent does treatment, days, and interaction of treatment times days explain variation in physiological stress, perceived comfort and teacher effectiveness? 
HO1: Differences in treatment, days, and treatment*days does not account for significant $(p>0.05)$ proportions of variance in teaching delivery as perceived by the students.

Ha1: Differences in treatment, days, and treatment *days accounts for a significant $(p<0.05)$ proportion of variance in teaching delivery as perceived by the students.

HO2: Differences in treatment, days, and treatment*days does not account for significant $(p>0.05)$ proportions of variance in learning environment as perceived by the students.

Ha2: Differences in treatment, days, and treatment *days accounts for a significant $(p<0.05)$ proportion of variance in learning environment as perceived by the students.

HO3: Differences in treatment, days, and treatment*days does not account for significant $(p>0.05)$ proportions of variance in assessment as perceived by the students.

Ha3: Differences in treatment, days, and treatment *days accounts for a significant $(p<0.05)$ proportion of variance in assessment as perceived by the students.

HO4: Differences in treatment, days, and treatment*days does not account for significant $(p>0.05)$ proportions of variance in perceived comfort as perceived by the teacher. 
Ha4: Differences in treatment, days, and treatment *days accounts for a significant $(p<0.05)$ proportion of variance in perceived comfort as perceived by the teacher.

HO5: Differences in treatment, days, and treatment*days does not account for significant $(p>0.05)$ proportions of variance in heart rate low of the teacher. Ha5: Differences in treatment, days, and treatment *days accounts for a significant $(p<0.05)$ proportion of variance in heart rate low of the teacher. HO6: Differences in treatment, days, and treatment*days does not account for significant $(p>0.05)$ proportions of variance in heart rate average of the teacher.

Ha6: Differences in treatment, days, and treatment *days accounts for a significant $(p<0.05)$ proportion of variance in heart rate average of the teacher.

HO7: Differences in treatment, days, and treatment*days does not account for significant $(p>0.05)$ proportions of variance in heart rate high of the teacher. Ha7: Differences in treatment, days, and treatment *days accounts for a significant $(p<0.05)$ proportion of variance in heart rate high of the teacher. HO8: Differences in treatment, days, and treatment*days does not account for significant $(p>0.05)$ proportions of variance in stress response of the teacher. Ha8: Differences in treatment, days, and treatment *days accounts for a significant $(p<0.05)$ proportion of variance in stress response of the teacher. HO9: Differences in treatment, days, and treatment*days does not account for significant $(p>0.05)$ proportions of variance in steps of the teacher. 
Ha9: Differences in treatment, days, and treatment *days accounts for a significant $(p<0.05)$ proportion of variance in steps of the teacher.

\section{Population and Sample}

The target population for this study was preservice Agricultural Educators at a Midwestern land-grant university. The accessible population consisted of preservice educators for the Fall of 2017 semester $(n=16)$.

Subsequent to Institutional Review Board (IRB) guidelines, participants were recruited via an initial recruitment letter. As participants indicated interest in study participation an IRB approved consent letter was distributed to participants. Both letters explained potential risk associated with the study, the research project, and participants for this project.

Day 1

Table 4.1

Teacher Information Day 1

\begin{tabular}{lllll}
\hline & \multicolumn{2}{c}{ Control $(n=6)$} & \multicolumn{2}{c}{ Treatment $(n=4)$} \\
\cline { 2 - 5 } & $M$ & $S D$ & $M$ & $S D$ \\
\hline Heart Rate Level low $^{\mathrm{a}}$ & 79.00 & 9.48 & 79.75 & 13.72 \\
Heart Rate Level average $^{\mathrm{a}}$ & 96.17 & 9.62 & 99.25 & 11.59 \\
Heart Rate High $^{\mathrm{a}}$ & 122.17 & 9.06 & 127.25 & 7.54 \\
\hline
\end{tabular}

Note. ${ }^{\mathrm{a}}$ Heart rate reported in beats per minute.

As shown in table 4.1, the treatment mean score for Heart Rate low on Day 1, was $79.00(S D=9.48)$ for the control group, and the mean treatment score was $79.75(S D=$ 13.72). The control mean score for Heart Rate Average on Day 1 was $96.17(S D=9.62)$ 
and the mean treatment score was $99.25(S D=11.59)$. The control mean score for Heart Rate High on Day 1, was $122.17(S D=9.06)$ and the mean treatment score was 127.25 $(S D=7.54)$

Table 4.2

Teacher Information Day 1

\begin{tabular}{lllll}
\hline & \multicolumn{2}{c}{ Control $(n=6)$} & \multicolumn{2}{c}{ Treatment $(n=4)$} \\
\cline { 2 - 5 } & $M$ & $S D$ & $M$ & $S D$ \\
\hline Stress Response $^{\mathrm{a}}$ & 79.83 & 5.38 & 67.75 & 8.18 \\
Steps $^{\mathrm{b}}$ & 440.67 & 171.15 & 424.50 & 59.17 \\
\hline
\end{tabular}

Note. ${ }^{\mathrm{a}}$ Anchors for stress response was scaled 0-100 as measured by the device. ${ }^{\mathrm{b}}$ Anchors for steps were steps taken during teaching.

As shown in table 4.2, the mean score for the control group for Stress Response on Day 1 was $79.83(S D=5.38)$ and the mean treatment score was $67.75(S D=8.18)$. The control group mean score for Steps on Day 1, was $440.67(S D=171.15)$ and the mean treatment score was $424.50(S D=59.17)$.

Table 4.3

Teacher Information Day 1

\begin{tabular}{lllll}
\hline & \multicolumn{2}{c}{ Control $(n=8)$} & \multicolumn{2}{c}{ Treatment $(n=7)$} \\
\cline { 2 - 5 } & $M$ & $S D$ & $M$ & $S D$ \\
\hline Teaching Delivery $^{\mathrm{a}}$ & 4.03 & 1.06 & 4.58 & 0.15 \\
Learning Environment $^{\mathrm{a}}$ & 4.28 & 0.62 & 4.71 & 0.22 \\
Assessment $^{\mathrm{a}}$ & 4.01 & 0.99 & 4.75 & 0.20 \\
Perceived Comfort $^{\mathrm{b}}$ & 2.87 & 1.12 & 3.28 & 1.60 \\
\hline
\end{tabular}

Note. ${ }^{\mathrm{a}}$ Anchors for psychosocial constructs was $1=$ Strongly Disagree, $2=$ Disagree, $3=$ Neutral, 4=Agree, and $5=$ Strongly Agree. ${ }^{\mathrm{b}}$ Anchors for perceived comfort were $0=$ very low, 2-3 = Moderate, 5=Very high 
As shown in table 4.3, the treatment mean score for Teaching Delivery on Day 1 for the control group was $4.03(S D=1.06)$ and the mean treatment teaching delivery score was $4.58(S D=0.15)$. The mean score for Learning Environment on Day 1 for the control group was $4.28(S D=0.62)$ and the mean treatment score was $4.71(S D=0,22)$. The control mean score for Assessment on Day 1, was $4.01(\mathrm{SD}=0.99)$ out of a possible 5 , and the mean treatment score was $4.75(S D=0.20)$. The control mean score for Perceived Comfort on Day 1, was $2.87(\mathrm{SD}=1.12)$ and the mean treatment score was $3.28(S D=1.60)$.

Day 2

Table 4.4

Teacher Information Day 2

\begin{tabular}{lllll}
\hline & \multicolumn{2}{c}{ Control $(n=6)$} & \multicolumn{2}{c}{ Treatment $(n=3)$} \\
\cline { 2 - 5 } & $M$ & $S D$ & $M$ & $S D$ \\
\hline Heart Rate Level low $^{\mathrm{a}}$ & 74.83 & 5.30 & 79.00 & 12.16 \\
Heart Rate Level average $^{\mathrm{a}}$ & 95.17 & 5.45 & 94.33 & 10.07 \\
Heart Rate High $^{\mathrm{a}}$ & 125.00 & 8.55 & 120.00 & 4.36 \\
\hline
\end{tabular}

Note.. ${ }^{\mathrm{a}}$ Heart rate reported in beats per minute.

As shown in table 4.4, the control group mean score for Heart Rate Level Low on Day 2, was $74.83(S D=5.30)$ and the mean treatment group heart rate low was $79.00(S D$ $=12.16$ ) beats per minute. The control mean score for Heart Rate Average on Day 2, was $95.16(S D=5.45)$ and the mean treatment score was $94.33(S D=10.07)$. The control mean score for Heart Rate High on Day 2, was $125.00(S D=8.55)$ and the mean treatment score was $120.00(S D=4.36)$. 
Table 4.5

Teacher Information Day 2

\begin{tabular}{lllll}
\hline & \multicolumn{3}{c}{ Control $(n=6)$} & \multicolumn{2}{c}{ Treatment $(n=3)$} \\
\cline { 2 - 5 } & $M$ & $S D$ & $M$ & $S D$ \\
\hline Stress Response & 64.50 & 20.67 & 61.67 & 14.57 \\
Steps & 431.17 & 158.65 & 368.33 & 313.79 \\
\hline Note ${ }^{\mathrm{a}}$ Anchors for stress response was scaled $0-100$ as measured by the device ${ }^{\mathrm{b}}$
\end{tabular}

Note. ${ }^{a}$ Anchors for stress response was scaled 0-100 as measured by the device.

Anchors for steps were steps taken during teaching.

As shown in table 4.5, the control group mean score for Stress Response on Day 2, was $64.50(S D=20.67)$ and the mean treatment score was $61.67(S D=14.57)$. The control group mean score for Steps on Day 2, was $431.17(S D=158.65)$ and the mean treatment score was $368.33(S D=313.79) .4$

Table 4.4 Teacher Information Day 2

\begin{tabular}{lllll}
\hline & \multicolumn{2}{c}{ Control $(n=8)$} & \multicolumn{2}{c}{ Treatment $(n=7)$} \\
\cline { 2 - 5 } & $M$ & $S D$ & $M$ & $S D$ \\
\hline Teaching Delivery $^{\mathrm{a}}$ & 3.96 & 0.93 & 4.48 & 0.15 \\
Learning Environment $^{\mathrm{a}}$ & 4.19 & 1.04 & 4.49 & 0.47 \\
Assessment $^{\mathrm{a}}$ & 3.86 & 1.17 & 4.50 & 0.44 \\
Perceived Comfort $^{\mathrm{b}}$ & 3.00 & 1.41 & 3.85 & 1.34 \\
\hline
\end{tabular}

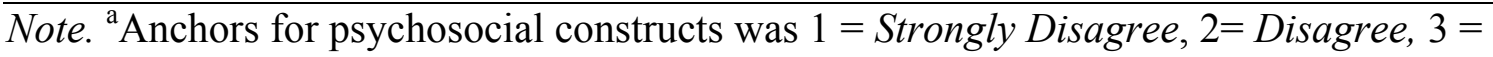
Neutral, 4=Agree, and 5 = Strongly Agree.

Researchers used identical data collection procedures for day two. As shown in table 4.4, the control group mean score for Teaching Delivery on Day 2, was $3.96(S D=$ $0.93)$ and the mean treatment score was $4.48(S D=0.15)$. The mean score for Learning Environment on Day 2 was $4.19(S D=1.04)$ for the control group and the mean Learning Environment treatment score was $4.49(S D=0.47)$. The control mean score for Assessment on Day 2, was $3.86(S D=1.17)$ and the mean treatment score was $4.50(S D$ 
$=0.44)$. The control group mean score for Perceived Comfort on Day 2, was $3.00(\mathrm{SD}=$ $1.41)$ and the mean treatment score was $3.85(S D=1.34)$.

Research question 4

\section{$\underline{\text { Teaching Delivery }}$}

For teaching delivery, the overall model explained a significant portion of variance $F(16,13)=5.06, p<0.05$. Researchers failed to reject the null hypotheses for individual variables of treatment $F(1,13)=2.12, p>0.05$, day $F(1,13)=0.30, p>0.05$, and treatment*day $F(1,13)=0.01, p>0.05$ factors did not account for significant proportions of variance in the model (see table 4.7). Researchers detected a large effect size (partial $\eta^{2}=$ 0.140 ) for the treatment vs. control, a small effect size (partial $\eta^{2}=0.023$ ) for days, and no effect size (partial $\left.\eta^{2}=0.00\right)$ for interaction * day.

Table 4.7

Analysis of Variance Summary Table for Teaching Delivery

\begin{tabular}{lllllll}
\hline Source & df & $\begin{array}{l}\text { Type III } \\
\text { SS }\end{array}$ & MS & $F$ & $p$ & $\begin{array}{l}\text { partial } \\
\eta^{2}\end{array}$ \\
\hline Treatment & 1 & 2.10 & 2.10 & 2.12 & 0.17 & 0.140 \\
Day & 1 & 0.06 & 0.06 & 0.30 & 0.59 & 0.023 \\
Treatment*Day & 1 & 0.01 & 0.01 & 0.01 & 0.95 & 0.00 \\
Case & 13 & 12.88 & 0.99 & & & \\
\hline Nore: & & & & & &
\end{tabular}

Note: ${ }^{*}=p<0.05$

Learning environment 
For learning environment, the overall model explained a significant portion of variance $F(16,13)=6.89, p<0.05$. Researchers failed to reject the null hypotheses for individual variables of treatment $F(1,13)=1.20, p>0.05$, day $F(1,13)=1.51, p>0.05$, and treatment*day $F(1,13)=0.31, p>0.05$ factors did not account for significant proportions of variance in the model (see table 4.8). Researchers detected a medium effect size (partial $\left.\eta^{2}=0.085\right)$ for the treatment vs. control, a medium effect size (partial $\left.\eta^{2}=0.104\right)$ for days, and a small effect size (partial $\left.\eta^{2}=0.024\right)$ for interaction * day.

Table 4.8

Analysis of Variance Summary Table for Learning Environment

\begin{tabular}{lllllll}
\hline Source & $\mathrm{df}$ & $\begin{array}{l}\text { Type III } \\
\text { SS }\end{array}$ & MS & $F$ & $p$ & $\begin{array}{l}\text { Partial } \\
\eta^{2}\end{array}$ \\
\hline Treatment & 1 & 0.98 & 0.98 & 1.20 & 0.29 & .085 \\
Day & 1 & 0.16 & 0.16 & 1.51 & 0.24 & .104 \\
Treatment*Day & 1 & 0.03 & 0.03 & 0.31 & 0.58 & .024 \\
Case & 13 & 10.63 & 0.82 & & & \\
\hline
\end{tabular}

Note: ${ }^{*}=p<0.05$

\section{Assessment}

For Assessment, the overall model explained a significant portion of variance $F(16,13)=3.16, p<0.05$. Researchers failed to reject the null hypotheses for individual variables of treatment $F(1,13)=3.47, p>0.05$, day $F(1,13)=0.86, p>0.05$, and treatment*day $F(1,13)=0.05, p>0.05$ factors did not account for significant proportions of variance in the model (see table 4.9). Researchers detected a large effect size (partial $\eta^{2}=$ 0.211 ) for the treatment vs. control, a medium effect size (partial $\left.\eta^{2}=0.602\right)$ for days, and $n o$ effect size $\left(\right.$ partial $\left.\eta^{2}=0.004\right)$ for interaction * day.

Table 4.9 
Analysis of Variance Summary Table for Assessment

\begin{tabular}{lllllll}
\hline Source & df & $\begin{array}{l}\text { Type III } \\
\text { SS }\end{array}$ & MS & $F$ & $p$ & $\begin{array}{l}\text { Partial } \\
\eta^{2}\end{array}$ \\
\hline Treatment & 1 & 3.60 & 3.60 & 3.47 & 0.08 & 0.211 \\
Day & 1 & 0.29 & 0.29 & 0.86 & 0.37 & 0.062 \\
Treatment*Day & 1 & 0.02 & 0.02 & 0.05 & 0.83 & 0.004 \\
Case & 13 & 13.48 & 1.04 & & & \\
\hline
\end{tabular}

Note: ${ }^{*}=p<0.05$

$\underline{\text { Perceived comfort }}$

For perceived comfort, the overall model explained a significant portion of variance $F(16,13)=9.28, p<0.05$. Researchers failed to reject the null hypotheses for individual variables of treatment $F(1,13)=0.87, p>0.05$, day $F(1,13)=2.74, p>0.05$, and treatment*day $F(1,13)=1.13, p>0.05$ factors did not account for significant proportions of variance in the model (see table 4.10). Researchers detected a medium effect size (partial $\left.\eta^{2}=0.062\right)$ for the treatment vs. control, a large effect size (partial $\left.\eta^{2}=0.174\right)$ for days, and a medium effect size (partial $\left.\eta^{2}=0.080\right)$ for interaction * day.

Table 4.10

Analysis of Variance Summary Table for Perceived Comfort

\begin{tabular}{lllllll}
\hline Source & df & $\begin{array}{l}\text { Type III } \\
\text { SS }\end{array}$ & MS & $F$ & $p$ & $\begin{array}{l}\text { Partial } \\
\eta^{2}\end{array}$ \\
\hline Treatment & 1 & 3.00 & 3.00 & 0.87 & 0.37 & 0.063 \\
Day & 1 & 0.91 & 0.91 & 2.74 & 0.12 & 0.174 \\
Treatment*Day & 1 & 0.37 & 0.37 & 1.13 & 0.31 & 0.080 \\
Case & 13 & 44.87 & 3.45 & & & \\
\hline
\end{tabular}

Note: ${ }^{*}=p<0.05$

Heart Rate Low 
For heart rate low, the overall model explained a significant portion of variance $F(12,6)=$ $8.14, p<0.05$. Researchers failed to reject the null hypotheses for individual variables of treatment $F(1,9)=0.07, p>0.05$, day $F(1,9)=0.02, p>0.05$, and treatment*day $F(1,9)=0.22, p>0.05$ factors did not account for significant proportions of variance in the model (see table 4.11). Researchers detected a medium effect size (partial $\eta^{2}=0.11$ ) for the treatment vs. control, no effect size (partial $\eta^{2}=0.003$ ) for days, and a small effect size (partial $\left.\eta^{2}=0.036\right)$ for interaction $*$ day.

\section{Table 4.11}

Analysis of Variance Summary Table for Heart Rate Low

\begin{tabular}{lllllll}
\hline Source & df & $\begin{array}{l}\text { Type III } \\
\text { SS }\end{array}$ & MS & $F$ & $p$ & $\begin{array}{l}\text { Partial } \\
\eta^{2}\end{array}$ \\
\hline Treatment & 1 & 11.21 & 11.21 & 0.07 & 0.79 & 0.11 \\
.Day & 1 & 0.27 & 0.27 & 0.02 & 0.90 & 0.003 \\
Treatment*Day & 1 & 3.27 & 3.27 & 0.22 & 0.66 & 0.036 \\
Case & 9 & 1362.85 & 1362.85 & & & \\
\hline
\end{tabular}

Note: $*=p<0.05$

\section{Heart Rate Average}

For heart rate average, the overall model explained a significant portion of variance $F(126)=4.89, p<0.05$. Researchers failed to reject the null hypotheses for individual variables of treatment $F(1,9)=0.00, p>0.05$, day $F(1,9)=0.19, p>0.05$, and treatment*day $F(1,9)=1.75, p>0.05$ factors did not account for significant proportions of variance in the model (see table 4.12). Researchers detected no effect size (partial $\eta^{2}=$ 0.002 ) for the treatment vs. control, a small effect size (partial $\eta^{2}=0.031$ ) for days, and a large effect size (partial $\eta^{2}=0.225$ ) for interaction $*$ day.

\section{Table 4.12}


Analysis of Variance Summary Table for Heart Rate Average

\begin{tabular}{lllllll}
\hline Source & df & $\begin{array}{l}\text { Type III } \\
\text { SS }\end{array}$ & MS & $F$ & $p$ & $\begin{array}{l}\text { Partial } \\
\eta^{2}\end{array}$ \\
\hline Treatment & 1 & 0.24 & 0.24 & 0.00 & 0.97 & 0.002 \\
Day & 1 & 3.75 & 3.75 & 0.19 & 0.68 & 0.031 \\
Treatment*Day & 1 & 33.75 & 33.75 & 1.75 & 0.23 & 0.225 \\
Case & 9 & 1011.08 & 122.34 & & & \\
\hline
\end{tabular}

Note: ${ }^{*}=p<0.05$

$\underline{\text { Heart Rate High }}$

For heart rate high, researchers failed to reject the null hypothesis, as the overall model did not account for a significant portion of variance $F(12,6)=0.64, p>0.05$. Researchers failed to reject the null hypotheses for individual variables of treatment $F(1,9)=0.33, p>0.05$, day $F(1,9)=0.48, p>0.05$, and treatment*day $F(1,9)=1.75, p>0.05$ factors did not account for significant proportions of variance in the model (see table 4.13). Researchers detected a small effect size (partial $\left.\eta^{2}=0.036\right)$ for the treatment vs. control, a medium effect size (partial $\left.\eta^{2}=0.074\right)$ for days, and a large effect size (partial $\left.\eta^{2}=0.207\right)$ for interaction * day.

Table 4.13

Analysis of Variance Summary Table for Heart Rate High

\begin{tabular}{lllllll}
\hline Source & df & $\begin{array}{l}\text { Type III } \\
\text { SS }\end{array}$ & MS & $F$ & $p$ & $\begin{array}{l}\text { Partial } \\
\eta^{2}\end{array}$ \\
\hline Treatment & 1 & 18.36 & 18.36 & 0.33 & 0.58 & 0.036 \\
Day & 1 & 38.4 & 38.4 & 0.48 & 0.52 & 0.074 \\
Treatment*Day & 1 & 126.15 & 126.15 & 1.75 & 0.26 & 0.207 \\
Case & 9 & 502.98 & 55.89 & & & \\
\hline
\end{tabular}

Note: ${ }^{*}=p<0.05$

\section{Stress Response}


For stress response, researchers failed to reject the null hypothesis, as the overall model did not account for a significant portion of variance $F(12,6)=0.81, p>0.05$. Researchers failed to reject the null hypotheses for individual variables of treatment $F(1,9)=0.84, p>0.05$, day $F(1,9)=1.16, p>0.05$, and treatment*day $F(1,9)=0.18, p>0.05$ factors did not account for significant proportions of variance in the model (see table 4.14). Researchers detected a medium effect size (partial $\left.\eta^{2}=0.081\right)$ for the treatment vs. control, a large effect size (partial $\eta^{2}=0.162$ ) for days, and a small effect size (partial $\eta^{2}$ $=0.029)$ for interaction $*$ day.

Table 4.14

Analysis of Variance Summary Table for Stress Response

\begin{tabular}{lllllll}
\hline Source & df & $\begin{array}{l}\text { Type III } \\
\text { SS }\end{array}$ & MS & $F$ & $p$ & $\begin{array}{l}\text { Partial } \\
\eta^{2}\end{array}$ \\
\hline Treatment & 1 & 132.17 & 132.17 & 0.84 & 0.38 & 0.081 \\
Day & 1 & 288.20 & 288.20 & 1.16 & 0.32 & 0.162 \\
Treatment*Day & 1 & 44.20 & 44.20 & 0.18 & 0.69 & 0.029 \\
Case & 9 & 1416.02 & 157.33 & & & \\
\hline
\end{tabular}

Note: ${ }^{*}=p<0.05$

\section{$\underline{\text { Steps }}$}

For steps, researchers failed to reject the null hypothesis, as the overall model did not account for a significant portion of variance $F(12,6)=1.12, p>0.05$. Researchers failed to reject the null hypotheses for individual variables of treatment $F(1,9)=0.13, p>0.05$, day $F(1,9)=0.01, p>0.05$, and treatment*day $F(1,9)=0.11, p>0.05$ factors did not account for significant proportions of variance in the model (see table 4.15). Researchers detected a small effect size (partial $\eta^{2}=0.030$ ) for the treatment vs. control, no effect size (partial $\left.\eta^{2}=0.002\right)$ for days, and a small effect size (partial $\left.\eta^{2}=0.017\right)$ for interaction $*$ day. 
Table 4.15

Analysis of Variance Summary Table for Steps

\begin{tabular}{lllllll}
\hline Source & Df & Type III SS & MS & $F$ & $p$ & $\begin{array}{l}\text { Partial } \\
\eta^{2}\end{array}$ \\
\hline Treatment & 1 & 4661.76 & 4661.76 & 0.13 & 0.73 & 0.030 \\
Day & 1 & 258.34 & 258.34 & 0.01 & 0.92 & 0.002 \\
Treatment*Day & 1 & 2673.34 & 2673.34 & 0.11 & 0.76 & 0.017 \\
Case & 9 & 328182.23 & 36464.69 & & & \\
\hline
\end{tabular}

Note: $*=p<0.05$ 


\section{CHAPTER V}

\section{SUMMARY, CONCLUSIONS, IMPLICATIONS, AND RECOMMENDATIONS Purpose of the Study}

The purpose of this study was to identify how the differences in teacher preparation impact the physiological stress preservice teachers experience within the agricultural mechanics laboratory setting, specifically when related to project construction. To address this, several objectives were developed.

\section{Research Questions}

1. What is the measured physiological stress level (heart rate high, heart rate low, stress response and steps) of treatment preservice teachers versus nontreatment preservice teachers?

2. What is the perceived comfort level of treatment preservice teachers' vs nontreatment preservice teachers?

3. What is the perceived teacher effectiveness level (delivery, assessment and learning environment) of treatment preservice teachers' vs non-treatment preservice teachers, from student perspective?

4. To what extent does treatment, days, and interaction of treatment times days explain variation in physiological stress, perceived comfort and teacher effectiveness?

HO1: Differences in treatment, days, and treatment*days does not account for significant $(p>0.05)$ proportions of variance in teaching delivery as perceived by the students. 
Ha1: Differences in treatment, days, and treatment *days accounts for a significant $(p<0.05)$ proportion of variance in teaching delivery as perceived by the students.

HO2: Differences in treatment, days, and treatment*days does not account for significant $(p>0.05)$ proportions of variance in learning environment as perceived by the students.

Ha2: Differences in treatment, days, and treatment *days accounts for a significant $(p<0.05)$ proportion of variance in learning environment as perceived by the students.

HO3: Differences in treatment, days, and treatment*days does not account for significant $(p>0.05)$ proportions of variance in assessment as perceived by the students.

Ha3: Differences in treatment, days, and treatment *days accounts for a significant $(p<0.05)$ proportion of variance in assessment as perceived by the students.

HO4: Differences in treatment, days, and treatment*days does not account for significant $(p>0.05)$ proportions of variance in perceived comfort as perceived by the teacher.

Ha4: Differences in treatment, days, and treatment *days accounts for a significant $(p<0.05)$ proportion of variance in perceived comfort as perceived by the teacher.

HO5: Differences in treatment, days, and treatment*days does not account for significant $(p>0.05)$ proportions of variance in heart rate low of the teacher. 
Ha5: Differences in treatment, days, and treatment *days accounts for a significant $(p<0.05)$ proportion of variance in heart rate low of the teacher.

HO6: Differences in treatment, days, and treatment*days does not account for significant $(p>0.05)$ proportions of variance in heart rate average of the teacher.

Ha6: Differences in treatment, days, and treatment *days accounts for a significant $(p<0.05)$ proportion of variance in heart rate average of the teacher.

HO7: Differences in treatment, days, and treatment*days does not account for significant $(p>0.05)$ proportions of variance in heart rate high of the teacher. Ha7: Differences in treatment, days, and treatment * days accounts for a significant $(p<0.05)$ proportion of variance in heart rate high of the teacher. HO8: Differences in treatment, days, and treatment*days does not account for significant $(p>0.05)$ proportions of variance in stress response of the teacher. Ha8: Differences in treatment, days, and treatment *days accounts for a significant $(p<0.05)$ proportion of variance in stress response of the teacher. HO9: Differences in treatment, days, and treatment*days does not account for significant $(p>0.05)$ proportions of variance in steps of the teacher.

Ha9: Differences in treatment, days, and treatment * days accounts for a significant $(p<0.05)$ proportion of variance in steps of the teacher. 


\section{Limitations of the Study}

The following were identified as limitation to the study:

1. This study used time and place sampling of an intact group of preservice educators. Therefor caution should be taking for interpreting the results of this study beyond the confines of preservice teachers within an agricultural mechanics course in Missouri.

2. Preservice teachers shared their perceptions as a part of the study, however researchers did not record observational data within the confines of the study and cannot verify absolute accuracy of those perceptions.

3. Data collection was limited to preservice agricultural education majors at the University of Missouri.

4. The participants were $75 \%$ female, and $25 \%$ male. $100 \%$ of the participants were Caucasian.

\section{Research design}

This study utilized quasi-experimental design research methods, utilizing nonequivalent control group design (Campbell \& Stanley, 1966).

This process involves a treatment and a control group, however the groups are within predefined groups which are not controlled by the design of the researcher. Groups constitute naturally occurring groups, such as those in predesigned groups, such as classrooms. The assignment of the treatment is assumed to be random, however under the researcher's control (Cambell \& Stanley, 1966). These methods can be assumed to 
control for main effects, such as history, testing and instrumentation. (Campbell \& Stanley, 1966)

This purposive sampling design was utilized, because true randomization could not be accomplished, due to the course being required as within the agricultural education teacher option required course at the University of Missouri.

Sample size will be a limitation to this study, consisting of 16 participants, the researcher acknowledges the limitations of the findings to application with only this sample.

\section{Population}

The target population for this study was preservice agricultural educators at the University of Missouri. The accessible population consisted of preservice educators (soon to be student teaching) for the Fall of 2017 semester ( $\mathrm{n}=16$ ).

Subsequent to Institutional Review Board (IRB) guidelines, participants were recruited via an initial recruitment letter. As participants indicated an interest to be part of the study, an IRB approved consent letter was distributed to participants. Both letters explained potential risk associated with the study, the research project, and participants for this project. 


\section{Instrumentation}

This study utilized four instruments to gather information from the preservice agricultural educators- Firstbeat ambulatory heart rate monitors, pre-class questionnaires, post-teaching reflection questionnaires, and project construction rubrics.

The first instrument utilized focused on the ambulatory heart rate monitors which were similar to those worn by athletes. The device connects directly to the skin via two chest electrodes and the data were downloaded periodically throughout the study into analytic software via USB for data analysis. Participants placed the monitors on themselves prior to the agricultural teaching methods course beginning each course meeting time and removed them once the course was completed each day. Participants wore the devices the previous semester and several weeks prior to the data being collected to acclimate the participants with the monitors. The monitors measured HRV and movement via accelerometer within the device. These devices have been shown to measure physiological stress, stress response, stress recovery, respiration and motion (McCraty \& Atkinson, 1996).

The second instrument (Appendix D) was a daily journal. This questionnaire was given to all participants at the beginning of each class period and included questions regarding their perceived comfort, measured on a six-point scale: $0=$ Very Low, 1, 23=Moderate, 4, \& 5=Very High and provided background information for monitor data accuracy. Information was in regard to caffeine, alcohol and drug intake was documented within this journal. Some data were removed from the first instrument due to answer placed on the second instrument in regard to drug usage particularly to reduce stress. 
The third instrument (Appendix C) measured teacher perceived effectiveness from the students' perspective. Teacher perceived effectiveness was measured utilizing an paper and pencil instrument (Peterson, Wahlquist, \& Bone, 2000) previously developed for a similar population with a Cronbach's alpha value of 0.91 and test-retest correlation of 0.96 (Peterson, Wahlquist, \& Bone, 2000). The scale consists of 12 items on a 5-point Likert type scale: $1=$ Strongly Disagree, $2=$ Disagree, $3=$ Neutral, \& 4=Agree, 5=Strongly Agree. Face and content validity were established by a panel of four experts in agricultural mechanics education. The instrument was field tested prior to the study on 16 similar preservice teachers enrolled in an agricultural mechanics teaching method course at Tarleton State University. The instruments yielded Cronbachs's alphas reliability coeffecients of 0.87 and test-retest correlation of 0.92 .

The fourth instrument was a project construction rubric, each project was scored utilizing the same educational expert and rubric (Appendix B) throughout the course for project quality scoring at the completion of each project. The rubric scores for each project were compared to the treatment and control groups to determine if any significant differences exist.

\section{Data collection procedures}

Data were collected from participants in person during their preservice preparation course in the Fall of 2017. Participants were in the final year of teacher preparation coursework at the University of Missouri (they would soon student teach and then graduate). The sixteen participants agreed to participant in the study by signing an 
IRB approved consent form after responding to the recruitment letter distributed to students within the course. Participants were assured of their confidentiality, data storage security and potential risks via these documents as required by IRB.

The agricultural mechanics teaching methods course was designed to teach preservice teachers how to manage an agricultural mechanics laboratory, construct projects effectively, and safely after they had become agricultural educators. The course scaffolds students from initial knowledge establishment of nomenclature, micro teaching of individual tools and their uses and concludes with student built projects. Students also serve in the role of "teacher for the day" on a rotational schedule throughout the course. This allows for the students to gain the depth of knowledge required prior to the construction of their projects. The course syllabus can be seen within Appendix A.

Sixteen preservice educators were given notification of their date of instruction, the type of project that they would construct and the number of students they will be instructing on the first day of the course. The sixteen participants were randomly placed into four groups for each of the four projects they would construct within the confines of the agricultural mechanics teaching methods course. Although the sampling was randomized through placement of groups, the sampling was purposive in nature. Participants each assumed the role of teacher for one project, leaving them with three students in their group. Once the project was completed, the "teacher" of the previous project rotated to a student role and another group member assumed the teacher role for the next project. This system allowed all sixteen participants to assume the role of the teacher for one project. This method alleviated any one participant from increasing their 
comfort level teaching any of the projects. The rotational schedule is shown in Figure 3.1 below.

\begin{tabular}{l|l|l|}
\hline \multicolumn{2}{c}{} & \multicolumn{2}{l}{ Prepared } \\
\cline { 2 - 3 } Metal Project 1 & $\mathrm{T} 1$ & $\mathrm{~S} 1$ \\
\cline { 2 - 3 } & $\mathrm{S} 2$ & $\mathrm{~S} 3$ \\
\cline { 2 - 3 } & & \\
\cline { 2 - 3 } Metal Project 2 & $\mathrm{~S} 4$ & $\mathrm{~T} 2$ \\
\cline { 2 - 3 } & $\mathrm{S} 5$ & $\mathrm{~S} 6$ \\
\hline Wood Project 1 & $\mathrm{S} 7$ & $\mathrm{~S} 8$ \\
\hline & $\mathrm{T} 3$ & $\mathrm{~S} 9$ \\
\hline & & \\
\hline Wood Project 2 & $\mathrm{S} 10$ & $\mathrm{~S} 11$ \\
\cline { 2 - 3 } & $\mathrm{S} 12$ & $\mathrm{~T} 4$ \\
\cline { 2 - 3 } & &
\end{tabular}

Prepared
\begin{tabular}{|l|l|}
\hline T5 & S13 \\
\hline S14 & S15 \\
\hline & \\
\hline S16 & T6 \\
\hline S17 & S18 \\
\hline
\end{tabular}

Unprepared
\begin{tabular}{|l|l|}
\hline T9 & S 25 \\
\hline S26 & S27 \\
\hline
\end{tabular}

Unprepared
\begin{tabular}{|l|l|}
\hline T13 & S 37 \\
\hline S38 & S 39 \\
\hline
\end{tabular}

\begin{tabular}{|l|l|}
\hline S28 & T10 \\
\hline S29 & S30 \\
\hline
\end{tabular}

\begin{tabular}{|l|l|}
\hline S40 & T14 \\
\hline S41 & S42 \\
\hline
\end{tabular}

\begin{tabular}{|l|l|}
\hline S19 & S20 \\
\hline T7 & S21 \\
\hline
\end{tabular}

\begin{tabular}{|l|l|}
\hline S31 & S32 \\
\hline T11 & S33 \\
\hline
\end{tabular}

\begin{tabular}{|l|l|}
\hline S43 & S44 \\
\hline T15 & S45 \\
\hline
\end{tabular}

\begin{tabular}{|l|l|}
\hline $\mathrm{S} 22$ & $\mathrm{~S} 23$ \\
\hline $\mathrm{S} 24$ & $\mathrm{~T} 8$ \\
\hline
\end{tabular}

\begin{tabular}{|l|l|}
\hline S34 & S35 \\
\hline S36 & T12 \\
\hline
\end{tabular}

\begin{tabular}{|l|l|}
\hline S46 & S47 \\
\hline S48 & T16 \\
\hline
\end{tabular}

Figure 3.1 Research Design

A total of four groups existed within the rotational schedule. This design was chosen to allow each participant to assume the role of the teacher for one project. The participants were randomly assigned to their groups and remained as an intact group throughout the study. The four groups were divided into two treatment groups and two control groups.

The treatment and control groups had access to all of the same resources for the projects to be constructed. The participants were only allowed to utilize the provided bill of materials and construction plans during their project construction.

The control groups were defined by the following: (1) the control group did not receive any outside assistance prior to the completion of their projects, (2) the control group participants within the teacher role, received the same guidance during the construction of the projects as the treatment group within the confines of the course meeting time, and (3) the control group did not receive any guidance outside of class meeting time regarding their project. 
The treatment groups were defined by the following: (1) received guidance ahead of time for the project where they would assume the teacher role, (2) guidance consisted of the participant building the project they taught ahead of their teaching time with the University instructor for the course, (3) the participant completed the project achieving a grade of $95 \%$ or better on their first attempt, prior to teaching their students.

All participants (both preservice teachers and students) began wearing ambulatory heart rate monitors at the beginning of the course each day two weeks prior to the first data being collected to acclimate participants to the wearing monitors. Participants wore the monitors daily within the course and took them off each day at the conclusion of the course. Participants had additionally worn the monitors in the previous spring semester for acclimation to the monitors. In addition to wearing the monitors participants completed instrument 2 (Appendix D) which was used to record their perceived comfort and provided background information for monitor data accuracy.

At the conclusion of course meeting time each day, participants within the role of student for that day, completed instrument 3 (Appendix C) that was designed to measure their perceived effectiveness as a teacher (Peterson, Wahlquist, \& Bone, 2000).

Participant characteristics were controlled for by utilizing purposive random assignment to groups and assignment to treatment, providing detailed instruction prior to project construction to 8 of the groups. Plans, materials, and tool availability were the same for all groups. Groups were separated into to different labs to avoid cross contamination during the project construction process. This isolation allowed for groups to work on their own without interference or influence from other groups. Despite 
isolation design, researchers acknowledge spill over (or discussion after class between the students) was a threat to the study.

Each project was scored utilizing the same educational expert and rubric, instrument 4 (Appendix B) throughout the course for project quality at the completion of each project. The rubric scores for each project were compared to the treatment and control groups to determine if any significant differences existed.

\section{Research Question One}

\section{Summary of Findings}

Research question one sought to measure the physiological stress level (heart rate high, heart rate low, stress response and steps) of treatment preservice teachers versus control preservice teachers when teaching project construction. Research question one was answered from the perspective of the treatment and non-treatment preservice teacher. The data were interval in nature; construct summated mean scores, median, mode, variance, standard deviation, and range were reported for preservice teachers within questions one. The day one treatment group heart rate high $(M=127.25 .00, S D=7.54)$ and control group heart rate high $(M=122.17, S D=9.06)$ revealed a slightly higher heart rate in the treatment group. While the day two treatment group heart rate high $(M=$ $120.00, S D=4.36)$ and control group heart rate high $(M=125.00, S D=8.55)$ showed a slightly lower heart rate for the treatment group. The day one treatment group heart rate low $(M=79.75, S D=13.72)$ and control group heart rate low $(M=79.00, S D=9.48)$ 
were similar. While the day two treatment group heart rate low $(M=79.00, S D=12.16)$ and control group heart rate low $(M=74.83, S D=5.30)$ showed a slightly lower heart rate. The day one treatment group steps $(M=424.50, S D=59.17)$ and control group steps $(M=440.67, S D=171.15)$ revealed less steps taken by the treatment group. While the day two treatment group steps $(M=368.33, S D=313.79)$ and control group steps $(M$ $=431.17, S D=158.65)$ a lower number of steps taken by the treatment group as well. The day one treatment group stress response $(M=67.75, S D=8.18)$ and control group steps $(M=79.83, S D=5.38)$ revealed less stress response by the treatment group. While the day two treatment group stress response $(M=61.67, S D=14.57)$ and control group stress response $(M=64.50, S D=20.67)$ a lower stress response taken by the treatment group as well.

\section{Conclusions}

It was concluded that the treatment group had fewer steps and less stress response, but higher heart rates on day one. While the statistical comparison of treatment and control groups did not reveal significant findings, the measured physiological stress of all teachers was above the average of a normal working level (Firstbeat, 2017). All participants were stressed with little to no recovery time within the 150 minute teaching window. (Firstbeat, 2017). Stress response for day one treatment, day one control, day two treatment, and day two control were all above the more than usual stress response of 60 (Firstbeat, 2014).

Previous researchers have established agricultural mechanics teachers perceive they are stressed when teaching ag mechanics, and agricultural mechanics teaching is 
physically demanding. This study adds to the body of knowledge regarding teacher stress by documenting the biological stress response to teaching project construction in the agricultural mechanics laboratory.

The day two treatment group experienced a reduction in stress on day two due to their treatment of completing the project ahead of time. Treatment group heart rates and stress were lower while their projects are being constructed on day two. Researchers compared the content taught on day one vs. day two; for day one teachers were teaching about rubrics, cutting materials out, but not necessarily constructing all of the projects they were completing lower level project construction. In contrast, day two required teachers to guide students through the complex process of project construction, including adapting instruction to account for student mistakes. Researchers concluded the treatment lowered stress on day two for the application of knowledge and problem solving strategies required for successful project construction. Both groups showed less steps on day two, indicating as teachers become more acclimated to teaching within the agricultural mechanics laboratory they could reduce their physiological stress. The treatment group was a lower number of steps than the control on both day one and day 2 .

\section{Implications}

Agricultural mechanics education is the top career choice among Missouri high school agriculture students (Chumbley et al., 2013). University preparation courses include teaching methods specific course for agricultural mechanics. Despite this specific teaching methods course, overall participants engaging in the act of teaching, (both treatment and control) are all stressed at an elevated level. 
Agricultural mechanics teacher preparation courses provide modeling to lower stress within a controlled environment. Stringham \& Swan (2012) asserted the integration of modeling to teach agricultural mechanics skills which could be dangerous, burdensome or costly could be the solution.

Student lead project construction is valuable in the teacher preparation process (Agnew \& Shinn, 1990), providing practical educational experiences to better prepare educators. Agricultural mechanics course instructors were able to generate an authentic teaching environment through the teacher for a day model. Preservice students who received project construction instruction prior to their teacher for day experienced less physiological stress, particularly on day two. Although the stress scores diminished for both control and treatment from day one to day two, the treatment teachers were able to reduce their stress in a greater proportion and flip their higher heart rates from day one to lower rates on day two. Within the Lazarus Model (1991) these educators have progressed through the secondary appraisal, future expectancy and are progressing through the threat as they know this will be a routine portion of their future agricultural educator careers. Teacher education programs with agricultural mechanics methods courses and teacher for a day should incorporate pre-project construction treatments for all student-led project construction assignments

It is recommended University personnel intentionally replicate the treatment for all students in the agricultural mechanics methods course for each project as a stress reduction technique. Student teaching programs expanding their agricultural mechanics course to include not only what the tools are and how to use but also teaching methods within agricultural mechanics to reduce teacher physiological stress. With reduced 
physiological stress on beginning teachers with more experience, we would likely see less stress associated with agricultural mechanics instruction, and less teacher attrition from stress.

Teachers within the research project were completing small agricultural mechanics projects with very few students assigned to them. These same teachers will be completing larger, more complex projects with full size classes, increasing all of the difficulty related to agricultural mechanics teaching. It would seem logical, as all of these items such as increased class size, increased project complexity and removal of a structured environment these teachers who are all already stressed will face an even greater level of stress.

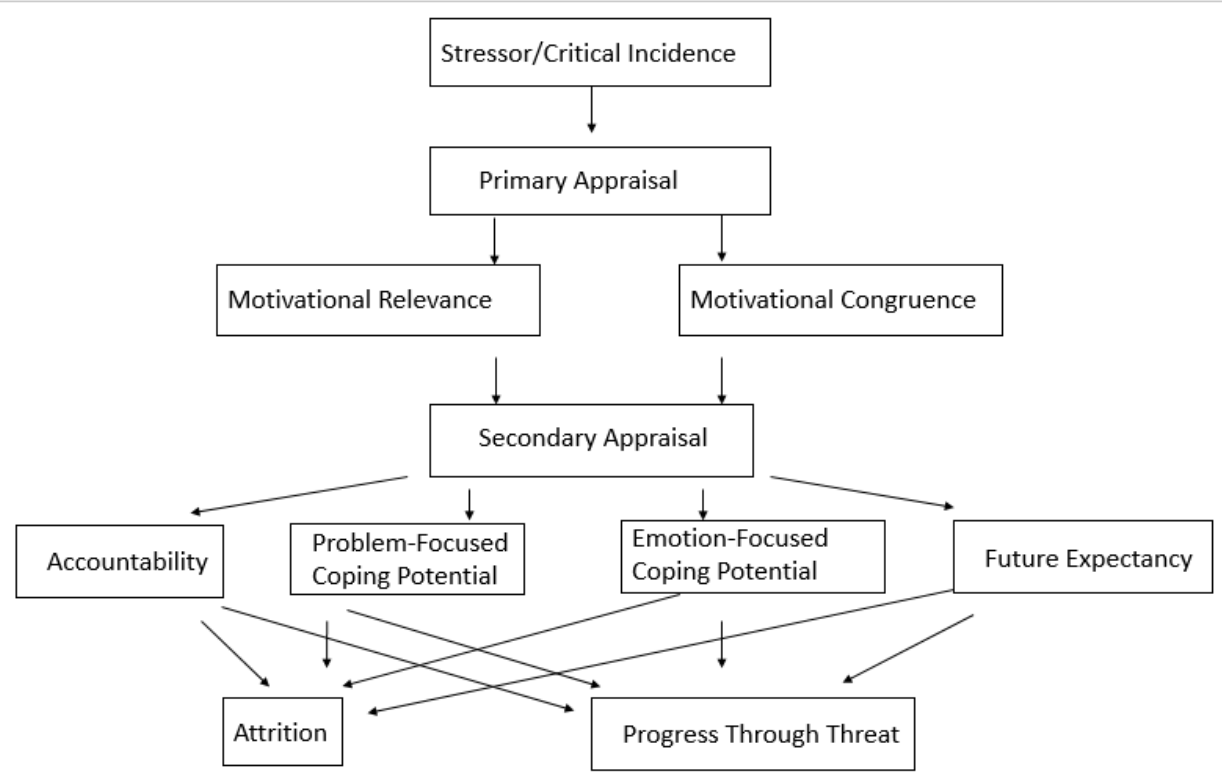

Figure 2. Model of Lazarus's Theory of Psychological Stress 


\section{Research Question Two}

\section{Summary of Findings}

Research question two sought to measure the perceived comfort level of treatment preservice teachers' vs non-treatment preservice teachers? Research question two was answered from the perspective of the teacher: on a scale from $1=$ Strongly Disagree, $2=$ Disagree, $3=$ Neutral, $4=$ Agree, and $5=$ Strongly Agree $($ Control, $M=2.87, S D=1.12$, Treatment, $M=3.28, S D=1.60)$ The data were interval in nature; construct summated mean scores, median, mode, variance, standard deviation, and range were reported for preservice teachers within questions two. Teacher perceived effectiveness were measured utilizing an instrument (Peterson, Wahlquist, \& Bone, 2000) previous developed for a similar population.

\section{Conclusions}

On average, participants were not comfortable leading their classmates in project construction; participants' overall perceived comfort levels were in the disagree to neutral categories when asked if they were confident concerning their teaching ability. In a specific instance, one of the treatment participants rated their comfort as a zero after building the project, ahead of time with a University instructor.

All teachers, both treatment and control, lacked confidence in carrying out their assigned teacher roles. Anderson (2010) found teachers with little or low confidence do not succeed consistently within the confines of the classroom. The Lazarus Model (1991) shows this to be true as well, participants who are within the confinement of the 
preservice teacher program are provided with a structure to assist with accountability, problem focused coping, emotion focused coping and future expectancy in hopes of accomplishing progression through the threat. The treatment group constructed their projects prior to teaching their students utilizing all tools and supplies, yet despite their experience, those teachers showed a lack of confidence similar to those who had not been exposed to the project prior to teaching.

Skills within the agricultural mechanics laboratory are visibly and easily assessed as either an individual can accomplish the task or they fail to accomplish the task. These skills and tasks within the laboratory such as using a cutting torch, or similar tools have very tangible assessments. An individual can either use them or not, it's not something you can stumble through and just find your way,

Increasing the agricultural mechanics time in the laboratory and exposure to tools, skills and processes would be recommended. Similarly, Rasty, Anderson, \& Paulsen (2017) found that teachers are more effective when the agricultural mechanics educator is exposed more courses over their lifetime.

\section{Implications}

Within this class, students are asked to develop their agricultural mechanics skills, teach classmates agricultural mechanics skills, and supervise classmates applying skills in constructing a small project. University personnel should consider adding a prior agricultural mechanics skill class in order to spend more time in teaching students how to teach skills and supervise student project construction. Educators accomplish skill development in a variety of teaching methods, however once students must put a variety 
of skills together to create a project, educators must scaffold the project construction portion (Schumacher \& Johnson, 1990). Once students accomplish the use a cutting torch, for example, they may not necessarily know how to teach how to use a cutting torch.

Teachers need to be confident in the subject matter they are teaching, not matter the content educators should prepare and possess a level of confidence that would allow them to educate their students. While these teachers were within small groups with peers they had self-perceived confidence issues. As these students progress they will be teaching the same content matter to classes of 25 or more students in a short amount of time. Confidence in content needs to be built to better prepare our teachers, which in turn will aid in their retention. These skills were directly modeled to the treatment group; however, the treatment group did not have significantly different results than the control. Some of the participants indicated lack of experience within the content area which should be increased to aid in a decrease in stressor events.

\section{Research Question Three:}

\section{Summary of Findings}

Research question three sought to determine the perceived teacher effectiveness level (delivery, assessment and learning environment) of treatment preservice teachers' vs non-treatment preservice teachers, from student perspective? Research question three was answered from the perspective of the student.: on a scale from $1=$ Strongly Disagree, 2=Disagree, $3=$ Neutral, 4=Agree, and $5=$ Strongly Agree The data were interval in nature; construct summated mean scores, median, mode, variance, standard 
deviation, and range were reported for preservice teachers within questions three.

Teacher perceived effectiveness were measured utilizing an instrument (Peterson, Wahlquist, \& Bone, 2000) previous developed for a similar population. Pilot tests were conducted on a similar population of preservice agricultural education students and found to be reliable and valid. The day one treatment group delivery $(M=4.58, S D=0.15)$ and control group delivery $(M=4.03, S D=1.06)$ revealed a slightly higher delivery ranking in the treatment group. While the day two treatment group delivery $(M=4.48, S D=$ $0.15)$ and control group delivery $(M=3.96, S D=0.93)$ again revealed a slightly higher delivery ranking in the treatment group. The day one treatment group assessment $(M=$ $4.75, S D=0.20)$ and control group assessment $(M=4.01, S D=0.99)$ revealed a slightly higher assessment ranking in the treatment group. While the day two treatment group assessment $(M=4.50, S D=0.44)$ and control group assessment $(M=3.86, S D=1.17))$ again revealed a slightly higher assessment ranking in the treatment group. The day one treatment group learning environment $(M=4.71, S D=0.22)$ and control group learning environment $(M=4.28, S D=0.62)$ revealed a slightly higher learning environment ranking in the treatment group. While the day two treatment group learning environment $(M=4.19, S D=1.04)$ and control group learning environment $(M=4.49, S D=0.47)$ revealed a slightly higher learning environment ranking in the control group.

\section{Conclusions}

The delivery portion of the teacher effectiveness model showed teachers were effective as perceived by the students in both the treatment and control groups, despite 
having low comfort levels. Participants rated their classmates as being effective at their teaching, as to be expected from senior level pre service teachers.

Learning environment scores did not differ between the treatment and control groups. Despite the attempt for instructors to create a realistic teaching scenario, the learning environment was impacted by support from the course instructors. Specifically, project construction supervision was not authentic within the research project, as University supervisors were in the laboratory setting, assisting with supplies, safety supervision, and answering questions from the peer teachers, thus creating a nonauthentic environment that will not be similar whenever they become classroom teachers.

Treatment teachers were perceived better by their students at delivery and assessment as compared to the non-treatment teachers. The confines of the research project could also create some complication with peers wanting peers to succeed (Carmona, Buunk, Peiro, Rodriguez, \& Bravo, 2006). These students and teachers were with the confines of a teacher preparation program together and spend a great deal of time learning to teach together bonding the students. Additionally, teachers had the support of teacher preparation program educators to rely on for assistance while teaching within the confines of this course, this will not be the case once they move forward as educators within a short period of time.

The researchers collected project grades via the class construction rubric. However, all students scored an "A" on their projects based on the rubric. These data triangulate the assertion that overall teaching was effective.

\section{Implications}


Learning environment within teacher preparation programs is created by faculty and staff, not just inclusive to the agricultural laboratory, but across other subjects as well and within teaching methods. For instance, in agricultural mechanics, the university faculty provides the boards, the metal materials, ensures the welders are functional, etc. Whereas when participants become high school teachers, they will have to provide all these things for their students. Participants will have to be prepared enough to have all the materials ready before the coursework starts for the next day.

Modeling is a desired behavior and important for agricultural mechanics education it is also an effective teaching tool for skill development. Stringham \& Swan (2012) asserted the integration of modeling to teach agricultural mechanics skills which could be dangerous, burdensome or costly could be the solution.

Power tool skills do not equate to project construction skills, and teaching tool usage successfully is a portion of project construction, but not equivalent to project construction. Blackburn, Robinson, \& Lamm (2014) stated innovative students are able to solve complex problems more completely within agricultural mechanics. Once the skill are taught, then the application of those skills begin in a supervised environment until mastery has been accomplished. These discreet skills should not be lumped together in research on teaching stress in the agricultural mechanics laboratory.

Teachers within the study overall found a way to teach their students effectively, overall projects completed received an overall rating of "A". Students throughout the ratings of their teachers rated their teachers were effective. As indicated above the participants are all within a student teaching cohort and could desire to see their peers succeed. Although the teachers were rated as doing an effective job at teaching their 
students the question must be asked at what cost? The teachers perceive themselves as not doing a good job and having low comfort levels while teaching, yet somehow, they are succeeding overall. Prepared or unprepared teachers navigated through their specific challenges to be rated well by their students. These teachers were all set up for success, they had plans, bill of materials and cut lists for their projects so preparation was completed, a step the teachers will have to complete on their own once graduated and teacher educators in a few short months. Additionally, the higher scores could likely be a part of the teachers' backgrounds, which were senior teacher education students enrolled in a teacher prep program at a land grant university. The teacher preparation program has created the environment of proven successful teacher educators in past graduates. The unique environment of teaching within the agricultural mechanics laboratory does create a number of complex issues, teachers and students must learn to manage in order to be successful within this learning environment.

\section{Research Question Four:}

\section{Summary of Findings}

Research question four sought to determine to what extent does treatment, days, and interaction of treatment times days explain variation in physiological stress, perceived comfort and teacher effectiveness. Research question four was answered from the perspective of the student and teacher. The data were interval in nature; construct summated mean scores, median, mode, variance, standard deviation, and range were 
reported for preservice teachers within questions three. Teacher perceived effectiveness were measured utilizing an instrument (Peterson, Wahlquist, \& Bone, 2000) previous developed for a similar population. Pilot tests were conducted on a similar population of preservice agricultural education students and found to be reliable and valid.

For teaching delivery, differences in treatment, days, and treatment*days explained a significant portion of variance. Researchers failed to reject the null hypotheses for individual variables of treatment, and treatment*day factors did not account for significant proportions of variance in the model. Researchers detected a large effect size for the treatment vs. control, a small effect size for days, and no effect size for interaction * day.

For Assessment, the overall model explained a significant portion of variance. Researchers failed to reject the null hypotheses for individual variables of treatment, day, and treatment*day factors did not account for significant proportions of variance in the model (see table 4.9). Researchers detected a large effect size for the treatment vs. control, a medium effect size for days, and no effect size for interaction * day.

For perceived comfort, the overall model explained a significant portion of variance. Researchers failed to reject the null hypotheses for individual variables of treatment, day, and treatment*day factors did not account for significant proportions of variance in the model. Researchers detected a medium effect size for the treatment vs. control, a large effect size for days, and a medium effect size for interaction * day.

For heart rate low, the overall model explained a significant portion of variance. Researchers failed to reject the null hypotheses for individual variables of treatment, day, and treatment*day factors did not account for significant proportions of variance in the 
model Researchers detected a medium effect size for the treatment vs. control, no effect size for days, and a small effect size for interaction * day.

For heart rate average, the overall model explained a significant portion of variance. Researchers failed to reject the null hypotheses for individual variables of treatment, day, and treatment*day factors did not account for significant proportions of variance in the model Researchers detected no effect size for the treatment vs. control, a small effect size for days, and a large effect size for interaction * day.

For heart rate high, researchers failed to reject the null hypothesis, as the overall model did not account for a significant portion of variance. Researchers failed to reject the null hypotheses for individual variables of treatment, day and treatment*day factors did not account for significant proportions of variance in the model. Researchers detected a small effect size for the treatment vs. control, a medium effect size for days, and a large effect size for interaction * day.

For stress response, researchers failed to reject the null hypothesis, as the overall model did not account for a significant portion of variance. Researchers failed to reject the null hypotheses for individual variables of treatment, day, and treatment*day factors did not account for significant proportions of variance in the model. Researchers detected a medium effect size for the treatment vs. control, a large effect size for days, and a small effect size for interaction* day.

For steps, researchers failed to reject the null hypothesis, as the overall model did not account for a significant portion of variance. Researchers failed to reject the null hypotheses for individual variables of treatment, day and treatment*day factors did not 
account for significant proportions of variance in the model. Researchers detected a small effect size for the treatment vs. control, no effect size for days, and a small effect size for interaction * day.

\section{Conclusions}

The treatment accounted for large differences in teaching delivery and assessment; medium differences in learning environment, perceived comfort, heart rate low (control was lower), and stress response; and a small effect size in heart rate high (treatment higher day one, control higher day two), and steps. Researchers concluded the treatment of modeling project construction for peer teachers resulted in improved instruction from the perspective of the students in the areas of teaching delivery and assessment. Teaching delivery more specifically in regard to explanations, well prepared, and utilization of examples. Assessment, more specifically, referred to communicating student performance, grading of projects and providing feedback for future improvement.

The days accounted for a large effect size for perceived comfort, stress response, a medium effect size for learning environment, assessment, heart rate high, and a small effect size for teaching delivery and heart rate average. Both treatment and control teachers felt much more comfortable and showed less stress response on day two.

Researchers did not anticipate the proportion of variance from day one to day two within the treatment and control groups. The course is a semester long class and researchers failed to appreciate the variance within project construction days on how novice teachers might change with experience through the process. Project construction is difficult and stressful for students, but the teacher for a day assignment works in that the students can 
manage project construction with more confidence and less stress after doing it as a part of this class.

Within agricultural mechanics, project construction is new and novel, typically agricultural educators do not repeat projects with the same group of students. Agricultural educators move quickly through the confines of each course, not permitting of a lull, there is a steep learning curve, and removing time to build self-confidence (Torres, Lambert, \& Tummons, 2012).The benefits of treatment time invested in construction of their projects prior to teaching is revealed on day two, participants which received the treatment, revealed their comfort, heart rate, stress response, delivery and assessment as lower than the control group. When referring to the work or projects the teachers were completing on day one of project construction students are cutting things out, measuring, locating the proper tools, etc. On day two students are putting projects together so creating a scenario where researchers would likely see higher stressor events on day two as opposed to day one. Researchers determined the first day of project construction is stressful regardless of preparation type, but teachers' stress is reduced with experience on day two.

\section{Implications}

Saucier, Terry, \& Schumacher (2009) recommended agricultural mechanics educators to seek additional development within the content area. Participants within the study who had completed the project had better success with their students on day two, researchers would like to further explore repeated project construction and lowered stress 
response. Participants who have completed the same project a multitude of times and their rise or reduction in stress levels.

Thoron, Myers, \& Cody (2008) found educators experienced stress when not receiving the same laboratory settings they had previously experienced. Participants should be exposed to the University laboratory settings prior to the beginning of the agricultural teaching methods course. Participants were in an unfamiliar environment and maintained heart rates were at an elevated rate throughout day one and day two, along with across treatment and non-treatment groups. Encouraging familiarity with the diverse laboratory settings could alleviate a portion of stressor events educators are experiencing.

Preservice educators will be taking on the role of teacher shortly after this course, once they become responsible they must acknowledge the need to be able to run towards problems versus running from problems. These students participate in a fire extinguisher demonstration for example, which help students understand that it's their responsibility to act in loco parentis. During this demonstration, participants were obviously fearful, however they learned to run towards the problem. The participants all utilized the fire extinguisher and successfully extinguished the fire.

Gu \& Day (2007) found resiliency to be an effective method for educators to process through these stressful situations. Teachers within the study were rated by their students as delivering a quality education. Rasty, Anderson, \& Paulsen (2017) found the more courses an agricultural mechanics educator is exposed to over a lifetime increases the importance of those skills to be taught effectively.

Tummons, Langley, Reed \& Paul (2016) looked specifically at females within the agricultural mechanics laboratory who experienced stress to the point of possessing 
mortality concerns. Similarly, teachers amongst day one and day two continued to have stressor events at an elevated level, Firstbeat (2014) despite students rating their teachers as creating a successful learning environment.

\section{Recommendations for Practice}

The first recommendation is directed towards teacher preparation programs. Agricultural education students are likely to teach agricultural mechanics as a high school agriculture teacher (Phipps, Osborne, Dyer, \& Ball, 2008). The agricultural mechanics preparation curriculum should include early coursework in agricultural mechanics skill instruction early in the educational careers to allow the primary and secondary appraisal, followed by the perception of individual coping ability of the Lazarus Model (1991) to begin. This will allow the two-part appraisal phase to begin within the confines of being a student before they are asked to teach agricultural mechanics content.

Through the Lazarus Model (1991), we know a stress event occurs, such as requiring novice teachers to teach project construction. Once the event occurs, the participants enter the primary appraisal phase determining if it is motivationally relevant or important, since the course is required the students move forward with the secondary appraisal phase. The secondary appraisal phase which includes accountability, problem and emotional focused copping, and future expectancy. The first three of these is provided through the University system and the fourth, future expectancy is acknowledged through the future expectation to be required to teach project construction once obtaining an agricultural educator position. With all of these events combined each participant ends at either attrition or progression through the threat. 
The second recommendation is for school administrators to come up with a solution from a liability standpoint of lack of knowledge or control of substances used by students before class. Firstbeat removed some student data in response to validity issues stemming from self-reported substance use among participants. How are teachers to know if students are taking prescription or other substances prior to class? How do we teach preservice teachers to handle situations where their own students are under the influence of a substance? What is the liability of a teacher if a student has an accident under their supervision? This creates a multitude of safety concerns.

The third recommendation is for teacher preparation programs to work with students pursing agricultural education positions within agricultural mechanics content specifically to subside their fears and concerns. Data revealed University instructors or agricultural mechanics instructors in general should lead more in project construction through modeling. Those teachers who do not receive this additional training are likely to meet the attrition stage of the Lazarus (1991) model, exiting agricultural education.

The fourth recommendation is for educators to work toward identify and recruit those students who possess problem focused coping skills while in a stressed environment. These are the students who succeeded within this study, this would also align with the Lazarus (1991) model some individuals cope while focusing on the problem and some do not. While those do not could be taught as was in the case with students early in this course who were fearful of utilizing a fire extinguisher until taught how to use it properly. What is the relationship between students' lack of problem focused coping skills and substance use, stress, and attrition? What internal and external pressures do students feel in terms of teaching agricultural mechanics and project construction in their role as 
agriculture teacher?

The fifth recommendation is increase modeling to reduce teacher stress within the agricultural mechanics laboratory. As students are exposed to stressor events which are novel, they seem to become more comfortable with the items once the novelty dissipates. The students embraced the stress of day one and should be shown how to use problem focused strategies to succeed.

The sixth recommendation is in regards specifically to project construction. University personnel should intentionally work with students who will be teaching project construction and have those teachers build their projects before they teach students.

\section{Recommendations for Future Research}

Little research has been conducted on teachers within the agricultural mechanics project construction within teacher preparation programs. Specifically, knowledge the students enter the program with and knowledge student are supposed to exit the program with.

A larger population is needed, the study replicated with other groups across agricultural mechanics programs would allow for better transferability. While this study had several models that possessed significant interactions, the lack of number of participants across broader populations hindered the research from making accurate conclusions.

Researchers recommended replicating this study with current practicing agriculture teachers who are not comfortable in the agricultural mechanics laboratory and 
alternatively certified teachers.

Additionally, expert teachers should be measured to determine their confidence, delivery, and stress levels of these items and their measured recovery (calming down of the body). This would provide a baseline of experts to know where teacher preparation program educators should be. Additionally, teachers in the 3-5-year time frame should be measured as this is the time agricultural educators separate from teaching.

Researchers would recommend identifying teacher preparation programs with more required laboratory time and measure the stress level of the students and those programs. Exploring the dynamic of more time, more preparation and laboratory time can reduce the stress levels of students.

Additionally, a comparative study of classroom subjects, such as animal science or horticulture versus conducting laboratory skills and agriculture mechanics. We know teachers are stressed when project construction within agricultural mechanics begins, however do these teachers experience the same stress with other subjects they are required to teach?

Exploration of experienced students within agricultural mechanics should conducted to seek out those students who have completed a project in high school, or outside of the classroom environment and how those students respond to stress as compared to their peers.

Identifying how much stress is skill related, safety related, project management related would be of value to agricultural education teacher preparation programs and should be further explored. 
Researchers appreciate the experience of teachers who have been constructing projects with their students for years. Researchers would like to explore this experience to see if there is a point where educators of any experience level enter recovery mode within the agricultural mechanics laboratory or do expert teachers experience the same stress with no recovery. 


\section{Appendix A}

Course Syllabus

Agricultural Education \& Leadership 3320

Metal Fabrication and Laboratory Management

Fall Semester 2017

Instructor:

Dr. John Tummons

123 Gentry Hall

Cell: (573)-680-9467

tummonsi@missouri.edn

Times and Locations

Tuesday and Thursday 8:00am - 10:30 am

Open lab Wednesday afternoon and by appointment

$107 / 130 \mathrm{Ag}$ Engiweering

\section{Course Description}

Application of metal fabrication skills, incluaing cutting, bending, and welding, using a variery of processes. Operations of hand tools and power equipment used in project construction. Also includes laboratory management, instructional strategies, and assessment techniques related to secondary agriculture programs. Junior standing required.

\section{Essential Question}

How do I gafely and effectively manage learning in a laboratory?

\section{Course Objectives}

At the conclusion of this class, the student will learn how to:

> Implement a safety training $\delta$ assessment program for an agricultural mechanics laboratory in a secondary school.

> Teach and evaluate students in an agricultural mechanics laboratory.

> Identify. plan and supervise student agricultural mechanics project construction.

> Perform easential technical akills in netal fabrication, wood construction, plumbing, and project design

- Evaluate projects based on the factors of cost, cuality of construction, and resources needed

\section{Required Textbooks- (Bring Power tool book and course packet to class each day)}

1. Hoemer \& Bettis Power tool gafety and operation (and teacher anawer key), 2008 Hobs Publications hittp//www. finnexco.com hobar.html

2 Course Packet- Safery Teats (Available from the Mizzou Store)

3. Lincoln Instructor's resources: hittp/www.lincolnelectric.com/en-us/education-center/trainingmaterials/Pages/training-materials aspx (will be provided)

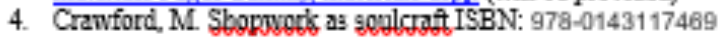

Suggested Textbook for novices-

1. Herren. Ray V Agricultural Mechanics. Fundamentals und Applications $\left(5^{\text {th }}\right.$ or $6^{\star}$ Edition). Cengage Learning

Helpful websites

- Courses missouri.edu Canvas website for Ag Bd 3320

- https//dese.mo.gov/sites/default/files/Standard5\%20\&\%200ualitys\%20Indicators.pdf

- http//www-im5.tamuedu/doc:2/8411 pdf-DMS safety and lab procedures guide

- httpg//dese.mo.gov/college-career-readiness/career-education/agricultural-education/agriculturaleducation - Competency profiles 
Course Materials Required (Student must provide):

- Clear safety glasses ANSI Z87 or better

- Gauntlet Style Leather Welding Gloves

- $100 \%$ Cotton Lab Coat or Long sleeve shirt

- $100 \%$ Cotton Welding Cap or Ball Cap

- $100 \%$ Cotton Jeans or Pants

- Leather, closed toe shoes or boots (No temis shoes!)

- Welding Helmet with $=10$ lens

- Pliers, Slip Joint, 6" (or gimilar)

- 10'-16' Tape Measure

- SD memory card for camcorder (same as Ag Ed 4330)

- Padlock (for locker to store PPE)

Policies:

1. Academic Honestr-Don't cheat. Academic integrity is fundamental to the activities and principles of a university. All members of the academic community must be confident that each person's work bas been responsibly and honorably accuired, developed, and presented. Any effort to gain an advantage not given to all students is dishonest whether or not the effort is successful. The academic community regards breaches of the academic integrity rules as extremely serious matters. Sanctions for such a breach may include academic sanctions from the instructor, including failing the course for any violation, to disciplinary sanctions ranging from probation to expulsion. When in doubt about plagiarism, paraphrasing, quoting, collaboration, or any other form of cheating, consult the course instructor.

2. ADA-Ask if you need assistance. Students with Disabilities: If you anticipate berriers related to the format or requirements of this course, if you have emergency medical information to share with me, or if you veed to make arrangements in case the building must be evacuated, please let me know $29500 n$ as possible. If diszbility related accommodztions are necessary (for erample, a note taker, extended time on exams, captioning), please register with the Office of Disability Services (http//disabilityservices missouri.edu), S5 Memorial Union, 882-4696, and then notify me of your eligibility for reasonable accommodations. For other MU resources for students with disabilities, click on "Disability Resources" on the MU homepage.

3. Intellectupl Pluralism- Respect fellow students and iustructor. The University comminity welconses intellectual diversity and respects student rights. Students who have questions or concems regarding the atmosphere in this class (including respect for diverse opinions) may contact the Departmental Chair or Divisional Director; the Director of the Offfice of Students Rights and Responsibilities (hittp//osm missouriedu); or the $M U$ Equity Office (hrtp://equity.missouri.ech), or by email at equity@gigsouri.edu. All students will bave the opportunity to submit an monymous evaluation of the instructor(s) at the end of the course

4. Executive Order \#38, Academic Inquiry, Courge Discussion and Privacy-Respect classroom conversations. University of Missouri System Executive Order No. 38 lays out principles regarding the sanctity of clasaroom discussions at the university. The policy is described fully in Section 200.015 of the Collected Rules and Regulations. In this class, students may make audio or video recordings of course activity unless specifically prohibited by the faculty member. However, the redistribution of audio or video recordings of statements or comments from the course to individuals who are not students in the course is prohibited without the express permission of the faculty member and of any students who are recorded. Students found to have violated this policy are subject to discipline in accordance with provisions of Section 200.020 of the Collected Rules and Regulations of the University of Missouri pertaining to student conduct matters.

5. Nondiscrimination Statement-Value all people. Faculty and staff in the College of Agriculture, Food and Natural Resources are committed to cultural diversity and nondiscrimination toward all people with regards to race, color, religion, national origin, ancestry, gender, age, all veterans, and sexual orientation.

6. Professionalism-Effort will be rewarded. Professionals in the public schools are guided by certain values and characteristics. Professional characteristica on which you will be judged in this course include punctuality. attendance, collegial attitude, and perticipation. Since this is a laboratory-based class, class attendance and participation are critical for studert success. 
Toward this effort, we expect the following -

2. Take responsibility for your own learning-you will be asked to teach this in the near future.

Good enough isn't good enough!

- Come to class every day.

- Arrive to class on time (or early).

- Come to class mentally and physically prepared to work, including appropriate PPE.

- Actively participate in the class and laboratory activities.

- Respect dates and deadlines

b. Treat your neighbor the way you want to be treated

Attendance: Class attendance is important. However, occasions arise where other educational activities take priority: If you plan to miss a class, you are expected to contact the course instructor prior to class (unless it is an energency). If the instructor deems the absence acceptable, professionaliam points will be awarded if the mahe-Up work is completed. It is the student"s responsibility to request for make-up. Frequent absences will be dealt with on a caseby-case basis. Unexcused absences will result in a 25 -point loss in professionalism $\left(\mathrm{P}^{2}\right)$ points. Unexcused absences may be penalized beyond the available $\mathrm{P}^{2}$ points.

- Tardiness and leaving early will not be toierated unless it is deemed an emergency. You nust plan ahead to show up to class or lab on time, just like you would do if you were teaching at a school. Similarly, you must plan to be at school the whole day. Your grade will be decucted by 10 point for being tardy leaving early the first 5 minutes and 20 points for being tardy/leaving early past 5 minutes. Deductions are not limited to your total professionalism poirts.

Assignments: Completing assignments in a timely manner can also be a way to demonstrate your professionalism. All assignments are due at the start of class, with the exception of the welding skills, which are che at the end of the class. Late asgignments will be scored a " 0 " unless previously approved by the instructor (before the due date) Notifying the instructor does not constitute approval; the instructor will not give approval except in extreme unforeseen emergencies.

Each student will be allowed to submit one late assigmment for credit under the following conditions: For each day the assignment is turned in late, including weekend5, the instructor will deduct $20 \%$ from the student's grade on that assignment No credit will be given for assigrments submitted over one week late. Students who have questions regardiag missing participation points or how an assignmeat was graded will have a 7-day review period (affer the class of assigament is returaed) to request a instructor review/regrade. The instructor will ignove any review requested followiag the 7 day review period.

Assignments: (scoring guides will be provided for assignments $\pi 7-13$ )

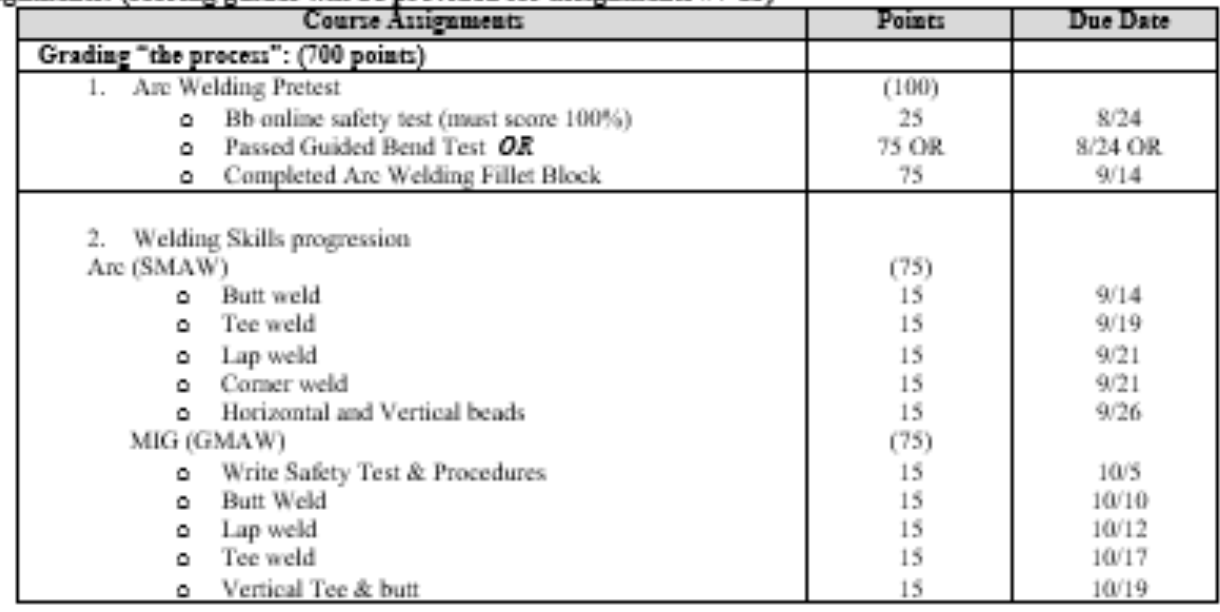

Agrisultural Education 3320

Course Syllabus - page 3 


\begin{tabular}{|c|c|c|}
\hline $\begin{array}{l}\text { 3. Oxy-fucl Torch skill progressioa } \\
\text { o Bb online Safesy Test (unust seore 100\%) } \\
\text { o Setup asd shut down performance } \\
\text { o Heating and bending rod } \\
\text { o Cutting flat metal } \\
\text { o Piencing a hole }\end{array}$ & $\begin{array}{c}(100) \\
20 \\
20 \\
20 \\
20 \\
20 \\
\end{array}$ & $\begin{array}{l}9 / 21 \\
9 / 28 \\
10 / 3 \\
10 / 5 \\
10 / 10 \\
\end{array}$ \\
\hline 4. Power Tool Demonstration, safety test, and reflection & 100 & Various tìnes \\
\hline $\begin{array}{l}\text { 5. Ag Mechanics skill demonstration and assessmeat } \\
1 \mathrm{am} \text { goup letter: }\end{array}$ & 100 & Various times \\
\hline $\begin{array}{l}\text { 6. Project leader } \\
\text { My students will build: }\end{array}$ & 50 & Various times \\
\hline 7. Participation and Professionalisen $\left(\mathrm{P}^{2}\right)$ & 100 & Each day \\
\hline \multicolumn{3}{|l|}{ Grading "the product": (500 points) } \\
\hline 8. Metal Faboication Projects & 50 & $10 \times 12 ; 10 / 31$ \\
\hline 9. Woodworking Projects & 50 & $11 / 16 ; 11 / 30$ \\
\hline 10. New shop construction plan & 100 & $10 \sqrt{24}$ \\
\hline 11. Student Project Plan & 100 & $10 / 10$ \\
\hline 12. Lab Management Plan & 50 & $9 / 7$ \\
\hline 1.3. Exam 1 & 50 & $8 / 31$ \\
\hline 14. Final Project & 100 & TВА \\
\hline TOTAL & 1200 & \\
\hline
\end{tabular}

\section{Assignment Descriptions:}

1. Passed Arc Welding Guided Bend Teat OR. Completed Fillet Welding Block - Prior to class on 8/24, you must receive a $100 \%$ on the $\mathrm{Bb}$ Arc Welding Safety Quiz before you can use the welder (25 points). All students will take an arc welding pretest on Aug $24^{\text {hi }}-1$ side, 1 pass butt weld. The instructor will perform a destructive guided bend test to check the weld' $s$ integrity. Those students who pass the guided bend test will receive 75 points and will not have to complete the fillet block Students who do not pass the guided bend test will receive 0/75points.

However, students who do not pass can eam those 75 points by completing an angle iron fillet welding block and submitting to the instructor before September $14^{\text {th}}$. Students can work on the fillet block both during class and outaide of class time. The block muat be completed before you can submit any further welding or cutting skill assigments- (and those assignments will be subject to late work policy).

No completed block, 0 for block and all arc and MIG welding skills

- Open shop times for practice, instruction, or project work will be beld on Wednesday afternoons and by appointment.

2. Arc and MIG Welding Skills Progression- Students will perform several types and positions of welds common in project fabrication. Welds are diue on or before the due date, and the grade given on due date will be the grade recorded Students must pass guided bend or fillet block before they start on this assignment

- Welding skills are sequential and build upon one another; students must pass each weld skill at $80 \%$ proficient before they can attempt the next weld, regardless of due date. Students will receive full credit $(15 / 15)$ for each weld receiving a passing grade ( $80 \%$ or better) submitted on or before the due date. Students will receive no credit for welds which do not receive a passing grade on or before the che date. Students may work abead at no penalty. Don't fall behind!

3. Ory-Acetvlene Torch Skill progression-Students will demonatrate proficiency with the ory-acetylene torch by passing a set-up and shut-down demonstration and cutting and bending mild steel in various gituations. Students muat pass the $\mathrm{Bb}$ online safety test with $100 \%$ before they are allowed to use the torch.

- Students will receive full credit (20/20 points) for each skill receiving a passing grade ( $80 \%$ or better) submitted on or before the due date. Students muat pass each akill at $80 \%$ proficient before they can attempt the nest skill Students will receive no credit for skills which do not receive a passing grade on or before the due date Students may work ahesd at no penalty. Don't fall behind! 
4. Power Tool Demonstration, Safery Test, and Reflection- The instructor will assign each student a power tool used in the Ag Mechanics shop. The student will be responsible to teach the class the safe use of the tool. Further, the student will be responsible to demonstrate how to use the tool and will test their classmates on the safe use of the tool. The demonstration will be recorded; the student will watch the recording and will complete a feedback sheet (provided).

5. Agricultural Mechanics Teaching Demonstrations-In groups of 2-3 students, you will plan, deliver, and assess your classmates an agricultural mechanics skill commonly taught in Miasouri high school Ag progrems. Your group will present a total of four times. All groups will present on Aug $25^{\text {it }}$; the other three demonstration topics and dates will be assigned the first day.

6. Teacher for a day-A major objective of this class is to prepare you to teach and supervise in the sbop. Students will be broken into groups of 4 people to complete 4 individual projects. You will serve as the teacher for one of the projects. Details will be provided in class.

7. Class work and participetion-Regular attendance is expected. If you must miss a class for any reason please contact the instructor by either phone or e-mail prior to the absence. You will be responsible for obtaining bandouts and/or materials that vere distributed during your absence. Most high school Principals will want you to assign daily points in your classes. We have chosen to model this and will assign participation points as follows (atudent will receive point level from the lowest mark): Note: On the ffrst day of ciass, all professionalism points are wicurad on the Blackboard grade book. As the course continues, points ave deatucted when point losses occw alse to missing ciass or lab, being tardy to class or lab, or from quick quiz scores. Daily Expectations:

\begin{tabular}{|c|c|c|}
\hline Category & -10 points for any violabion & No points deducted \\
\hline Safety & $\begin{array}{l}\text { Students engages in any unsale } \\
\text { behavior }\end{array}$ & $\begin{array}{l}\text { Student engages in behaviors safe } \\
\text { for self and classmates }\end{array}$ \\
\hline Prepanatioe & $\begin{array}{l}\text { Student most bornow PPE from } \\
\text { teacher and is prepared after } \\
\text { bocrowing what is needed. }\end{array}$ & $\begin{array}{l}\text { Student brings all required PPE } \\
\text { and is preparod foe class work at } \\
8.0002 \text {. }\end{array}$ \\
\hline Work Ethic & $\begin{array}{l}\text { Student nuast be reminded is } \\
\text { engages in class work by teacher }\end{array}$ & $\begin{array}{l}\text { Student owns the work and works } \\
\text { independeatly }\end{array}$ \\
\hline Clean-up & Student doesn't help clean up & $\begin{array}{l}\text { Student compleicly cleans their } \\
\text { work area and checks/helps other } \\
\text { classmates. }\end{array}$ \\
\hline Atsitude & $\begin{array}{l}\text { Student is disrespectilal or } \\
\text { disconteous }\end{array}$ & Student is belpful and courteous \\
\hline
\end{tabular}

8. Metal fabrication projects-Students will complete 2 individual metal fabrication projects. Students will receive the average score of the two projects. Projects will be graded using the attached project scoring guide.

9. Woodworking projects- Students will complete 2 individual woodworking projects. Students will receive the average score of the two projects. Projects will be graded using the attached project scoring guide.

10. New shop construction plan- The design and layout of a shop impacts productivity and safety. Students will design the "ideal" high achool agriculture building (or similar substitute)

11. Student proiect plam-Students can leam lots of skills from small projects. Your task is to pick one small project (saitable for a junior high, $\mathrm{Ag} I$ or Ag 2 class) and create a complete get of plans (cut list, bill of materials, stepby-step directions, and scaled drawings) to share with classmates.

12. Lab management plan- Clear expectations are critical for success. You will create a general shop safety test, safery rules, shop management documents, and procechures for managing a high school shop (or similar substitute).

13. Exam 1-it's a written test. Bring a writing utensil.

14. Final exam- Using incuiry-based techniques, students will construct a tool, based on the specifications provided.

$A+=99.0-100$ COURSE GRADING SCALE (Percent)

$A=94.0-989$

$\mathrm{B}+=87.0-89.9$

$\mathrm{C}+=77.0-79.9$

$B=84.0-86.9$

$=74.0-76.9$

$\mathrm{D}+=67.0-69.9$

A- $=90.0-93.9$

B- $=80.0-83.9$

C. $=70.0-73.9$

$\mathrm{D}=64.0-66.9$

$F=$ below 64.0

Agrisultural Education 3320

Course Syllabus - page 5 
Project Eraluation Scoring Guide

\begin{tabular}{|c|c|c|c|}
\hline Name & Project & & \\
\hline Description & $\begin{array}{c}\text { Points } \\
\text { possible }\end{array}$ & $\begin{array}{l}\text { Student } \\
\text { Score }\end{array}$ & Comments \\
\hline $\begin{array}{l}\text { Project Planning: } \\
\text { Working scaled drawings } \\
\text { (minimum top, side, and end views) } \\
\text { Step by step instructions } \\
\text { Cut list } \\
\text { Bill of materials } \\
\text { Project matches plans } \\
\text { Degree to which project matches original } \\
\text { plans }\end{array}$ & 10 & & \\
\hline $\begin{array}{l}\text { Project Construction: } \\
\text { Quality of workmanship } \\
\circ \text { Quality of fit } \\
\circ \text { Quality of finish or preservation } \\
\circ \text { Fully functional and durable }\end{array}$ & $\begin{array}{l}10 \\
10 \\
10\end{array}$ & & \\
\hline $\begin{array}{l}\text { Use of proper materials } \\
\qquad \text { Project is designed to last } \\
\circ \text { Project is correctly engineered }\end{array}$ & 10 & & \\
\hline Total & 50 & & \\
\hline
\end{tabular}




\section{7 - CLASS SCHEDULE \& TENTATIVE TEACHING CALENDAR}

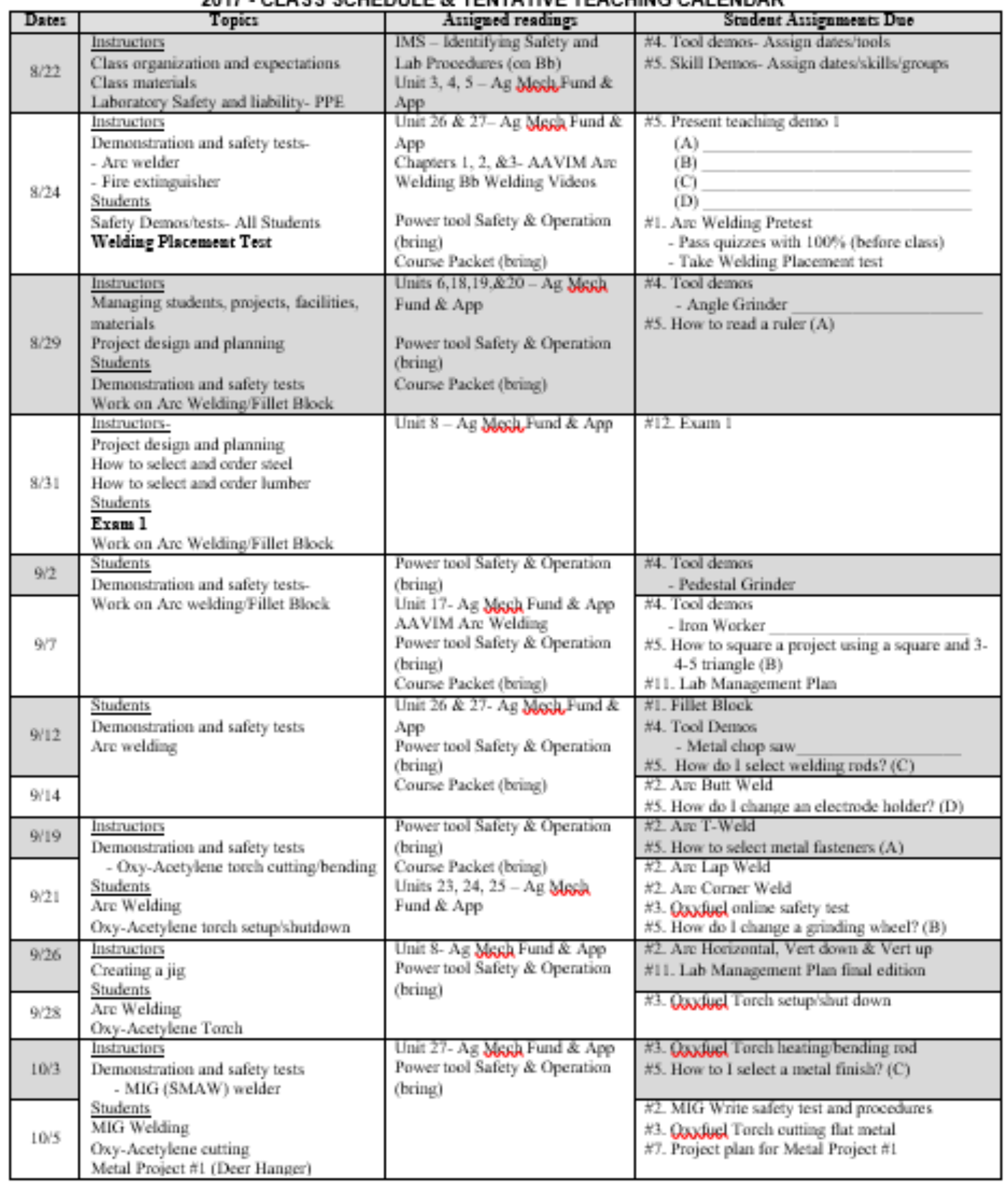

Agricultural Education 3320

Course Syllabus - page ? 


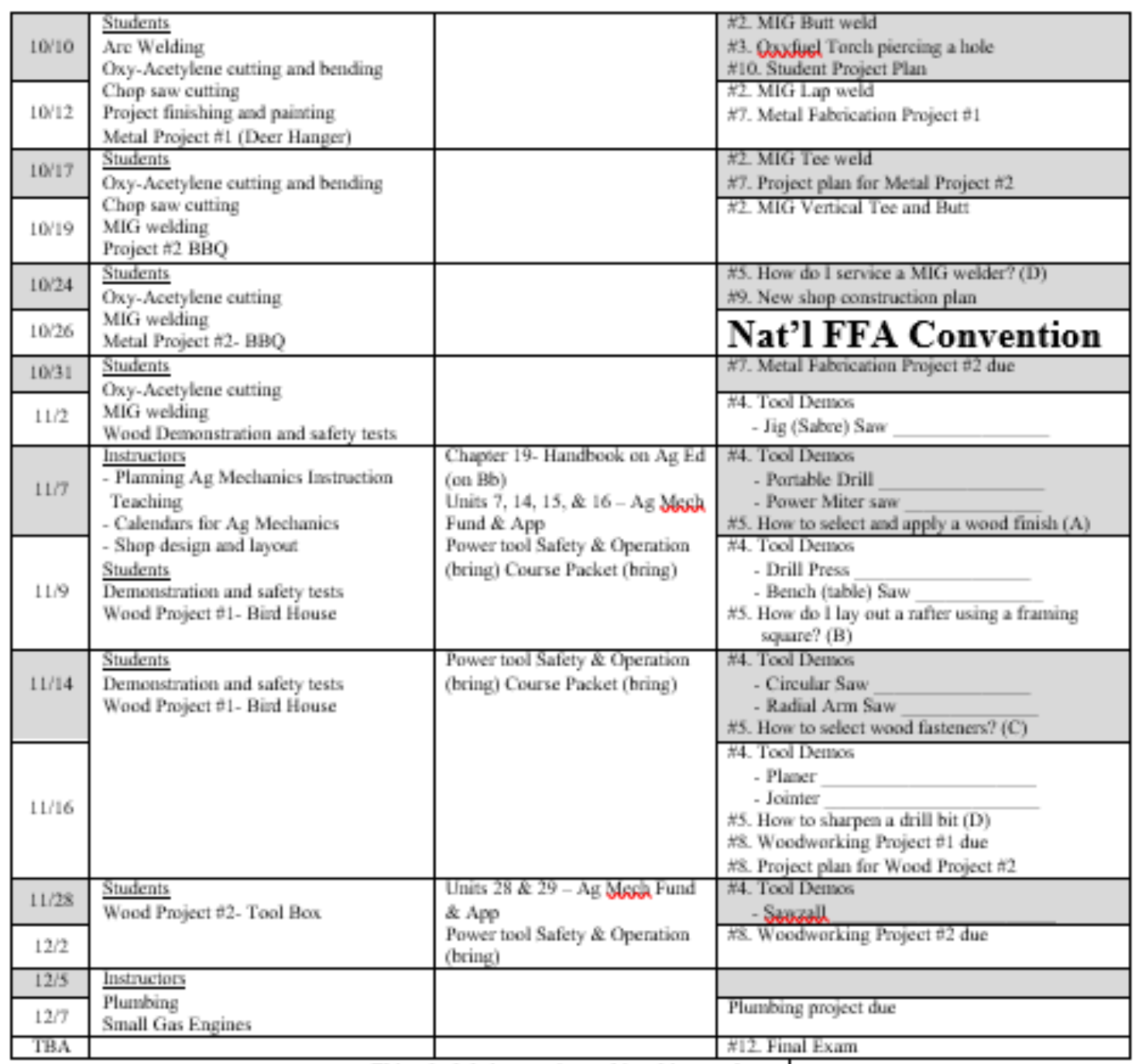

This schedale is tencative and is subject to change 
Appendix B

Participant Questionnaire- Project Evaluation Scoring Guide 
Project Evaluation Scoring Guide

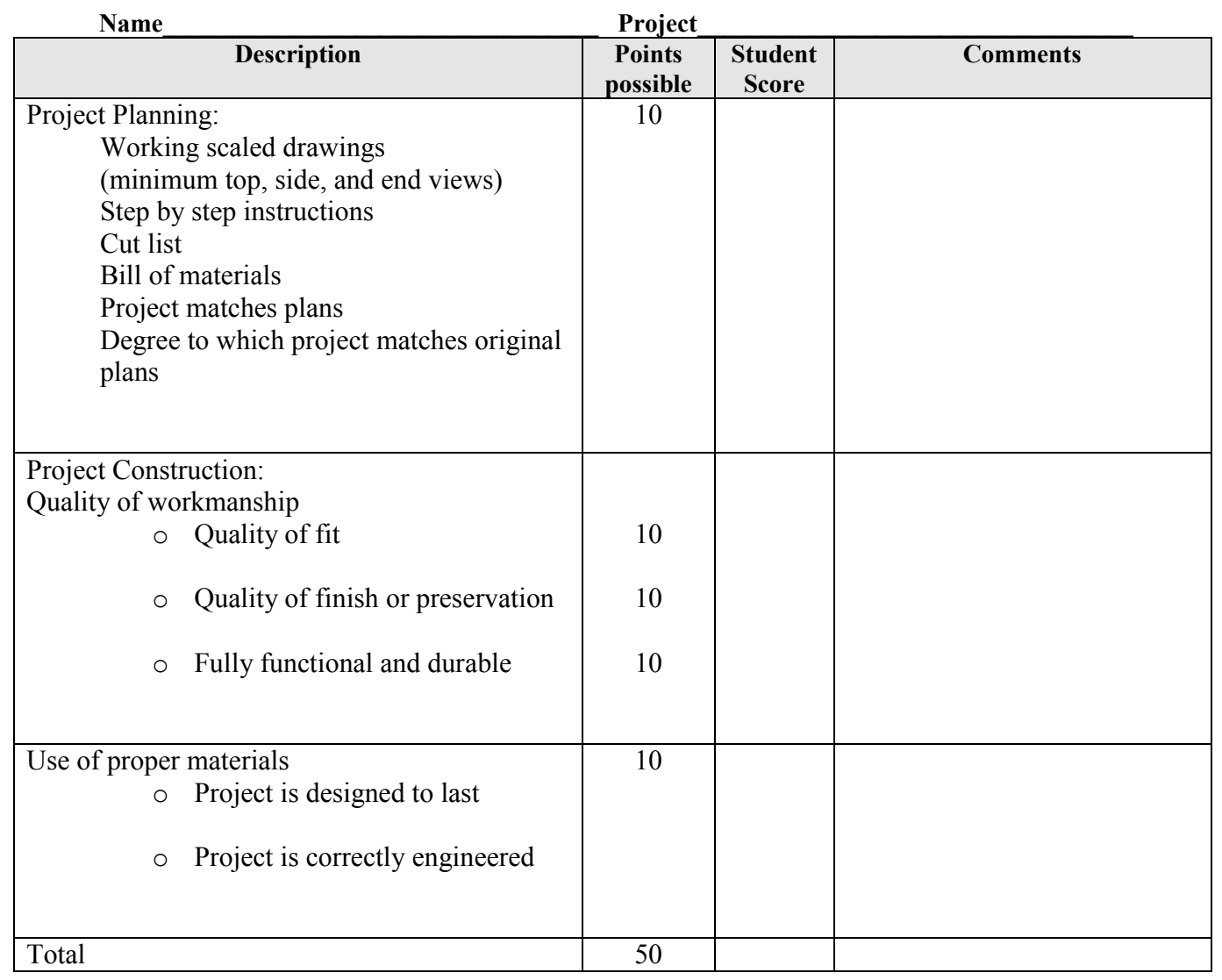




\section{Appendix C \\ Participant Questionnaire- Student Evaluation of Teacher Effectiveness Questionnaire}

\section{Student Evaluation of Teacher Effectiveness Questionnaire}

Teaching Delivery

This instructor was consistently well-prepared.

This instructor was audible and clear.

This instructor was knowledgeable and enthusiastic about the topic.

This instructor effectively used examples/illustrations to promote learning.

This instructor fostered questions and/or class participation.

This instructor clearly explained important information/ideas/concepts.

This instructor effectively used teaching methods appropriate to this class

(e.g., critiques, discussion, demonstrations, group work).

\section{Learning Environment}

This instructor responded appropriately to questions and comments.

This instructor stimulated student thinking and learning.

This instructor promoted an atmosphere of mutual respect regarding diversity in student demographics and viewpoints, such as race, gender, or politics.

This instructor was approachable and available for extra help.

This instructor used class time effectively.

This instructor helped students to be independent learners, responsible for their own learning.

\section{Assessment}

I was well-informed about my performance during this course meeting time.

Project was graded fairly based on clearly communicated criteria.

This instructor provided feedback that helped me improve my skills in this subject area.
SA (5) $\quad A(4) \quad N(3) \quad \underline{\underline{D}}(2) \quad S D(1)$

$\begin{array}{lllll}5 & 4 & 3 & 2 & 1\end{array}$

$\begin{array}{lllll}5 & 4 & 3 & 2 & 1\end{array}$

$\begin{array}{lllll}5 & 4 & 3 & 2 & 1\end{array}$

$\begin{array}{lllll}5 & 4 & 3 & 2 & 1\end{array}$

$\begin{array}{lllll}5 & 4 & 3 & 2 & 1\end{array}$

$\begin{array}{lllll}5 & 4 & 3 & 2 & 1\end{array}$

$\begin{array}{lllll}5 & 4 & 3 & 2 & 1\end{array}$

SA (5) $\quad A(4) \quad N(3) \quad \underline{\underline{D}(2)} \quad \mathrm{SD}(1)$

$\begin{array}{lllll}5 & 4 & 3 & 2 & 1\end{array}$

$\begin{array}{lllll}5 & 4 & 3 & 2 & 1\end{array}$

$\begin{array}{lllll}5 & 4 & 3 & 2 & 1\end{array}$

$\begin{array}{lllll}5 & 4 & 3 & 2 & 1\end{array}$

$\begin{array}{lllll}5 & 4 & 3 & 2 & 1\end{array}$

$\begin{array}{lllll}5 & 4 & 3 & 2 & 1\end{array}$

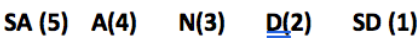

$\begin{array}{lllll}5 & 4 & 3 & 2 & 1\end{array}$

$\begin{array}{lllll}5 & 4 & 3 & 2 & 1\end{array}$

$\begin{array}{lllll}5 & 4 & 3 & 2 & 1\end{array}$ 


\section{Appendix D}

Participant Questionnaire- Participant Journal

Participant Journal

\section{Ag Mech Daily Journal \\ University of Missouri}

Name:

Please indicate consumption of the following for the past $24 \mathrm{hrs}$.

Alcohol (servings \& time of last drink):

Tobacco (units \& time of last consumption):

Medication (name \& time of consumption):

Caffeine (servings, type, \& time of last consumption

How was your sleep last night (duration and quality)?

Have you experienced any events that you would describe as stressful in the last 24 hrs? Please provide as much detail as you are comfortable with.

Please describe what you will be doing in the AgMech Shop today:

Please describe your level of comfort/confidence with what you are doing today:

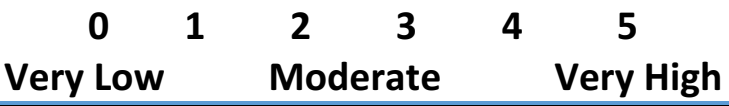

Time monitor Placed on Body:

Time you began working in the shop:

Please describe any notable events and an approximate time during your time in the shop:

Tiime you ended working in the shop:

Time Monitor was removed from body:

Other Comments: 


\section{Appendix E}

Participant Questionnaire- Student Consent Form

\section{Student Consent Form}

\section{Physiological Stress Within Agricultural Mechanics Teaching Methods Course}

IRB Project:

Student Consent to Participate in a Research Study

You are being invited to take part in a research study about the effects of stress on student enrolled within an Agricultural Education teaching methods course. If you volunteer to take part in this study, you will be one of about fourteen (14) students to do so.

The person in charge of the study is Jeff Reed of the University Of Missouri Department of Agricultural Education. We hope to examine stress that results from students working within the confines on this course.

The research will be conducted through the collection of an activity log (journal) and the physiological stress data with a heart rate monitor. Participants will be asked to wear a heart rate monitor during the course and lab assigned meeting times during the Spring and Fall 2017 semesters. Participants will also keep a log of activity during both the base line data collection period and class/lab time collection period. The heart rate monitor has two electrode pads, which attached to the chest. These monitors will be worn at all times during the course and lab assigned meeting time of the Spring and Fall 2017 semesters, except during showering and swimming. There is a possibility for a slight irritation to occur where the electrodes are placed. It is important to inform the researchers if this occurs. Cleaning the area which the electrodes are placed typically prevents this from occurring.

The information gathered from this study may be reported in academic articles or papers. To the best of our knowledge, the things you will be doing have no more risk of harm than you would experience in everyday life. For your participation in this study you will receive the wellness data from the heart rate monitors. Additionally, your willingness to take part may help society, as a whole better understand this research topic.

If you decide to take part in this study, it should be because you really want to volunteer. There are no costs associated with taking part in this study and you can terminate your participation at any time. You will still keep the benefits and rights you had before volunteering; you will not be treated differently if you decide to stop taking part in this study.

You will not lose any benefits or rights you would normally have if you choose not to volunteer. If you choose not to participate, you will not be included in the analysis. The 
research team may need to withdraw you from the study. This may occur if you are not able to follow the directions they give you or if they find that your being in the study is more risk than benefit to you.

We will make every effort to keep private all research records that identify you to the extent allowed by law. Participants will only be identified by an assigned code in research documents. The code list will be securely maintained in a separate, unconnected location. Your information will be combined with information from other participants taking part in this study. When we write about the study to share with other researchers, we will write about the combined information we have gathered. You will not be personally identified in these written materials. We may publish the results of the study; however, we will keep your name and other identifying information private.

The research team will also be utilizing the existing video security system to monitor any stressor events which may occur during the semester. The video will allow the team to see specifically what item/skill you were performing if a stressful event occurs. The security system is established throughout the building and maintained on a secure University of Missouri server.

There are risks to most studies and it must be discussed along with protections. We will make every effort to prevent anyone who is not on the research team from knowing you gave us information, or what the information is. Only Dr. Ball and Jeff Reed will have access to identifying information connecting your name to the data collected. All data will be kept in a locked cabinet or password protected computer file for seven years after the study is closed. At that time, materials will be destroyed.

Before you decide whether to accept this invitation to take part in this study, please ask any questions that might come to mind immediately. Later, if you have questions, suggestions, concerns, or complaints about this study, you can contact the principal investigator, Jeff Reed or his advisor Dr. Anna Ball at 573-882-7451. If you have questions about your rights as a volunteer in this research, contact the staff in the Office of Research Campus Institutional Review Board at the University of Missouri at 573882- 9585.

Signature of person agreeing to take part in the study Date

Printed name of person agreeing to take part in the study 


\author{
Appendix F \\ Participant Questionnaire- Recruitment Letter

\section{Recruitment Letter}

\section{Physiological Stress Within Agricultural Mechanics Teaching Methods Course}

IRB Project:

Dear [First Name],

You have been purposively selected as a student enrolled within an agricultural mechanics teaching methods course to participate in a research study titled, Physiological Stress Within Preservice Agricultural Mechanics Teaching Methods Course. Your participation in this study is entirely voluntary and you can withdraw at any time.

If you are interested in participating, the researchers will provide additional information. Before you decide whether to accept this invitation to take part in this study, please ask any questions that might come to mind immediately. Later, if you have questions, suggestions, concerns, or complaints about this study, you can contact the principal investigator, Jeff Reed at 573-8827451 or my advisor Dr. Anna Ball at ballan@missouri.edu. If you have questions about your rights as a volunteer in this research, contact the staff in the Office of Research Campus Institutional Review Board at the University of Missouri at 573-882- 9585.

Thanks for your consideration!

Jeff Reed

Primary Investigator 
Appendix G

Participant Questionnaire- SAS Outputs 
Teaching Delivery

The GLM Procedure

\begin{tabular}{|l|r|l|}
\hline \multicolumn{3}{|c|}{ Class Level Information } \\
\hline Class & Levels & Values \\
\hline Case & 15 & 123456789101112131415 \\
\hline Day & 2 & 12 \\
\hline Treatment & 2 & 01 \\
\hline
\end{tabular}

Number of Observations Read

\begin{tabular}{l|l} 
Number of Observations Used 30
\end{tabular} 
The GLM Procedure

Dependent Variable: Teaching_Delivery Teaching_Delivery

\begin{tabular}{|l|r|r|r|r|l|}
\hline Source & DF & $\begin{array}{r}\text { Sum of } \\
\text { Squares }\end{array}$ & Mean Square & F Value & Pr $>$ F \\
\hline Model & 16 & 15.03576482 & 0.93973530 & 5.06 & 0.0026 \\
\hline Error & 13 & 2.41606518 & 0.18585117 & & \\
\hline Corrected Total & 29 & 17.45183000 & & & \\
\hline
\end{tabular}

\begin{tabular}{|r|r|r|r|}
\hline R-Square & Coeff Var & Root MSE & Teaching_Delivery Mean \\
\hline 0.861558 & 10.15080 & 0.431105 & 4.247000 \\
\hline
\end{tabular}

\begin{tabular}{|l|r|r|r|r|r|}
\hline Source & DF & Type I SS & Mean Square & F Value & Pr $>$ F \\
\hline Treatment & 1 & 2.10233625 & 2.10233625 & 11.31 & 0.0051 \\
\hline Day & 1 & 0.05547000 & 0.05547000 & 0.30 & 0.5941 \\
\hline Day*Treatment & 1 & 0.00081482 & 0.00081482 & 0.00 & 0.9482 \\
\hline Case(Treatment) & 13 & 12.87714375 & 0.99054952 & 5.33 & 0.0025 \\
\hline
\end{tabular}

\begin{tabular}{|l|r|r|r|r|r|}
\hline Source & DF & Type III SS & Mean Square & F Value & Pr $>$ F \\
\hline Treatment & 1 & 2.10233625 & 2.10233625 & 11.31 & 0.0051 \\
\hline Day & 1 & 0.05612149 & 0.05612149 & 0.30 & 0.5920 \\
\hline Day*Treatment & 1 & 0.00081482 & 0.00081482 & 0.00 & 0.9482 \\
\hline Case(Treatment) & 13 & 12.87714375 & 0.99054952 & 5.33 & 0.0025 \\
\hline
\end{tabular}

\begin{tabular}{|c|c|c|c|c|c|}
\hline Tests & & $\begin{array}{r}\text { Using } \\
\text { as a }\end{array}$ & $\begin{array}{l}\text { pe III MS } \\
\text { r Term }\end{array}$ & $e$ & ent) \\
\hline Source & DF & Type III SS & Mean Square & F Value & $\mathrm{Pr}>\mathrm{F}$ \\
\hline Treatment & 1 & 2.10233625 & 2.10233625 & 2.12 & 0.1689 \\
\hline
\end{tabular}


The GLM Procedure

Least Squares Means

Standard Errors and Probabilities Calculated Using the Type III MS for Case(Treatment) as an Error Term

\begin{tabular}{|l|r|r|}
\hline & & \multicolumn{2}{|c|}{ H0:LSMean1=LSMean2 } \\
\cline { 3 - 3 } Treatment & Teaching_Delivery & $\operatorname{Pr}>|\mathbf{t}|$ \\
\hline $\mathbf{0}$ & 4.53000000 & 0.1689 \\
\hline $\mathbf{1}$ & 3.99937500 & \\
\hline
\end{tabular}

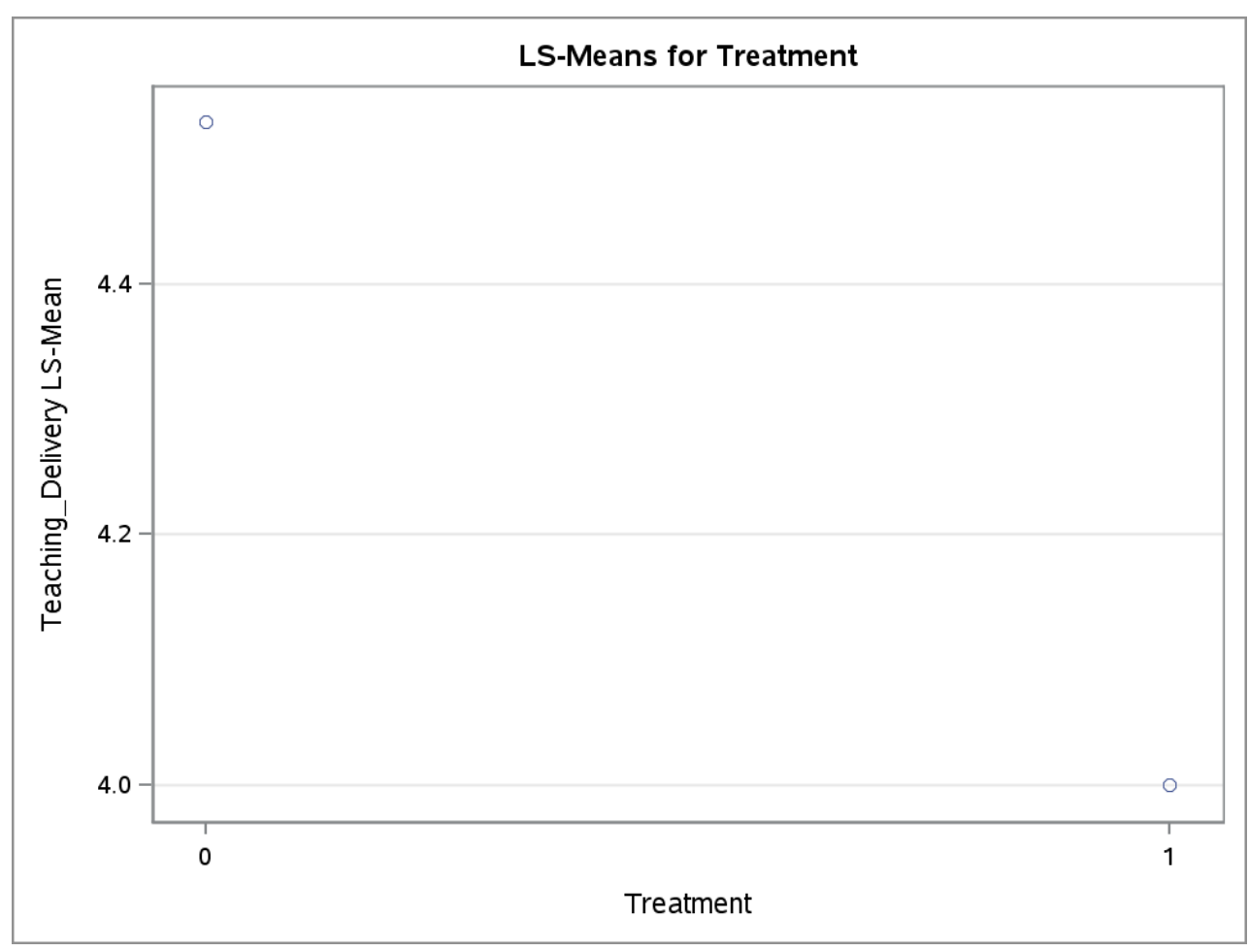


The GLM Procedure

Least Squares Means

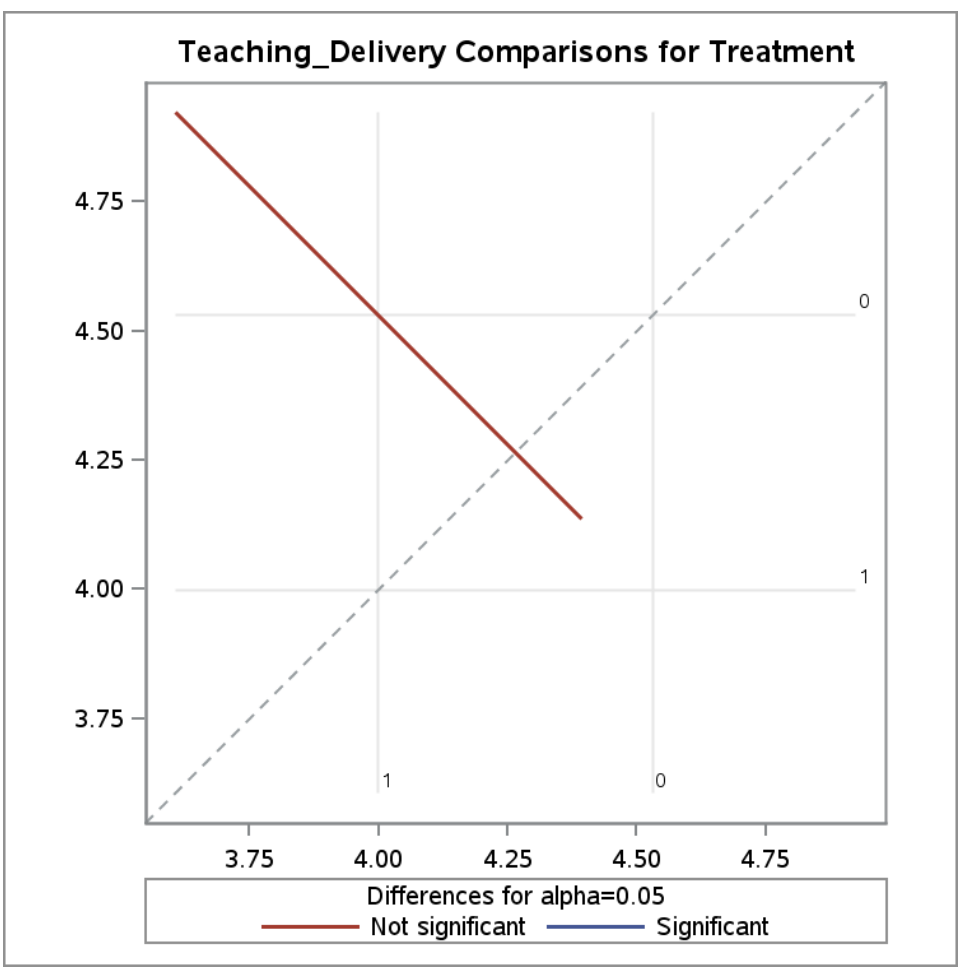

Teaching_Delivery T Grouping for LS-Means

of Treatment (Alpha $=0.05$ )

LS-means covered by the same bar are not significantly different.

Treatment Estimate

4.5300

3.9994

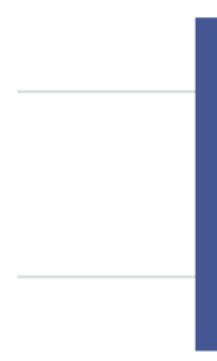




\section{Learning Environment}

11:29 Thursday, March 25, $2021 \quad 5$

The GLM Procedure

\begin{tabular}{|l|r|l|}
\hline \multicolumn{3}{|c|}{ Class Level Information } \\
\hline Class & Levels & Values \\
\hline Case & 15 & 123456789101112131415 \\
\hline Day & 2 & 12 \\
\hline Treatment & 2 & 01 \\
\hline
\end{tabular}

Number of Observations Read

\begin{tabular}{l|l} 
Number of Observations Used 30
\end{tabular} 


\section{Learning Environment}

\section{The GLM Procedure}

Dependent Variable: Learning_Environment Learning_Environment

\begin{tabular}{|l|r|r|r|r|r|}
\hline Source & DF & $\begin{array}{r}\text { Sum of } \\
\text { Squares }\end{array}$ & Mean Square & F Value & Pr > F \\
\hline Model & 16 & 11.80169429 & 0.73760589 & 6.89 & 0.0006 \\
\hline Error & 13 & 1.39098571 & 0.10699890 & & \\
\hline Corrected Total & 29 & 13.19268000 & & & \\
\hline
\end{tabular}

\begin{tabular}{|r|r|r|r|}
\hline R-Square & Coeff Var & Root MSE & Learning_Environment Mean \\
\hline 0.894564 & 7.420755 & 0.327107 & 4.408000 \\
\hline
\end{tabular}

\begin{tabular}{|l|r|r|r|r|r|}
\hline Source & DF & Type I SS & Mean Square & F Value & Pr > F \\
\hline Treatment & 1 & 0.98213357 & 0.98213357 & 9.18 & 0.0097 \\
\hline Day & 1 & 0.15265333 & 0.15265333 & 1.43 & 0.2536 \\
\hline Day*Treatment & 1 & 0.03366095 & 0.03366095 & 0.31 & 0.5844 \\
\hline Case(Treatment) & 13 & 10.63324643 & 0.81794203 & 7.64 & 0.0004 \\
\hline
\end{tabular}

\begin{tabular}{|l|r|r|r|r|r|}
\hline Source & DF & Type III SS & Mean Square & F Value & Pr > F \\
\hline Treatment & 1 & 0.98213357 & 0.98213357 & 9.18 & 0.0097 \\
\hline Day & 1 & 0.16166095 & 0.16166095 & 1.51 & 0.2408 \\
\hline Day*Treatment & 1 & 0.03366095 & 0.03366095 & 0.31 & 0.5844 \\
\hline Case(Treatment) & 13 & 10.63324643 & 0.81794203 & 7.64 & 0.0004 \\
\hline
\end{tabular}

\begin{tabular}{|c|c|c|c|c|c|}
\hline \multicolumn{6}{|c|}{$\begin{array}{c}\text { Tests of Hypotheses Using the Type III MS for Case(Treatment) } \\
\text { as an Error Term }\end{array}$} \\
\hline Source & DF & Type & Mean Sq & F Value & $\mathrm{Pr}>\mathrm{F}$ \\
\hline Tre & 1 & 0.98213357 & 0.98213357 & 1.20 & 0.2931 \\
\hline
\end{tabular}


The GLM Procedure

Least Squares Means

Standard Errors and Probabilities Calculated Using the Type III MS for Case(Treatment) as an Error Term

\begin{tabular}{|l|r|r|}
\hline & & \multicolumn{2}{|c|}{ H0:LSMean1=LSMean2 } \\
\cline { 3 - 3 } Treatment & $\begin{array}{r}\text { Learning_Environment } \\
\text { LSMEAN }\end{array}$ & $\operatorname{Pr}>\mathbf{| t |} \mid$ \\
\hline $\mathbf{0}$ & 4.60142857 & 0.2931 \\
\hline $\mathbf{1}$ & 4.23875000 & \\
\hline
\end{tabular}

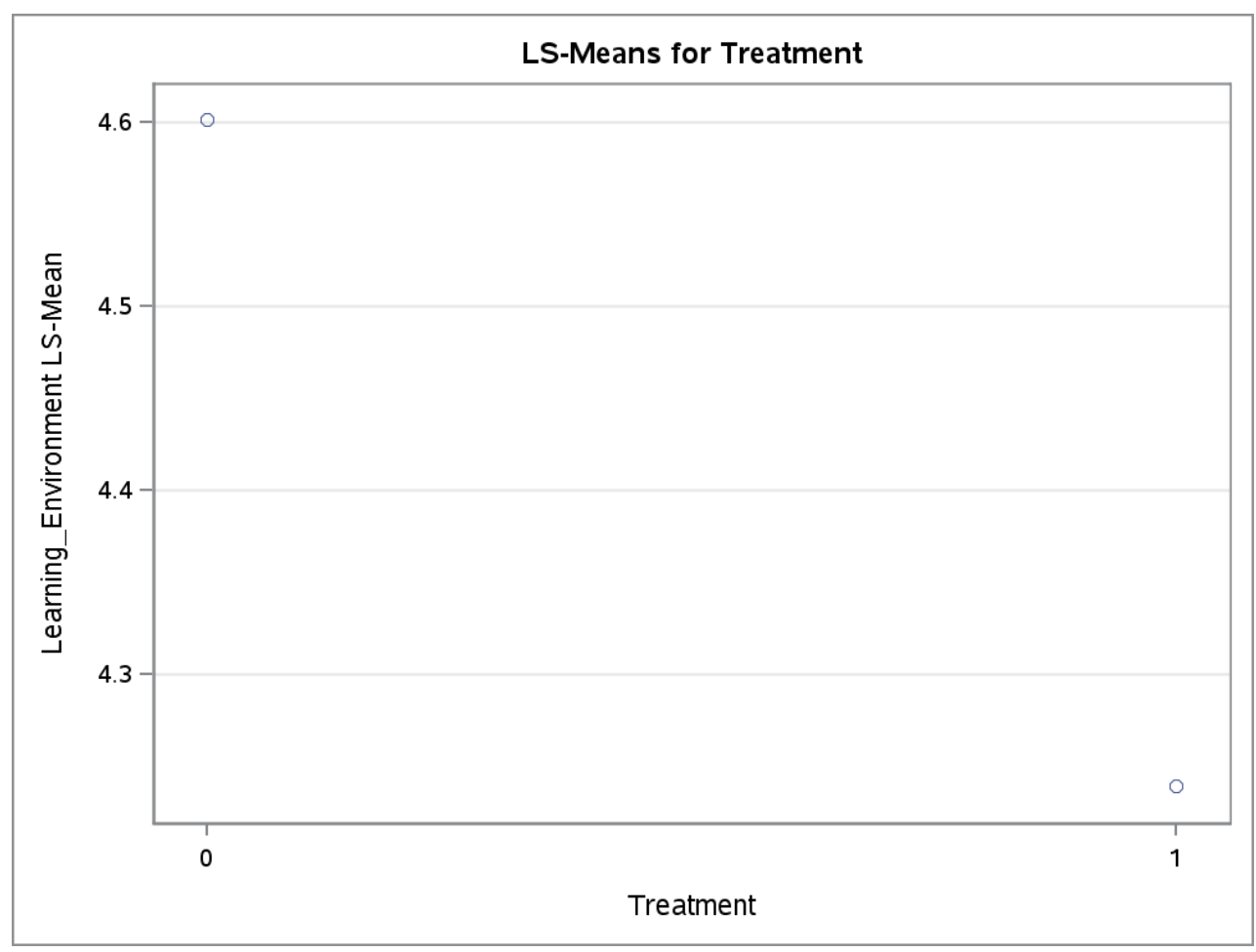


The GLM Procedure Least Squares Means
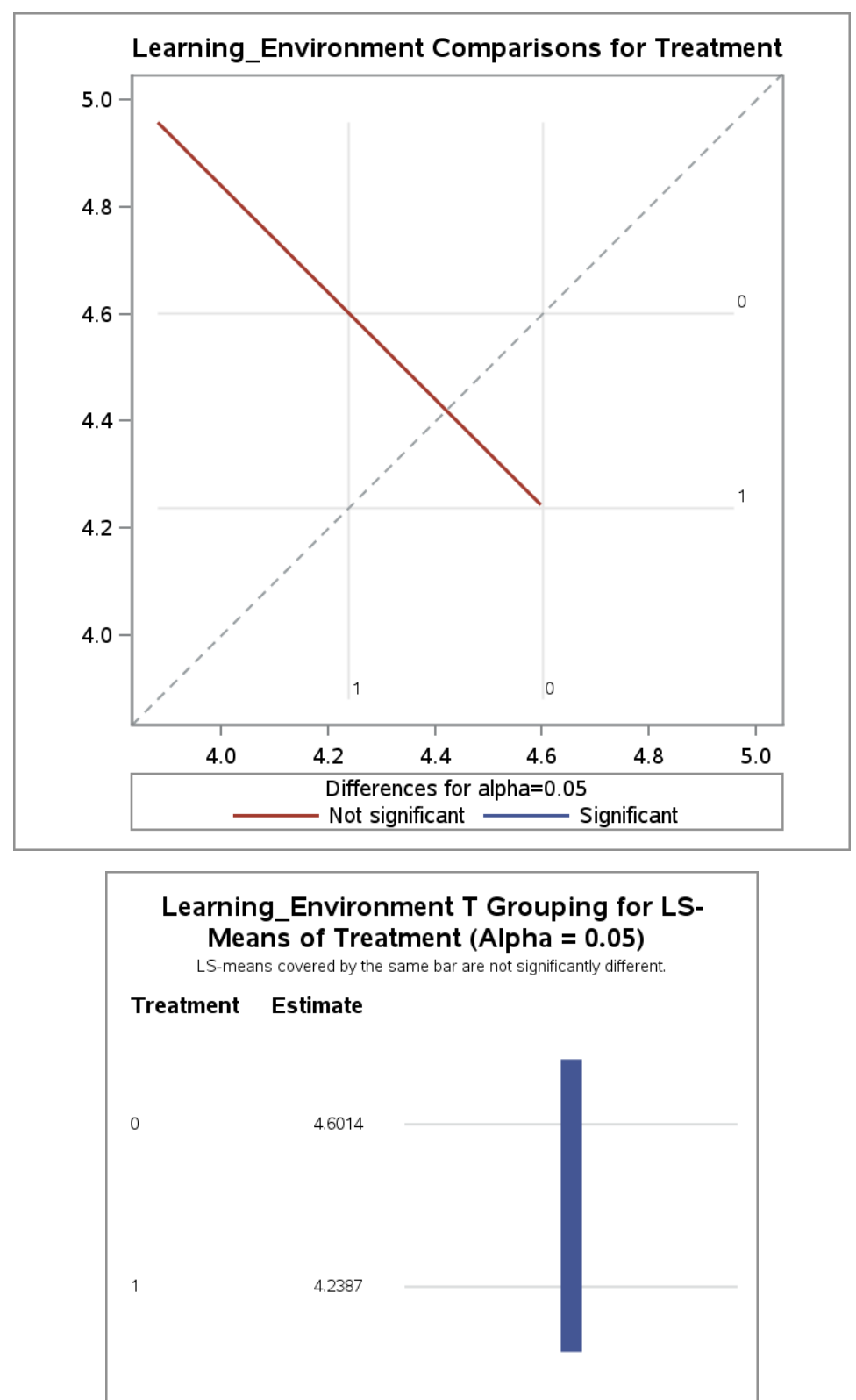
Assessment

11:29 Thursday, March 25, $2021 \quad 9$

The GLM Procedure

\begin{tabular}{|l|r|l|}
\hline \multicolumn{3}{|c|}{ Class Level Information } \\
\hline Class & Levels & Values \\
\hline Case & 15 & 123456789101112131415 \\
\hline Day & 2 & 12 \\
\hline Treatment & 2 & 01 \\
\hline
\end{tabular}

Number of Observations Read

\begin{tabular}{|l|l} 
Number of Observations Used 30
\end{tabular} 


\section{Assessment}

The GLM Procedure

Dependent Variable: Assessment Assessment

\begin{tabular}{|l|r|r|r|r|l|}
\hline Source & DF & $\begin{array}{r}\text { Sum of } \\
\text { Squares }\end{array}$ & Mean Square & F Value & Pr > F \\
\hline Model & 16 & 17.38314054 & 1.08644628 & 3.16 & 0.0211 \\
\hline Error & 13 & 4.47232946 & 0.34402534 & & \\
\hline Corrected Total & 29 & 21.85547000 & & & \\
\hline
\end{tabular}

\begin{tabular}{|r|r|r|r|}
\hline R-Square & Coeff Var & Root MSE & Assessment Mean \\
\hline 0.795368 & 13.76524 & 0.586537 & 4.261000 \\
\hline
\end{tabular}

\begin{tabular}{|l|r|r|r|r|r|}
\hline Source & DF & Type I SS & Mean Square & F Value & Pr > F \\
\hline Treatment & 1 & 3.60195482 & 3.60195482 & 10.47 & 0.0065 \\
\hline Day & 1 & 0.28616333 & 0.28616333 & 0.83 & 0.3784 \\
\hline Day*Treatment & 1 & 0.01665720 & 0.01665720 & 0.05 & 0.8293 \\
\hline Case(Treatment) & 13 & 13.47836518 & 1.03679732 & 3.01 & 0.0284 \\
\hline
\end{tabular}

\begin{tabular}{|l|r|r|r|r|r|}
\hline Source & DF & Type III SS & Mean Square & F Value & Pr $>$ F \\
\hline Treatment & 1 & 3.60195482 & 3.60195482 & 10.47 & 0.0065 \\
\hline Day & 1 & 0.29415054 & 0.29415054 & 0.86 & 0.3720 \\
\hline Day*Treatment & 1 & 0.01665720 & 0.01665720 & 0.05 & 0.8293 \\
\hline Case(Treatment) & 13 & 13.47836518 & 1.03679732 & 3.01 & 0.0284 \\
\hline
\end{tabular}

\begin{tabular}{|c|c|c|c|c|c|}
\hline Test & & $\begin{array}{l}\text { Using } \\
\text { as ar }\end{array}$ & $\begin{array}{l}\text { Type III MS } \\
\text { ror Term }\end{array}$ & ise( $(T$ & ent) \\
\hline Source & DF & Type III SS & Mean Square & F Value & $\operatorname{Pr}>\mathrm{F}$ \\
\hline Treat & 1 & 3.60195482 & 3.60195482 & 3.47 & 0.0851 \\
\hline
\end{tabular}


The GLM Procedure

Least Squares Means

Standard Errors and Probabilities Calculated Using the Type III MS for Case(Treatment) as an Error Term

\begin{tabular}{|l|r|r|}
\hline & & \multicolumn{2}{|l|}{ H0:LSMean1=LSMean2 } \\
\cline { 3 - 3 } Treatment & $\begin{array}{r}\text { Assessment } \\
\text { LSMEAN }\end{array}$ & $\operatorname{Pr}>\mid \mathbf{t t}$ \\
\hline $\mathbf{0}$ & 4.63142857 & 0.0851 \\
\hline $\mathbf{1}$ & 3.93687500 & \\
\hline
\end{tabular}

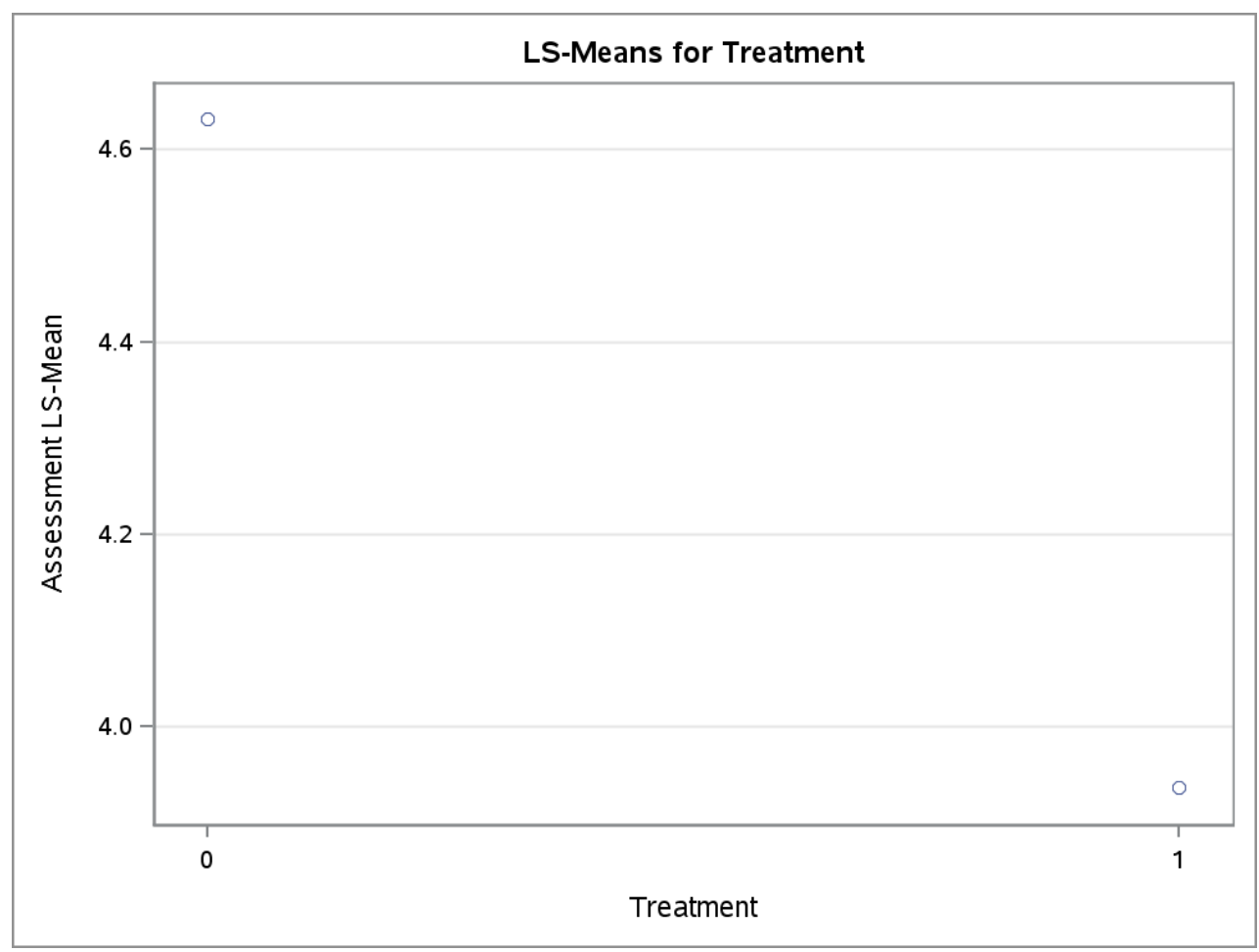


The GLM Procedure Least Squares Means

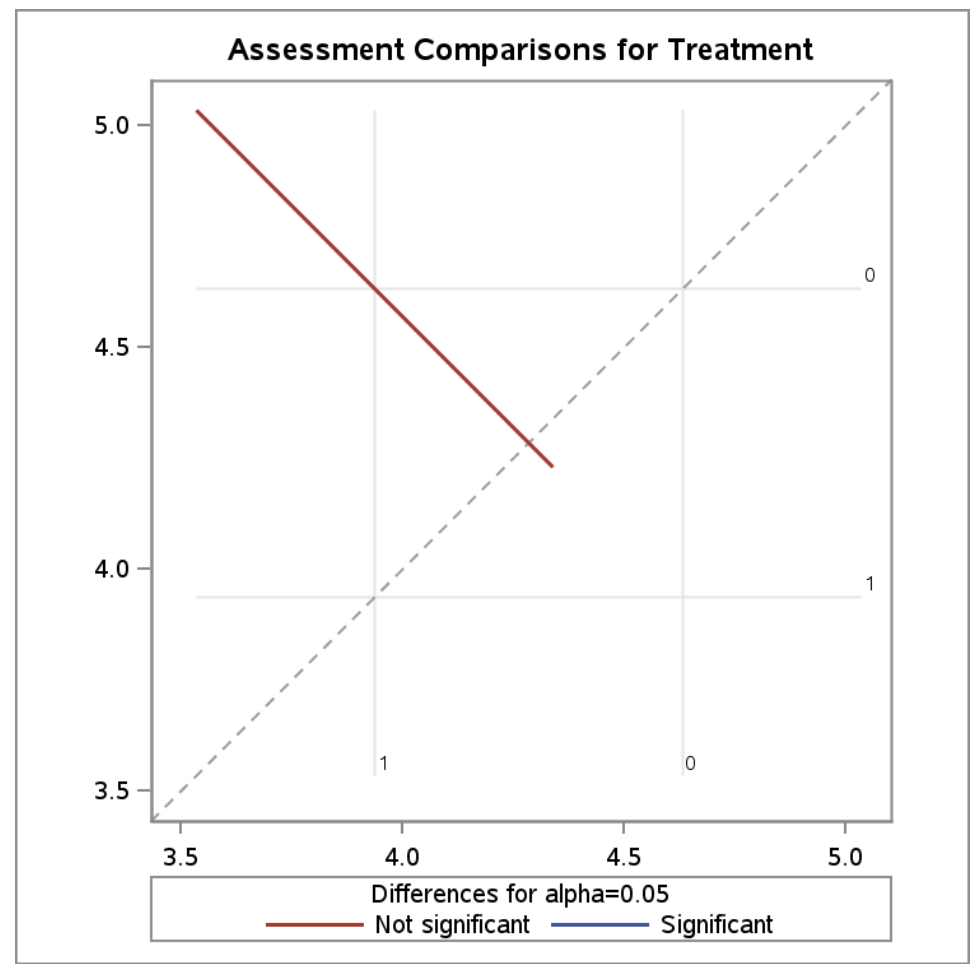

Assessment T Grouping for LS-Means of Treatment (Alpha $=0.05$ )

LS-means covered by the same bar are not significantly different

Treatment Estimate

4.6314

3.9369

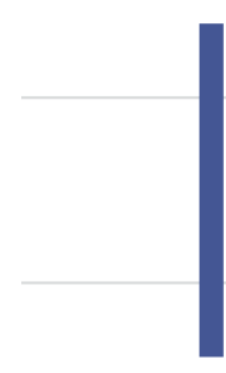




\section{Perceived Comfort}

11:29 Thursday, March 25, 2021

The GLM Procedure

\begin{tabular}{|l|r|l|}
\hline \multicolumn{3}{|c}{ Class Level Information } \\
\hline Class & Levels & Values \\
\hline Case & 15 & 123456789101112131415 \\
\hline Day & 2 & 12 \\
\hline Treatment & 2 & 01 \\
\hline
\end{tabular}

Number of Observations Read

Number of Observations Used 30 


\section{Perceived Comfort}

The GLM Procedure

Dependent Variable: Perceived_comfort Perceived_comfort

\begin{tabular}{|l|r|r|r|r|r|}
\hline Source & DF & $\begin{array}{r}\text { Sum of } \\
\text { Squares }\end{array}$ & Mean Square & F Value & Pr $>$ F \\
\hline Model & 16 & 49.07202381 & 3.06700149 & 9.28 & 0.0001 \\
\hline Error & 13 & 4.29464286 & 0.33035714 & & \\
\hline Corrected Total & 29 & 53.36666667 & & & \\
\hline
\end{tabular}

\begin{tabular}{|r|r|r|r|}
\hline R-Square & Coeff Var & Root MSE & Perceived_comfort Mean \\
\hline 0.919526 & 17.77630 & 0.574767 & 3.233333 \\
\hline
\end{tabular}

\begin{tabular}{|l|r|r|r|r|r|}
\hline Source & DF & Type ISS & Mean Square & F Value & Pr $>$ F \\
\hline Treatment & 1 & 3.00059524 & 3.00059524 & 9.08 & 0.0100 \\
\hline Day & 1 & 0.83333333 & 0.83333333 & 2.52 & 0.1362 \\
\hline Day*Treatment & 1 & 0.37202381 & 0.37202381 & 1.13 & 0.3079 \\
\hline Case(Treatment) & 13 & 44.86607143 & 3.45123626 & 10.45 & $<.0001$ \\
\hline
\end{tabular}

\begin{tabular}{|l|r|r|r|r|r|}
\hline Source & DF & Type III SS & Mean Square & F Value & Pr $>$ F \\
\hline Treatment & 1 & 3.00059524 & 3.00059524 & 9.08 & 0.0100 \\
\hline Day & 1 & 0.90535714 & 0.90535714 & 2.74 & 0.1218 \\
\hline Day*Treatment & 1 & 0.37202381 & 0.37202381 & 1.13 & 0.3079 \\
\hline Case(Treatment) & 13 & 44.86607143 & 3.45123626 & 10.45 & $<.0001$ \\
\hline
\end{tabular}

\begin{tabular}{|c|c|c|c|c|c|}
\hline & & $\begin{array}{l}\text { Using } \\
\text { as }\end{array}$ & $\begin{array}{l}\text { ype III MS } \\
\text { or Term }\end{array}$ & se( & ent) \\
\hline Source & DF & Type III SS & Mean Square & F Value & $\operatorname{Pr}>\mathrm{F}$ \\
\hline Treat & 1 & 3.0005952 & 3.00059524 & 0.87 & 0.3681 \\
\hline
\end{tabular}


The GLM Procedure

Least Squares Means

Standard Errors and Probabilities Calculated Using the Type III MS for Case(Treatment) as an Error Term

\begin{tabular}{|c|c|c|}
\hline \multirow[b]{2}{*}{ Treatment } & \multirow[b]{2}{*}{$\begin{array}{r}\text { Perceived_comfort } \\
\text { LSMEAN }\end{array}$} & H0:LSMean1=LSMean2 \\
\hline & & $\operatorname{Pr}>|t|$ \\
\hline 0 & 3.57142857 & 0.3681 \\
\hline 1 & 2.93750000 & \\
\hline
\end{tabular}

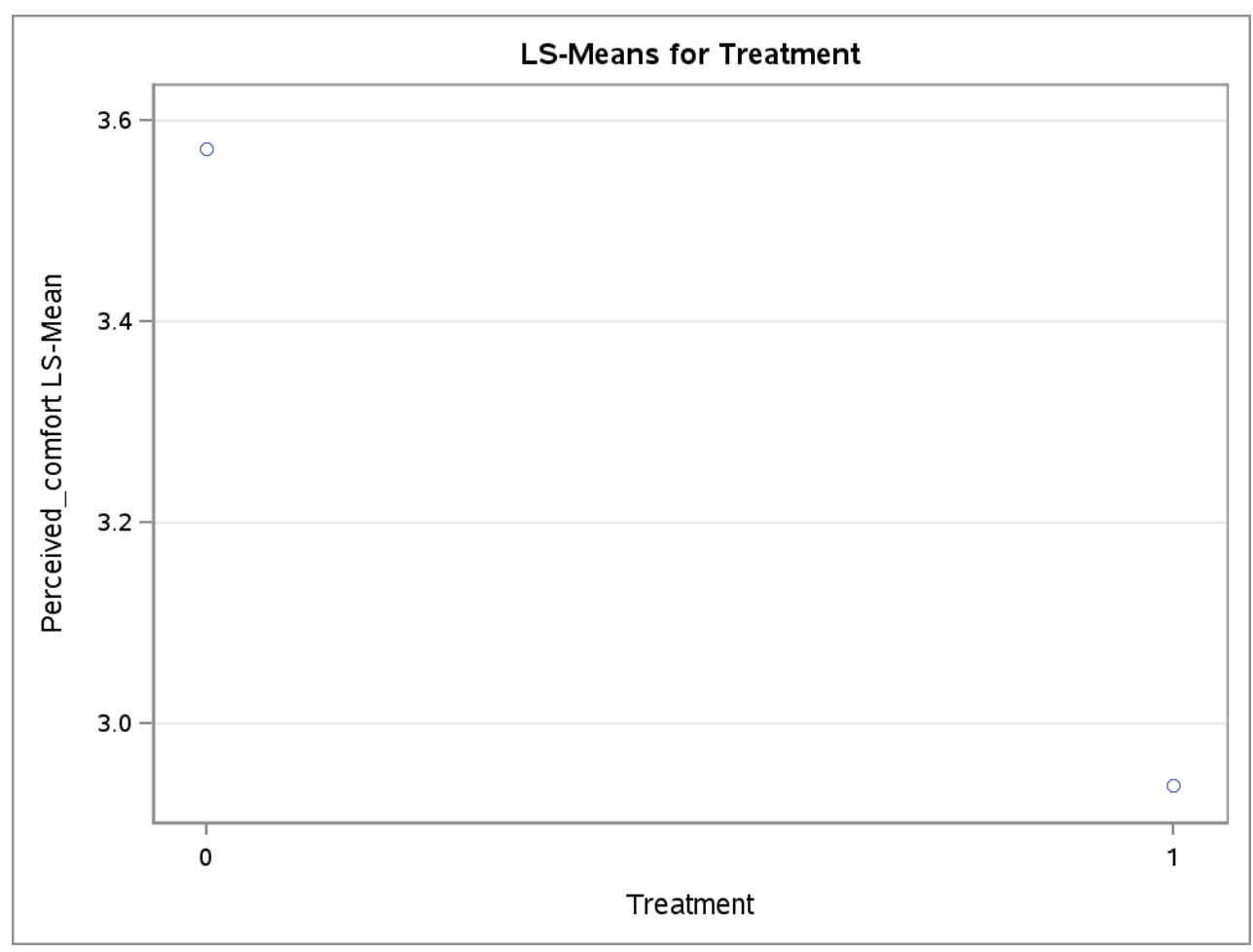


The GLM Procedure Least Squares Means

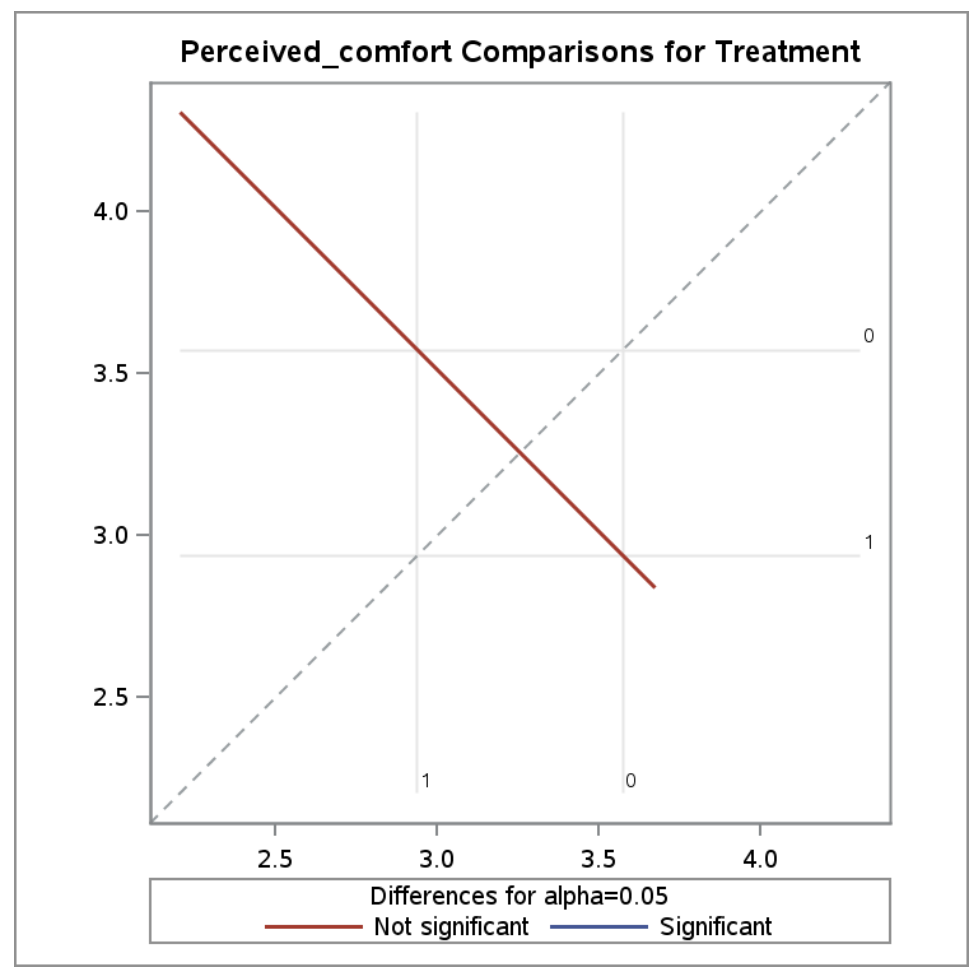

Perceived_comfort T Grouping for LS-Means of Treatment (Alpha $=0.05$ )

LS-means covered by the same bar are not significantly different

Treatment Estimate

3.5714

2.9375

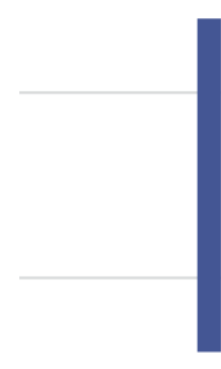


HR Low

11:29 Thursday, March 25, $2021 \quad 17$

The GLM Procedure

\begin{tabular}{|l|r|l|}
\hline \multicolumn{3}{|c|}{ Class Level Information } \\
\hline Class & Levels & Values \\
\hline Case & 15 & 123456789101112131415 \\
\hline Day & 2 & 12 \\
\hline Treatment & 2 & 01 \\
\hline
\end{tabular}

Number of Observations Read

\begin{tabular}{l|l} 
Number of Observations Used & 19
\end{tabular} 
HR Low

The GLM Procedure

Dependent Variable: HR_low HR_low

\begin{tabular}{|l|r|r|r|r|r|}
\hline Source & DF & $\begin{array}{r}\text { Sum of } \\
\text { Squares }\end{array}$ & Mean Square & F Value & Pr > F \\
\hline Model & 12 & 1443.792982 & 120.316082 & 8.14 & 0.0087 \\
\hline Error & 6 & 88.733333 & 14.788889 & & \\
\hline Corrected Total & 18 & 1532.526316 & & & \\
\hline
\end{tabular}

\begin{tabular}{|r|r|r|r|}
\hline R-Square & Coeff Var & Root MSE & HR_low Mean \\
\hline 0.942100 & 4.940299 & 3.845632 & 77.84211 \\
\hline
\end{tabular}

\begin{tabular}{|l|r|r|r|r|r|}
\hline Source & DF & Type I SS & Mean Square & F Value & Pr > F \\
\hline Treatment & 1 & 27.895363 & 27.895363 & 1.89 & 0.2187 \\
\hline Day & 1 & 40.312771 & 40.312771 & 2.73 & 0.1498 \\
\hline Day*Treatment & 1 & 12.734848 & 12.734848 & 0.86 & 0.3892 \\
\hline Case(Treatment) & 9 & 1362.850000 & 151.427778 & 10.24 & 0.0052 \\
\hline
\end{tabular}

\begin{tabular}{|l|r|r|r|r|r|}
\hline Source & DF & Type III SS & Mean Square & F Value & Pr > F \\
\hline Treatment & 1 & 11.211075 & 11.211075 & 0.76 & 0.4174 \\
\hline Day & 1 & 0.266667 & 0.266667 & 0.02 & 0.8976 \\
\hline Day*Treatment & 1 & 3.266667 & 3.266667 & 0.22 & 0.6550 \\
\hline Case(Treatment) & 9 & 1362.850000 & 151.427778 & 10.24 & 0.0052 \\
\hline
\end{tabular}

\begin{tabular}{|c|c|c|c|c|c|}
\hline \multicolumn{6}{|c|}{$\begin{array}{l}\text { Tests of Hypotheses Using the Type III MS for Case(Treatment) } \\
\text { as an Error Term }\end{array}$} \\
\hline Source & DF & Type III SS & Mean Square & F Value & $\mathrm{Pr}>\mathrm{F}$ \\
\hline Treatment & 1 & 11.21107456 & 11.21107456 & 0.07 & 0.7917 \\
\hline
\end{tabular}


The GLM Procedure

Least Squares Means

Standard Errors and Probabilities Calculated Using the Type III MS for Case(Treatment) as an Error Term

\begin{tabular}{|l|r|r|}
\hline & & H0:LSMean1=LSMean2 \\
\cline { 3 - 3 } Treatment & $\begin{array}{r}\text { HR_low } \\
\text { LSMEAN }\end{array}$ & Pr > |t| \\
\hline $\mathbf{0}$ & 79.4166667 & 0.7917 \\
\hline $\mathbf{1}$ & 77.7142857 & \\
\hline
\end{tabular}

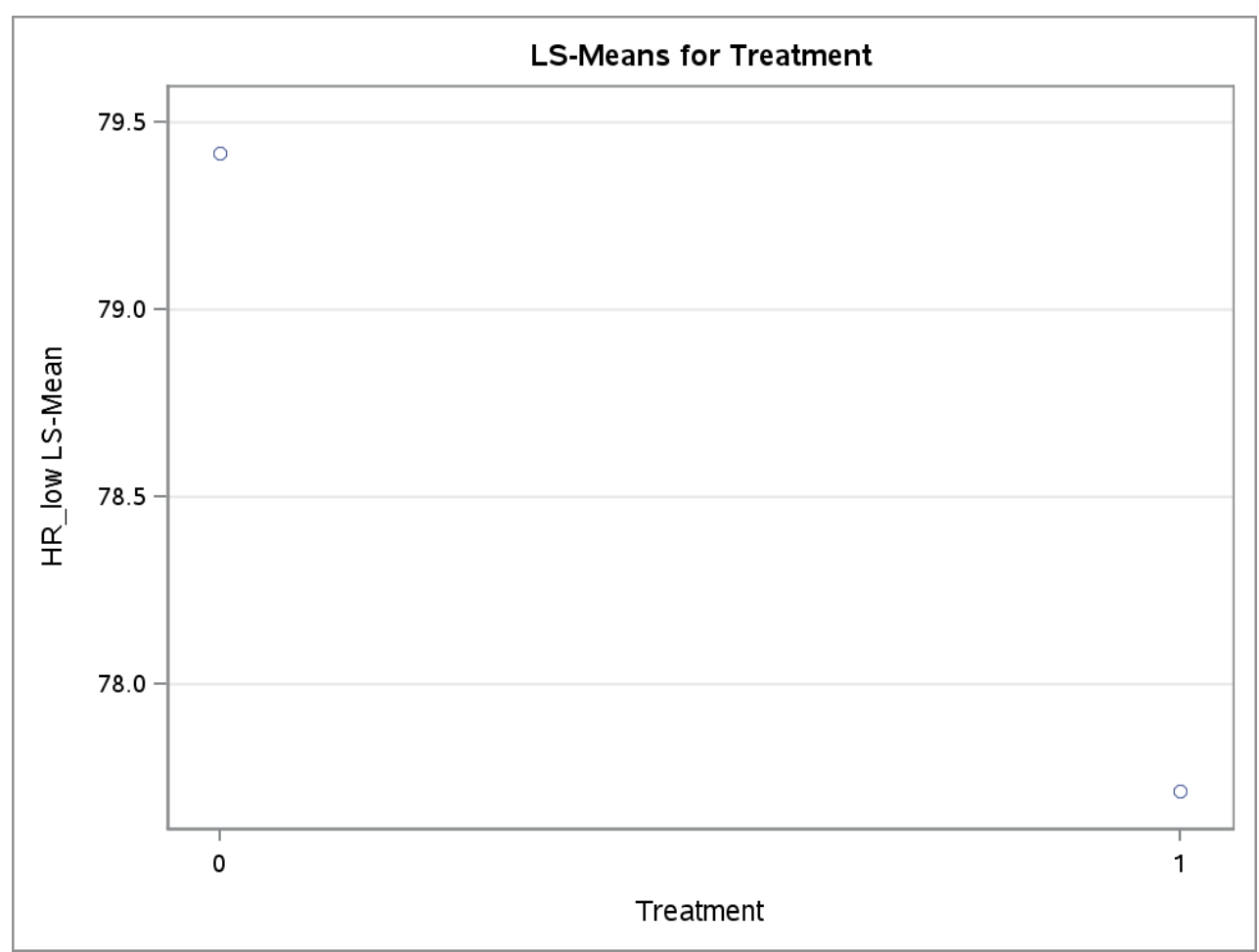


The GLM Procedure

Least Squares Means

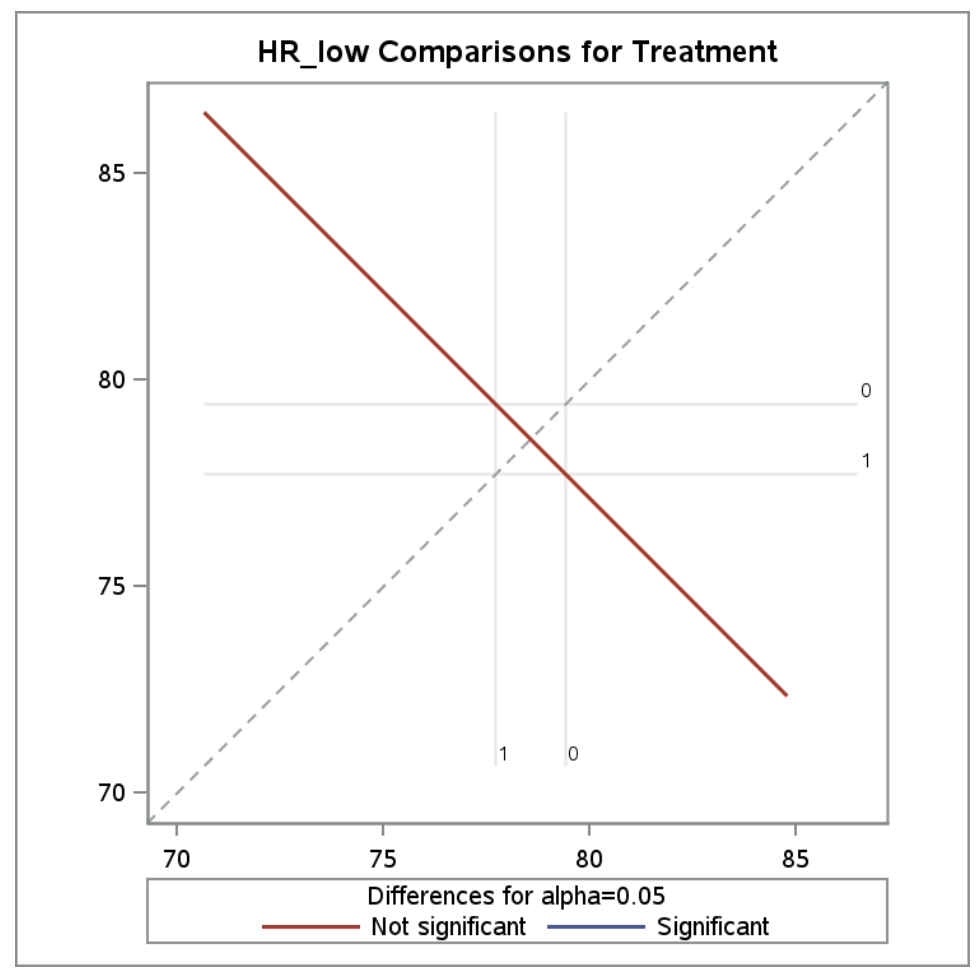

HR_low T Grouping for LS-Means of Treatment $($ Alpha $=0.05)$

LS-means covered by the same bar are not significantly different

Treatment Estimate

79.4167

77.7143

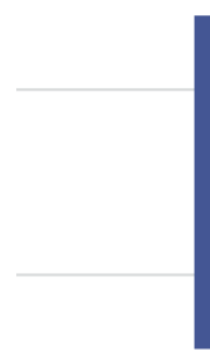


The GLM Procedure

\begin{tabular}{|l|r|l|}
\hline \multicolumn{3}{|c|}{ Class Level Information } \\
\hline Class & Levels & Values \\
\hline Case & 15 & 123456789101112131415 \\
\hline Day & 2 & 12 \\
\hline Treatment & 2 & 01 \\
\hline
\end{tabular}

Number of Observations Read

\begin{tabular}{l|l} 
Number of Observations Used & 19
\end{tabular} 
The GLM Procedure

Dependent Variable: HR_avg HR_avg

\begin{tabular}{|l|r|r|r|r|r|}
\hline Source & DF & $\begin{array}{r}\text { Sum of } \\
\text { Squares }\end{array}$ & Mean Square & F Value & Pr > F \\
\hline Model & 12 & 1155.157895 & 96.263158 & 4.98 & 0.0300 \\
\hline Error & 6 & 116.000000 & 19.333333 & & \\
\hline Corrected Total & 18 & 1271.157895 & & & \\
\hline
\end{tabular}

\begin{tabular}{|r|r|r|r|}
\hline R-Square & Coeff Var & Root MSE & HR_avg Mean \\
\hline 0.908745 & 4.570153 & 4.396969 & 96.21053 \\
\hline
\end{tabular}

\begin{tabular}{|l|r|r|r|r|r|}
\hline Source & DF & Type I SS & Mean Square & F Value & Pr > F \\
\hline Treatment & 1 & 9.634085 & 9.634085 & 0.50 & 0.5067 \\
\hline Day & 1 & 27.705628 & 27.705628 & 1.43 & 0.2764 \\
\hline Day*Treatment & 1 & 16.734848 & 16.734848 & 0.87 & 0.3881 \\
\hline Case(Treatment) & 9 & 1101.083333 & 122.342593 & 6.33 & 0.0179 \\
\hline
\end{tabular}

\begin{tabular}{|l|r|r|r|r|r|}
\hline Source & DF & Type III SS & Mean Square & F Value & Pr > F \\
\hline Treatment & 1 & 0.241776 & 0.241776 & 0.01 & 0.9146 \\
\hline Day & 1 & 3.750000 & 3.750000 & 0.19 & 0.6751 \\
\hline Day*Treatment & 1 & 33.750000 & 33.750000 & 1.75 & 0.2346 \\
\hline Case(Treatment) & 9 & 1101.083333 & 122.342593 & 6.33 & 0.0179 \\
\hline
\end{tabular}

\begin{tabular}{|c|c|c|c|c|c|}
\hline Test & & $\begin{array}{l}\text { Using t } \\
\text { as an }\end{array}$ & $\begin{array}{l}\text { Type III MS } \mathrm{f} \\
\text { rror Term }\end{array}$ & $\mathrm{se}(7$ & ent) \\
\hline Source & DF & Type III SS & Mean Square & F Value & $\operatorname{Pr}>\mathrm{F}$ \\
\hline Treatment & 1 & 0.24177632 & 0.24177632 & 0.00 & 0.9655 \\
\hline
\end{tabular}


The GLM Procedure

Least Squares Means

Standard Errors and Probabilities Calculated Using the Type III MS for Case(Treatment) as an Error Term

\begin{tabular}{|l|r|r|}
\hline & & H0:LSMean1=LSMean2 \\
\cline { 3 - 3 } Treatment & $\begin{array}{r}\text { HR_avg } \\
\text { LSMEAN }\end{array}$ & Pr > |t| \\
\hline $\mathbf{0}$ & 97.2500000 & 0.9655 \\
\hline $\mathbf{1}$ & 97.0000000 & \\
\hline
\end{tabular}

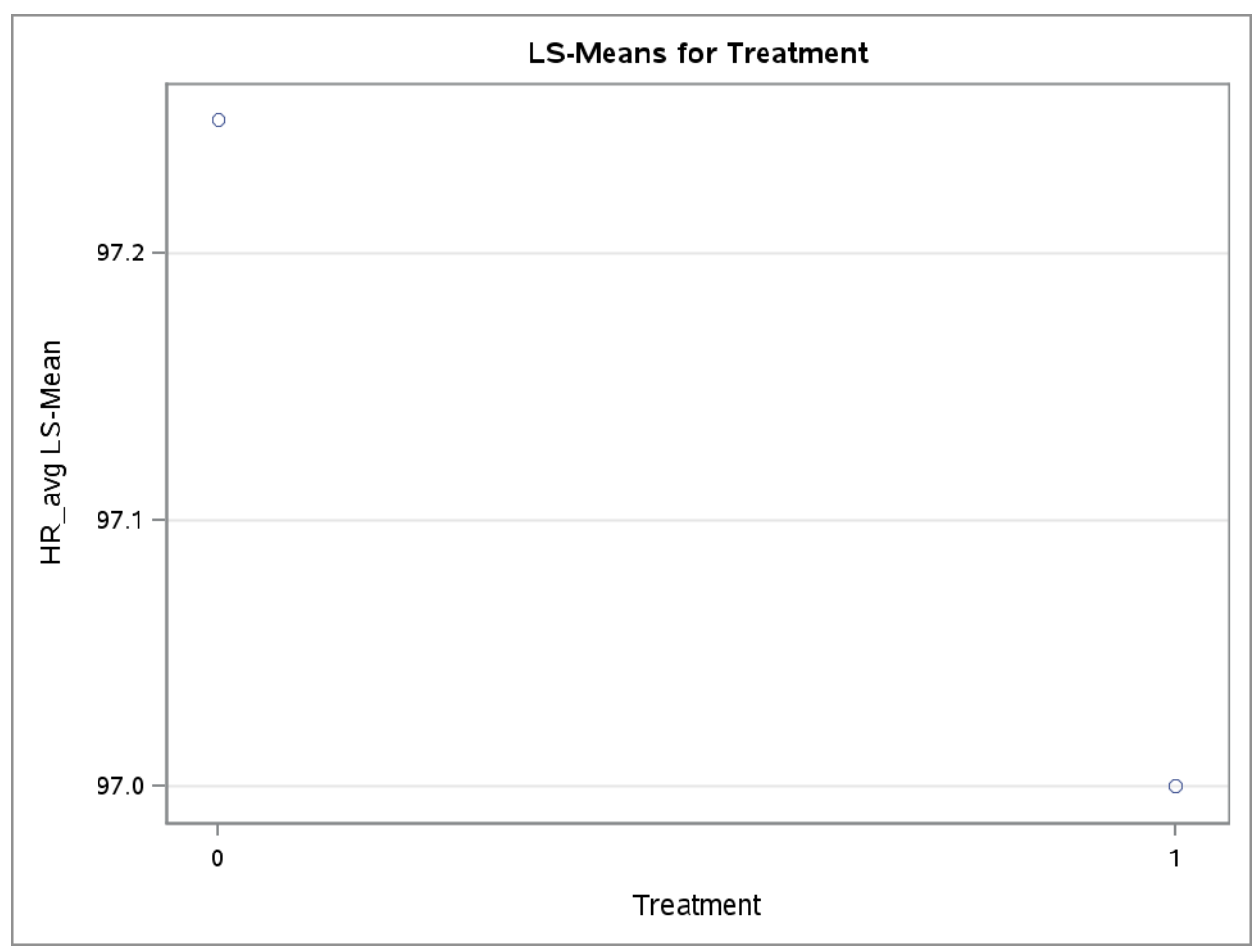


The GLM Procedure

Least Squares Means

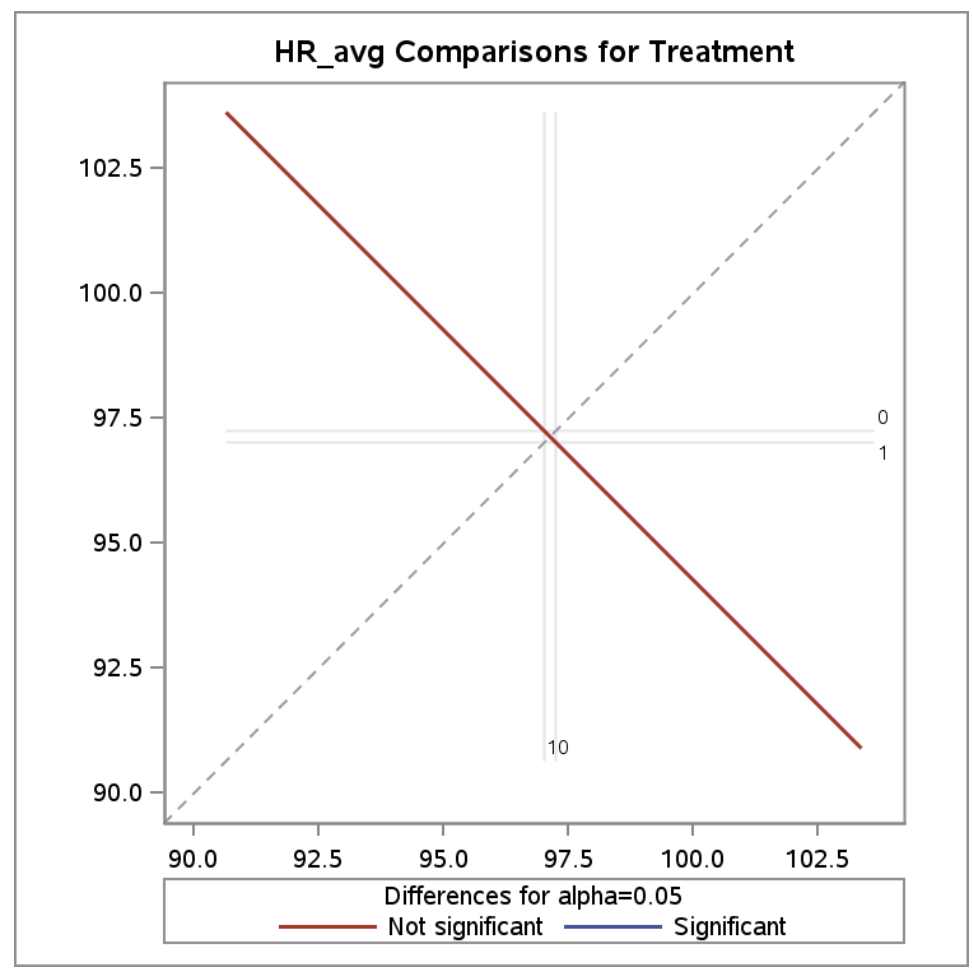

HR_avg T Grouping for LS-Means of Treatment (Alpha $=0.05)$

LS-means covered by the same bar are not significantly different

Treatment Estimate

97.2500

97.0000

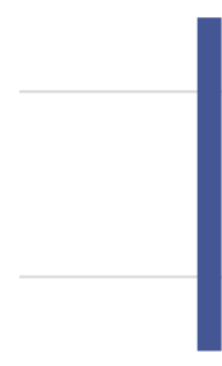


HR High

The GLM Procedure

\begin{tabular}{|l|r|l|}
\hline \multicolumn{3}{|c|}{ Class Level Information } \\
\hline Class & Levels & Values \\
\hline Case & 15 & 123456789101112131415 \\
\hline Day & 2 & 12 \\
\hline Treatment & 2 & 01 \\
\hline
\end{tabular}

Number of Observations Read

Number of Observations Used
11:29 Thursday, March 25, $2021 \quad 25$ 
HR High

The GLM Procedure

Dependent Variable: HR_High HR_High

\begin{tabular}{|l|r|r|r|r|r|}
\hline Source & DF & $\begin{array}{r}\text { Sum of } \\
\text { Squares }\end{array}$ & Mean Square & F Value & Pr $>$ F \\
\hline Model & 12 & 618.557895 & 51.546491 & 0.64 & 0.7592 \\
\hline Error & 6 & 482.600000 & 80.433333 & & \\
\hline Corrected Total & 18 & 1101.157895 & & & \\
\hline
\end{tabular}

\begin{tabular}{|r|r|r|r|}
\hline R-Square & Coeff Var & Root MSE & HR_High Mean \\
\hline 0.561734 & 7.244932 & 8.968463 & 123.7895 \\
\hline
\end{tabular}

\begin{tabular}{|l|r|r|r|r|r|}
\hline Source & DF & Type ISS & Mean Square & F Value & Pr $>$ F \\
\hline Treatment & 1 & 1.3840852 & 1.3840852 & 0.02 & 0.8999 \\
\hline Day & 1 & 3.2738095 & 3.2738095 & 0.04 & 0.8468 \\
\hline Day*Treatment & 1 & 110.9166667 & 110.9166667 & 1.38 & 0.2848 \\
\hline Case(Treatment) & 9 & 502.9833333 & 55.8870370 & 0.69 & 0.7010 \\
\hline
\end{tabular}

\begin{tabular}{|l|r|r|r|r|r|}
\hline Source & DF & Type III SS & Mean Square & F Value & Pr > F \\
\hline Treatment & 1 & 18.3601974 & 18.3601974 & 0.23 & 0.6497 \\
\hline Day & 1 & 38.4000000 & 38.4000000 & 0.48 & 0.5154 \\
\hline Day*Treatment & 1 & 126.1500000 & 126.1500000 & 1.57 & 0.2570 \\
\hline Case(Treatment) & 9 & 502.9833333 & 55.8870370 & 0.69 & 0.7010 \\
\hline
\end{tabular}

\begin{tabular}{|c|c|c|c|c|c|}
\hline res & & $\begin{array}{r}\text { Using } \\
\text { as } a\end{array}$ & $\begin{array}{l}\text { e III MS } \\
\text { Term }\end{array}$ & 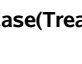 & nt) \\
\hline Source & DF & Type III SS & Mean Square & F Value & $\mathrm{Pr}>\mathrm{F}$ \\
\hline Tre & 1 & 18.36019737 & 18.360197 & 0.33 & 0.5806 \\
\hline
\end{tabular}


The GLM Procedure

Least Squares Means

Standard Errors and Probabilities Calculated Using the Type III MS for Case(Treatment) as an Error Term

\begin{tabular}{|l|r|r|}
\hline & & H0:LSMean1=LSMean2 \\
\cline { 3 - 3 } Treatment & $\begin{array}{r}\text { HR_High } \\
\text { LSMEAN }\end{array}$ & Pr > |t| \\
\hline $\mathbf{0}$ & 122.750000 & 0.5806 \\
\hline $\mathbf{1}$ & 124.928571 & \\
\hline
\end{tabular}

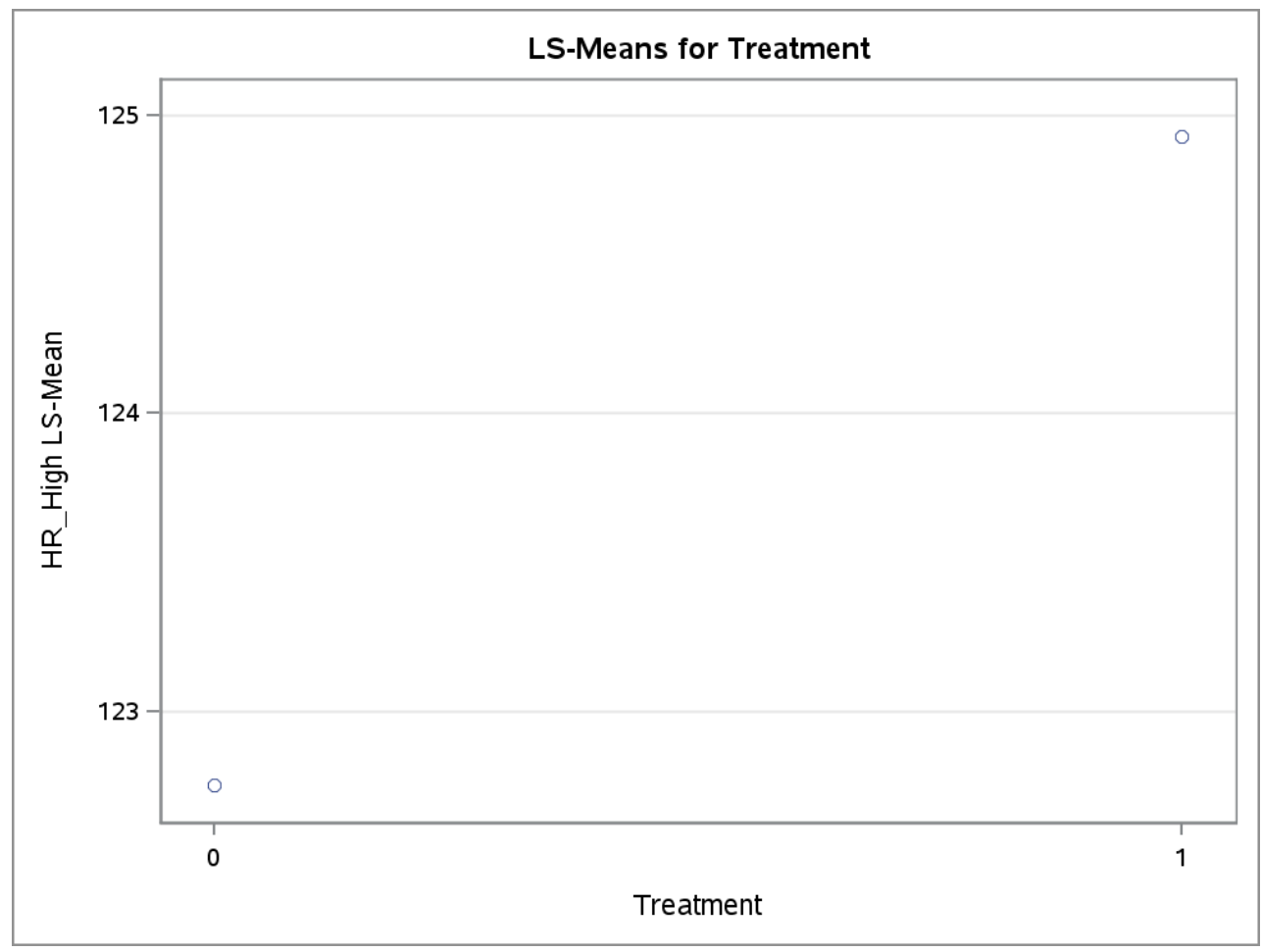


The GLM Procedure

Least Squares Means
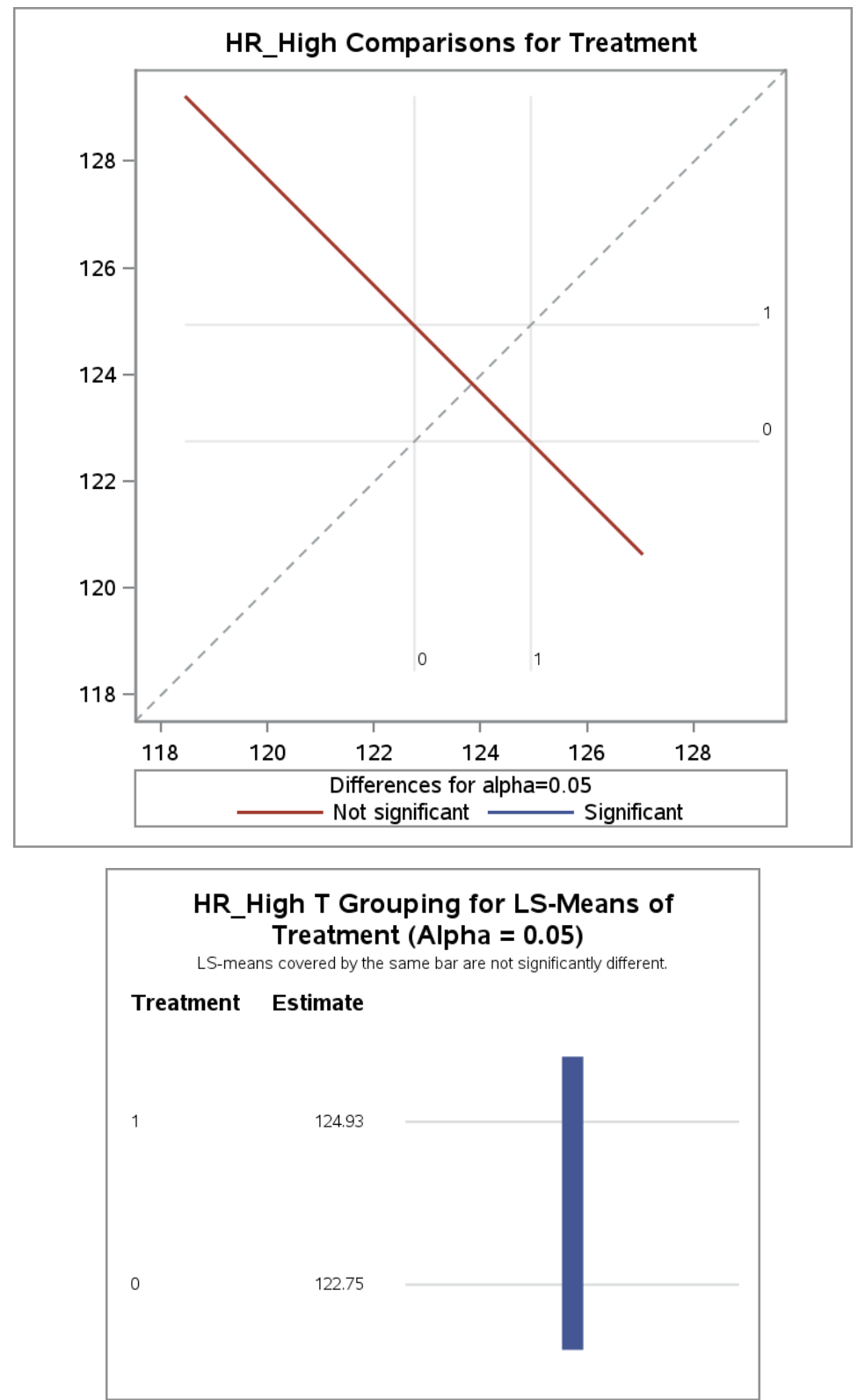
Stress Response

11:29 Thursday, March 25, $2021 \quad 29$

The GLM Procedure

\begin{tabular}{|l|r|l|}
\hline \multicolumn{3}{|c|}{ Class Level Information } \\
\hline Class & Levels & Values \\
\hline Case & 15 & 123456789101112131415 \\
\hline Day & 2 & 12 \\
\hline Treatment & 2 & 01 \\
\hline
\end{tabular}

Number of Observations Read

Number of Observations Used 19 
The GLM Procedure

Dependent Variable: StressResp StressResp

\begin{tabular}{|l|r|r|r|r|l|}
\hline Source & DF & $\begin{array}{r}\text { Sum of } \\
\text { Squares }\end{array}$ & Mean Square & F Value & Pr > F \\
\hline Model & 12 & 2402.898246 & 200.241520 & 0.81 & 0.6474 \\
\hline Error & 6 & 1489.733333 & 248.288889 & & \\
\hline Corrected Total & 18 & 3892.631579 & & & \\
\hline
\end{tabular}

\begin{tabular}{|c|r|r|r|}
\hline R-Square & Coeff Var & Root MSE & StressResp Mean \\
\hline 0.617294 & 22.64648 & 15.75719 & 69.57895 \\
\hline
\end{tabular}

\begin{tabular}{|l|r|r|r|r|r|}
\hline Source & DF & Type I SS & Mean Square & F Value & Pr > F \\
\hline Treatment & 1 & 218.107769 & 218.107769 & 0.88 & 0.3848 \\
\hline Day & 1 & 675.432900 & 675.432900 & 2.72 & 0.1502 \\
\hline Day*Treatment & 1 & 93.340909 & 93.340909 & 0.38 & 0.5623 \\
\hline Case(Treatment) & 9 & 1416.016667 & 157.335185 & 0.63 & 0.7418 \\
\hline
\end{tabular}

\begin{tabular}{|l|r|r|r|r|r|}
\hline Source & DF & Type III SS & Mean Square & F Value & Pr $>$ F \\
\hline Treatment & 1 & 132.171601 & 132.171601 & 0.53 & 0.4931 \\
\hline Day & 1 & 288.204167 & 288.204167 & 1.16 & 0.3227 \\
\hline Day*Treatment & 1 & 44.204167 & 44.204167 & 0.18 & 0.6878 \\
\hline Case(Treatment) & 9 & 1416.016667 & 157.335185 & 0.63 & 0.7418 \\
\hline
\end{tabular}

\begin{tabular}{|c|c|c|c|c|c|}
\hline \multicolumn{6}{|c|}{$\begin{array}{l}\text { Tests of Hypotheses Using the Type III MS for Case(Treatment) } \\
\text { as an Error Term }\end{array}$} \\
\hline Source & DF & Type III SS & Mean Square & F Value & $\operatorname{Pr}>\mathrm{F}$ \\
\hline Treatment & 1 & 132.1716009 & 132.1716009 & 0.84 & 0.3833 \\
\hline
\end{tabular}


The GLM Procedure

Least Squares Means

Standard Errors and Probabilities Calculated Using the Type III MS for Case(Treatment) as an Error Term

\begin{tabular}{|l|r|r|}
\hline & & \multicolumn{2}{|l|}{ H0:LSMean1=LSMean2 } \\
\cline { 3 - 3 } Treatment & $\begin{array}{r}\text { StressResp } \\
\text { LSMEAN }\end{array}$ & Pr $>|t|$ \\
\hline $\mathbf{0}$ & 65.0833333 & 0.3833 \\
\hline $\mathbf{1}$ & 70.9285714 & \\
\hline
\end{tabular}

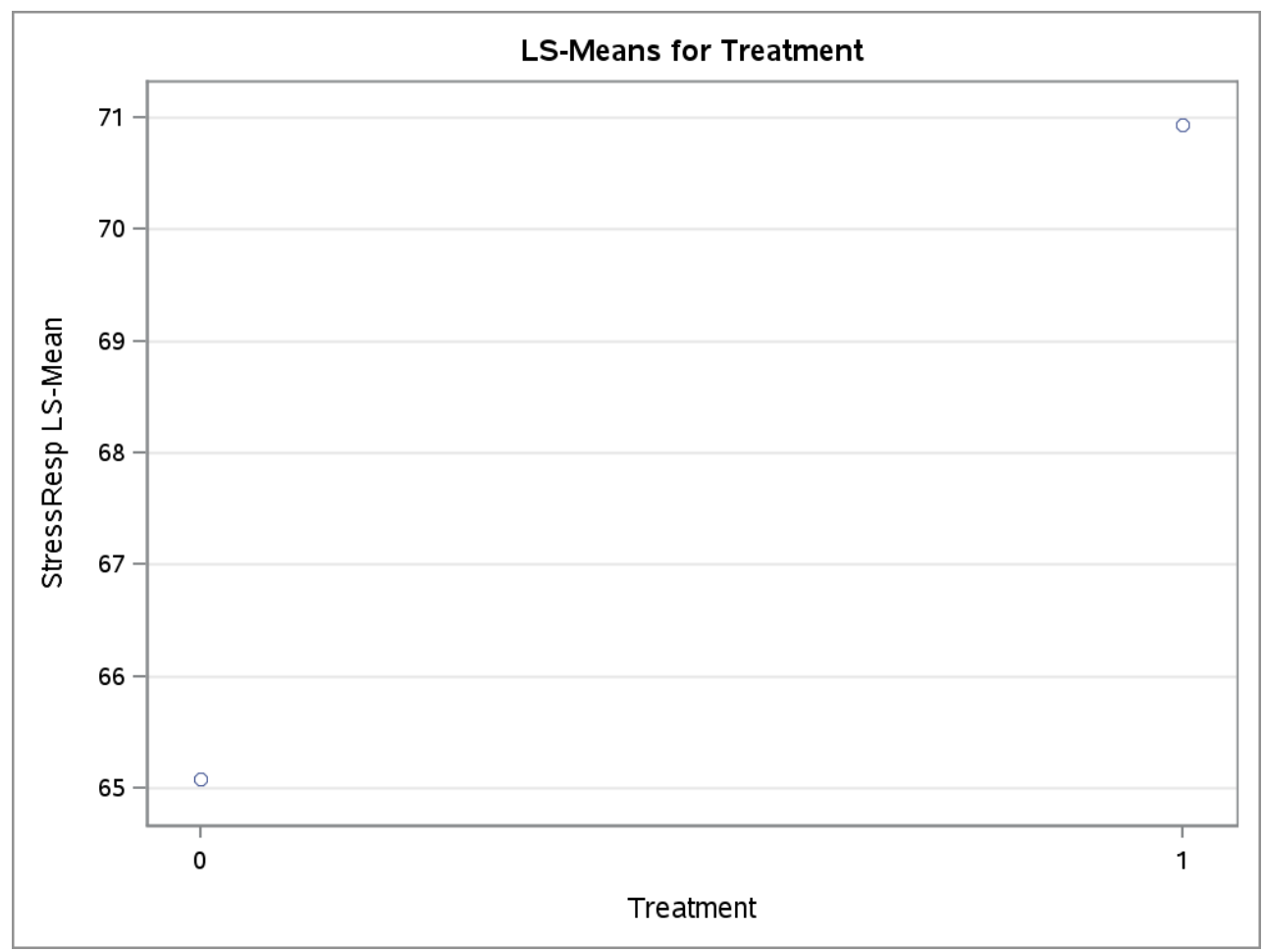


The GLM Procedure Least Squares Means

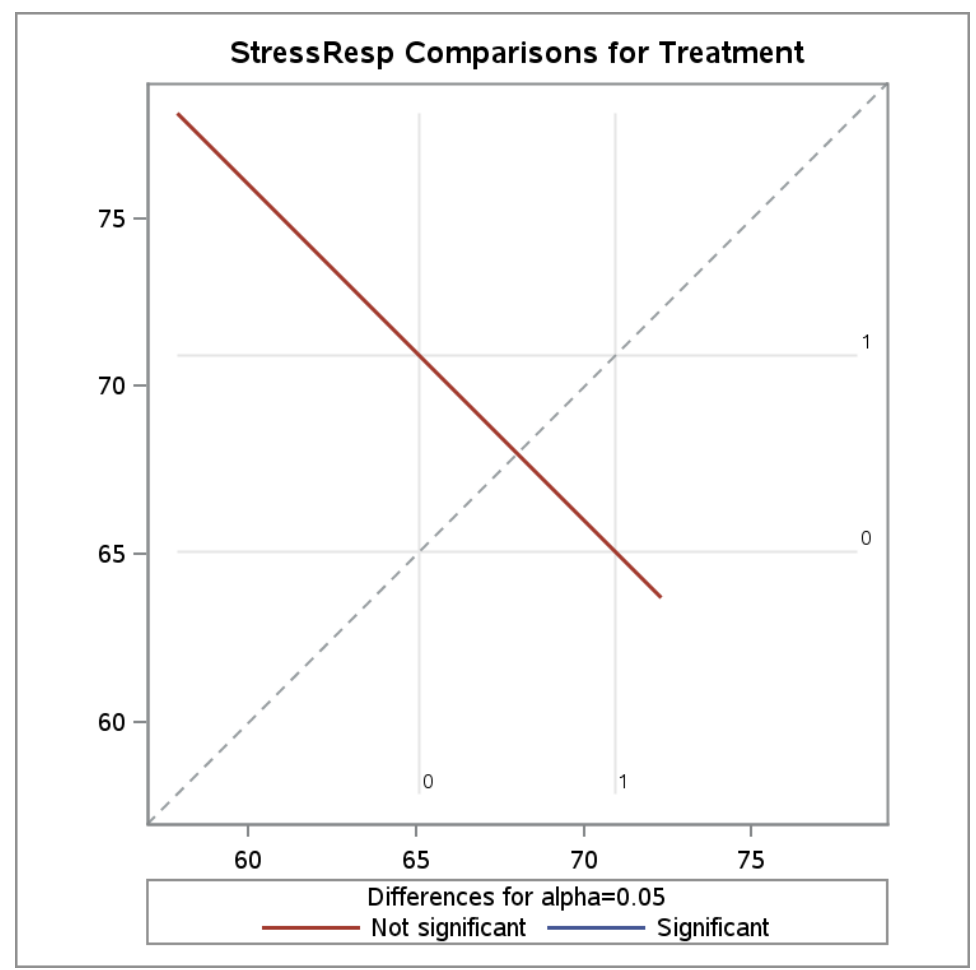

StressResp T Grouping for LS-Means of Treatment (Alpha $=0.05$ )

LS-means covered by the same bar are not significantly different

Treatment Estimate

70.9286

65.0833

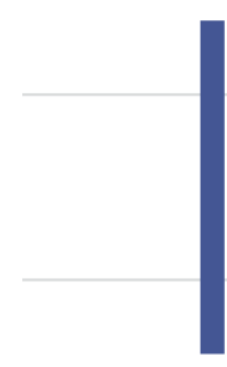


Steps

11:29 Thursday, March 25, $2021 \quad 33$

The GLM Procedure

\begin{tabular}{|l|r|l|}
\hline \multicolumn{3}{|c|}{ Class Level Information } \\
\hline Class & Levels & Values \\
\hline Case & 15 & 123456789101112131415 \\
\hline Day & 2 & 12 \\
\hline Treatment & 2 & 01 \\
\hline
\end{tabular}

Number of Observations Read

\begin{tabular}{l|l} 
Number of Observations Used & 19
\end{tabular} 
Steps

The GLM Procedure

Dependent Variable: Steps Steps

\begin{tabular}{|l|r|r|r|r|r|}
\hline Source & DF & $\begin{array}{r}\text { Sum of } \\
\text { Squares }\end{array}$ & Mean Square & F Value & Pr $>$ F \\
\hline Model & 12 & 339428.9263 & 28285.7439 & 1.12 & 0.4703 \\
\hline Error & 6 & 151567.6000 & 25261.2667 & & \\
\hline Corrected Total & 18 & 490996.5263 & & & \\
\hline
\end{tabular}

\begin{tabular}{|r|r|r|r|}
\hline R-Square & Coeff Var & Root MSE & Steps Mean \\
\hline 0.691306 & 37.58801 & 158.9379 & 422.8421 \\
\hline
\end{tabular}

\begin{tabular}{|l|r|r|r|r|r|}
\hline Source & DF & Type ISS & Mean Square & F Value & Pr $>$ F \\
\hline Treatment & 1 & 5567.8954 & 5567.8954 & 0.22 & 0.6553 \\
\hline Day & 1 & 3303.0400 & 3303.0400 & 0.13 & 0.7300 \\
\hline Day*Treatment & 1 & 2375.7576 & 2375.7576 & 0.09 & 0.7695 \\
\hline Case(Treatment) & 9 & 328182.2333 & 36464.6926 & 1.44 & 0.3377 \\
\hline
\end{tabular}

\begin{tabular}{|l|r|r|r|r|r|}
\hline Source & DF & Type III SS & Mean Square & F Value & Pr > F \\
\hline Treatment & 1 & 4661.7632 & 4661.7632 & 0.18 & 0.6825 \\
\hline Day & 1 & 258.3375 & 258.3375 & 0.01 & 0.9227 \\
\hline Day*Treatment & 1 & 2673.3375 & 2673.3375 & 0.11 & 0.7560 \\
\hline Case(Treatment) & 9 & 328182.2333 & 36464.6926 & 1.44 & 0.3377 \\
\hline
\end{tabular}

\begin{tabular}{|c|c|c|c|c|c|}
\hline Tests of $\mathrm{r}$ & ppoth & $\begin{array}{l}\text { eses Using the } \\
\text { as an E }\end{array}$ & $\begin{array}{l}\text { Type III MS for } \\
\text { ror Term }\end{array}$ & Zase(Trea & ment) \\
\hline Source & DF & Type III SS & Mean Square & F Value & $\operatorname{Pr}>\mathrm{F}$ \\
\hline Treatment & 1 & 4661.763158 & 4661.763158 & 0.13 & 0.7289 \\
\hline
\end{tabular}


The GLM Procedure

Least Squares Means

Standard Errors and Probabilities Calculated Using the Type III MS for Case(Treatment) as an Error Term

\begin{tabular}{|l|r|r|}
\hline & & H0:LSMean1=LSMean2 \\
\cline { 3 - 3 } Treatment & Steps LSMEAN & $\operatorname{Pr}>|\mathrm{t}|$ \\
\hline $\mathbf{0}$ & 407.000000 & 0.7289 \\
\hline $\mathbf{1}$ & 441.714286 & \\
\hline
\end{tabular}

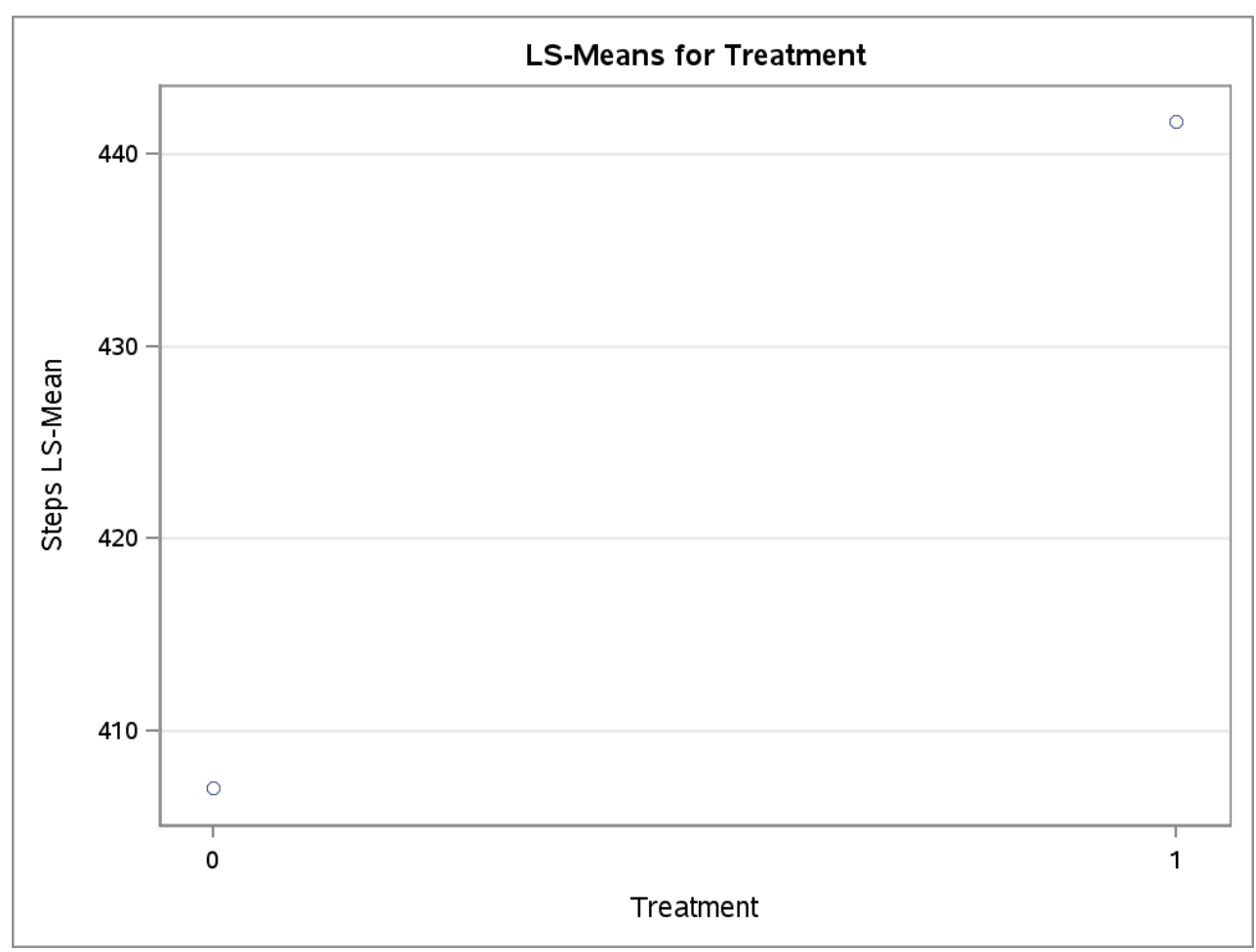


The GLM Procedure

Least Squares Means

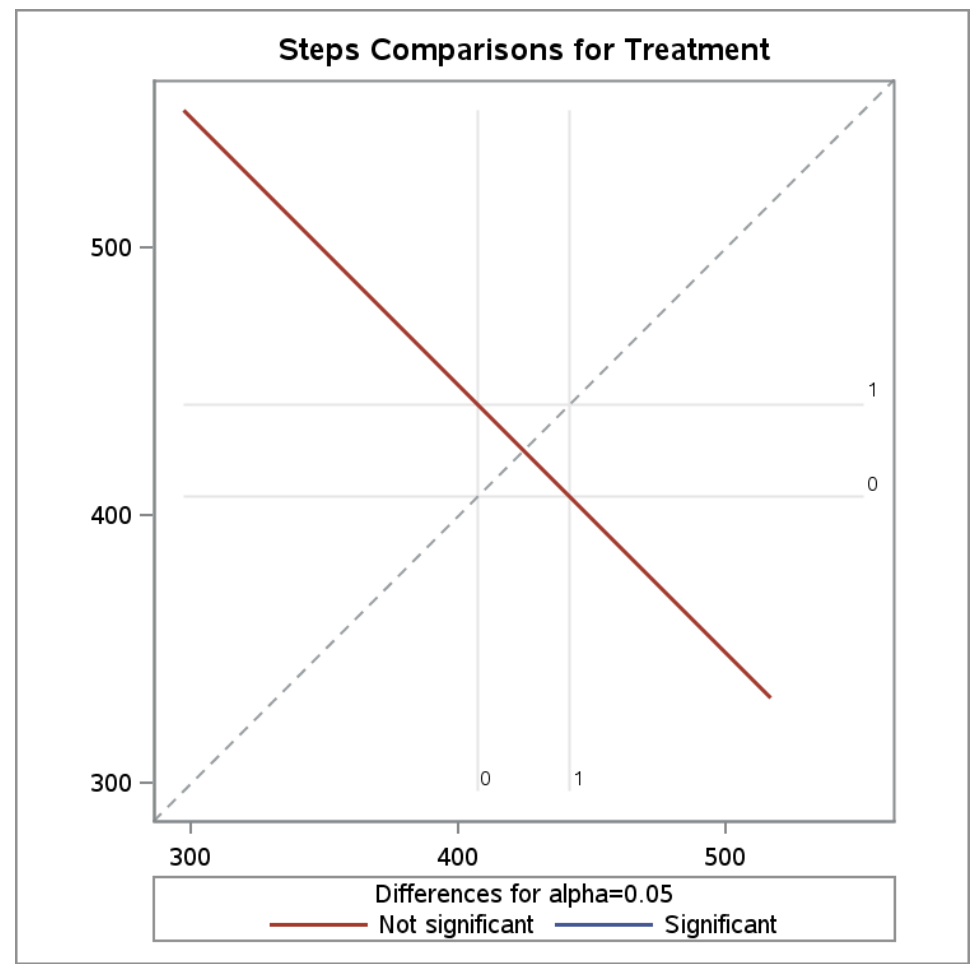

Steps T Grouping for LS-Means of Treatment $($ Alpha $=0.05)$

LS-means covered by the same bar are not significantly different

Treatment Estimate

441.71

0

407.00

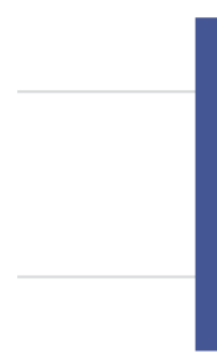




\section{References}

Admiraal, W. F., Wubbels, T., \& Korthagen, F. A. J. (2000). Effects of student teachers' coping behaviour. British Journal of Educational Psychology, 70, 33-52. doi: 10.1348/000709900157958

Agnew, D. M., \& Shinn, G. C. (1990). Effects of simulation on cognitive achievement in agricultural mechanics. Journal of Agricultural Education, 31(2), 12-16.

Anderson, M. (2010). Stressors identified by agricultural student teachers (Unpublished master's thesis). University of Kentucky. Lexington, KY.

Anderson, R., Velez, J., \& Anderson, S. (2014). Using the Health Belief Model to Comparatively Examine the Welding Safety Beliefs of Postsecondary Agricultural Education Students and their Non-agricultural Education Peers. Career and Technical Education Research, 39(1), 9-22.

Baker, A. J., Thoron, A. C., Myers, B. E., \& Cody, T. J. (2008). The influence of laboratory experience timing on student knowledge-level achievement in an undergraduate introductory agricultural mechanics course. NACTA Journal, 52(1), 6-9.

Bandura, A. (1986). Social foundations of though and action: A social cognitive theory. Englewood Cliffs, NJ: Prentice-Hall.

Bandura, A. (1997). Self-efficacy: The exercise of control, New York: W.H. Freeman.

Bennett, P. N., Iverson, M. J., Rohs, F. R., Langone, C. A., \& Edwards, M. C. (2002, February). Job satisfaction of agriculture teachers in Georgia and selected variables indicating their risk of leaving the teaching profession. Paper presented at the Southern Agricultural Education Research Conference, Orlando, FL.

Blackburn, J. J., \& Robinson, J. S. (2016). Determining the Effects of Cognitive Style, Problem Complexity, and Hypothesis Generation on the Problem Solving Ability of School-Based Agricultural Education Students. Journal of Agricultural Education, 57(2), 46-59.

Blackburn, J. J., Robinson, J. S., \& Lamm, A. J. (2014). How cognitive style and problem complexity affect preservice agricultural education teachers' abilities to solve problems in agricultural mechanics. Journal of Agricultural Education, 55(4), 133-147.

Bobek, B. L. (2002). Teacher Resiliency: A Key to Career Longevity. Clearing House, 75(4), 202. doi: 10.1080/00098650209604932 
Boone, Jr., H. N., \& Boone, D. A. (2010). An assessment of problems faced by high school agricultural education teachers. Journal of Agricultural Education, 50(1), 21-32. doi: 10.5032/jae.2009.01021

Brunetti, G. J. (2001). Why do they teach? A study of job satisfaction among long-term high school teachers. Teacher Education Quarterly, 28(3), 49-74.

Brunetti, G. J. (2006). Resilience under fire: Perspectives on the work of experienced, inner city high school teachers in the United States. Teaching and Teacher Education, 22(7), 812-825. doi: 10.1016/j.tate.2006.04.027

Brzozowski, R. J. (1988). The relationship of selected student and teacher characteristics with competency in agricultural mechanics (Doctoral dissertation, University of Missouri-Columbia).

Burris, S., Robinson, J. S., \& Terry, R. (2005). Preparation of pre-service teachers in agricultural mechanics. Journal of Agricultural Education, 46(3), 23

Byrne, J. J. (1998). Teacher as hunger artist: Burnout: Its causes, effects, and remedies. Contemporary Education, 69(2), 86-91.

Campbell, D. T., \& Stanley, J. C. (1966). Experimental and quasi-experimental designs for research. Handbook of research on teaching (NL Gage, Ed.), 171-246.

Carmona, C., Buunk, A. P., Peiro, J. M., Rodriguez, I., \& Bravo, M. J. (2006). Do social comparison and coping styles play a role in the development of burnout? Crosssectional and longitudinal findings. Journal of Occupational \& Organizational Psychology, 79(1), 85-99. doi: 10.1348/096317905X40808

Castro, A. J., Kelly, J., \& Shih, M. (2010). Resilience strategies for new teachers in highneeds areas. Teaching and Teacher Education, 26(3), 622-629. doi: 10.1016/j.tate.2009.09.010

Chenevey, J. L., Ewing, J. C., \& Whittington, M. S. (2008). Teacher burnout and job satisfaction among agricultural education teachers. Journal of Agricultural Education, 49(3), 12-22. doi: 10.5032/jae.2008.03012

Connor, K. M., \& Davidson, J. R. (2003). Development of a new resilience scale: The Connor-Davidson resilience scale (CD-RISC). Depression and anxiety, 18(2), 7682.

Croom, D. B. (2003). Teacher burnout in agricultural education. Journal of Agricultural Education, 44(2), 1-13. doi:10.5032/jae.2003.02001

Croom, D. B. (2008). The development of the integrated three-component model of agricultural education. Journal of Agricultural Education. 49(1), 110-120 
Delaney, J. P. A., \& Brodie, D. A. (2000). Effects of short-term psychological stress on the time and frequency domains of heart-rate variability. Perceptual and motor skills, 91(2), 515-5

Dillingham, J. M., Ramirez, G., \& Amsden, C. (1993). Perceptions of Texas agriscience and technology teachers regarding influence of gender in nontraditional agricultural mechanics programs. Journal of Agricultural Education, 34(1), 33 39.

Dyer, J. E., \& Andresen, R. J. (1999). Safety issues in agricultural education laboratories: A synthesis of research. Journal of Agricultural Education, 40, 46-54.

Edwards, M. C., \& Briers, G. E. (1998). Assessing the Inservice Needs of Entry-Phase Agriculture Teachers in Texas: A Discrepancy Model versus Direct Assessment. Proceedings of the American Vocational Association Convention. New Orleans, LA.

Evers, W. J. G., Tomic, W., \& Brouwers, A. (2004). Burnout among teachers: Students' and teachers' perceptions compared. School Psychology International, 25(2), 131148. doi: 10.1177/0143034304043670

Fletcher, W. E., \& Miller, A. (1995). An analysis of the agriscience laboratory safety practices of Louisiana vocational agricultural teachers. Proceedings of the 44th Annual Southern Agricultural Education Research Meeting, 149-157. Retrieved from http://www.eric.ed.gov/PDFS/ED382886.pdf

Foster, D., Lawver, R., \& Smith, A. (2014). National agricultural education supply \& demand study. Agribusiness, 64, 8-6.

Foster, R. (1986). Anxieties of agricultural education majors prior to and immediately following the student teaching experience. In Seeking Solutions for Tomorrow's Challenges: Proceedings of the Thirteenth Annual National Agricultural Education Research Meeting. Dallas, Texas. pp. 34-40.

Foster, R., Bell, L. C., \& Erskine, N. (1995). The importance of selected instructional areas in the present and future secondary agricultural education curriculum as perceived by teachers, principals, and superintendents in Nebraska. Journal of Agricultural Education, 36(3), 1-6.

Freudenberger, H. J. (1974). Staff burn-out. Journal of Social Issues, 30(1), 159-165. doi: 10.1111/j.1540-4560.1974.tb00706.x

Fullan, M. (2001). The new meaning of educational change (3rd ed.). New York, NY: Teachers College Press. 
Garton, B. L., \& Chung, N. (1996). The inservice needs of beginning teachers of agriculture as perceived by beginning teachers, teacher educators, and state supervisors. Journal of Agricultural Education, 37(2), 52-58.

Garton, B. L., \& Chung, N. (1997). An assessment of the inservice needs of beginning teachers of agriculture using two assessment models. Journal of Agricultural Education, 38, 51-58.

Grubb, W. N., \& Lazerson, M. (2005). Vocationalism in higher education: The triumph of the education gospel. The Journal of Higher Education, 76(1), 1-25.

Gu, Q., \& Day, C. (2007). Teachers resilience: A necessary condition for effectiveness. Teaching and Teacher Education, 23(8), 1302-1316. doi: 10.1016/j.tate.2006.06.006

Guglielmi, R. S., \& Tatrow, K. (1998). Occupational stress, burnout, and health in teachers: A methodological and theoretical analysis. Review of Educational Research, 68(1), 61-99. doi: 10.3102/00346543068001061

Hanson, R. (2009). Buddha's brain: The practical neuroscience of happiness, love, and wisdom. New Harbinger Publications.

Herren, R. V. (2010). Agricultural mechanics : fundamentals \& applications (6th ed.). Clifton Park, NY: Delmar Cengage Learning.

Hobfoll, S. E., \& Shirom, J. (1993). Stress and burnout in the workplace: Conservation of resources. In R. T. Golembiewski (Ed.), Handbook of organizational behavior (pp. 41-60). New York, NY: Dekker.

Howard, S., \& Johnson, B. (2004). Resilient teachers: resisting stress and burnout. Social Psychology of Education, 7(4), 399-420. doi: 10.1007/s11218-004-0975-0

Hubert, D. J., \& Leising, J. (2000). An assessment of agricultural mechanics course requirements in agriculture teacher education programs in the United States. Journal of Southern Agricultural Education Research, 50(1), 24-31.

Ingersoll, R. M., \& Smith, T. M. (2003). The wrong solution to the teacher shortage. Educational leadership, 60(8), 30-33.

Jarczok, M.N., Jarczok, M., Mauss, D., Koenig, J., Li, J., Herr, R.M., \& Thayer, J.F. (2013). Autonomic nervous system activity and workplace stressors-A systematic review. Neuroscience \& Biobehavioral Reviews, 37(8), 1810-1823. DOI:10.1016/j.neubiorev.2013.07.004 
Johnson, D. M. (1991). Student achievement and factors related to achievement in a state FFA agricultural mechanics contest. Journal of Agricultural Education, 32(3). 815.

Johnson, D. M., \& Schumacher, L. G. (1989). Agricultural mechanics specialists' identification and evaluation of agricultural mechanics laboratory management competencies: A modified Delphi approach. Journal of Agricultural Education, 30(3), 23-28

Johnson, D. M., \& Wardlow, G. W. (2017). Effects of an applied workshop on teacher self-efficacy and intent to teach hydraulics. Journal of Agricultural Systems, Technology, and Management, 28, 15-24.

Johnson, D. M., Schumacher, L. G., \& Stewart, B. R. (1990). An analysis of the agricultural mechanics laboratory management inservice needs of Missouri agriculture teachers. Journal of Agricultural Education, 31(2), 35-39.

Johnson, D. M., Wardlow, G. W., \& Franklin, T. D. (1997). Hands-on activities versus worksheets in reinforcing physical science principles: Effects on student achievement and attitude. Journal of Agricultural Education, 38(3), 9-17

Kantrovich, A. J. (2007). A national study of the supply and demand for teachers of agricultural education from 2004-2006 Supply and Demand Study. Morehead, KY: American Association for Agricultural Education.

King, D. L., Rucker, K. J., \& Duncan, D. W. (2013). Classroom instruction and FFA/SAE responsibilities creating the most stress for female teachers in the southeast. Journal of Agricultural Education, 54(4), 195-205. DOI: $10.5032 /$ jae.2013.04195

Knobloch, N. A., \& Whittington, M. S. (2003). Differences in teacher efficacy related to career commitment of novice agriculture teachers. Journal of Career and Technical Education, 20(1), 87-98.

Kyriacou, C. (2000). Stress-busting for teachers. London, UK: Stanley Thornes Ltd.

Kyriacou, C. (2003). Teacher stress: directions for future research. Educational Review, 53(1), 27-35. doi: 10.1080/0013191012003362 8

Lawver, D. E., Barton, J., Akers, C., Smith, J. H., \& Fraze, S. (2004). Agricultural mechanics curriculum for agricultural science teacher certification: A Delphi study. In Proceedings of the American Association of Agricultural Education Research Conference (Vol. 31, pp. 433-441). 
Layfield, K. D., \& Dobbins, T. R. (2002). Inservice needs and perceived competencies of South Carolina agricultural educators. Journal of Agricultural Education, 43(4), 46-55.

Lazarus, R. S. (1991). Emotion and adaptation. Oxford University Press on Demand.

Lazarus, R. S. (1993). From psychological stress to the emotions: A history of changing outlooks. Annual review of psychology, 44(1), 1-22.

Lazarus, R. S., \& Folkman, S. (1984). Stress, appraisal, and coping. New York, NY: Springer Pub. Co.

Lee, J.S. (1990, November). How healthy are agriculture teachers? The Agricultural Education Magazine, 62(12), 6, 21.

Leiter, M. P. (1991). Coping patterns as predictors of burnout: The function of control and escapist coping patterns. Journal of Organizational Behavior, 12(2), 123-144. doi: 10.1002/job.4030120205

Luthans, F., Youssef, C. M., \& Avolio, B. J. (2007). Psychological capital: Developing the human competitive edge. Oxford, UK: Oxford University Press.

Maslach, C. (1982). Burnout: The cost of caring. Englewood Cliffs, NJ: Prentice-Hall.

Maslach, C., Jackson, S. E., \& Leiter, M. P. (1996). Maslach Burnout Inventory Manual (3rd ed.). Palo Alto, CA: Consulting Psychologists Press.

Masten, A. S. (2001). Ordinary magic: Resilience processes in development. American Psychologist, 56(3), 227-238. doi: 10.1037/0003-066x.56.3.227

McCraty, R., Atkinson, M., Tiller, W. A., Rein, G., \& Watkins, A. D. (1995). The effects of emotions on short-term power spectrum analysis of heart rate variability. The American Journal of cardiology, 76(14), 1089-1093.

McCubbins, O. P., Anderson, R. G., Paulsen, T. H., \& Wells, T. (2016). Teacherperceived Adequacy of Tools and Equipment Available to Teach Agricultural Mechanics. Journal of Agricultural Education, 57(3), 223-236.

McKim, B. R., \& Saucier, P. R. (2011). Agricultural Mechanics Laboratory Management Professional Development Needs of Wyoming Secondary Agriculture Teachers. Journal of Agricultural Education, 52(3), 75-86.

McKim, B. R., \& Saucier, P. R. (2013). A 20-year comparison of teachers' agricultural mechanics laboratory management competency. Journal of Agricultural Education, 54(1), 153-166. 
Merriam-Webster, I. (2001). Merriam-Webster's collegiate dictionary. Springfield, Mass: Merriam-Webster.

Miller, G. M. (1989). Student arc welding noise exposures in agricultural mechanics laboratories. Journal of Agricultural Education, 30(2), 62-67.

Montgomery, C., \& Rupp, A. A. (2005). A meta-analysis for exploring the diverse causes and effects of stress in teachers. Canadian Journal of Education / Revue Canadienne de l'Education, 28(3), 458-486. doi: 10.2307/4126479

Morris, H. J. (2006). An analysis of retention factors that influence Georgia's secondary career and technical education teachers to remain in the teaching profession (Unpublished Doctoral dissertation, Georgia Southern University). Retrieved from http://dspaceprod.georgiasouthern.edu:8080/xmlui/handle/10518/1596

Myers, B. E., Dyer, J. E., \& Washburn, S. G. (2005). Problems facing beginning agriculture teachers. Journal of Agricultural Education, 46(3). doi: $10.5032 /$ jae. 2005.03047

Newcomb, L. H., Betts, S. I., \& Cano, J. (1987). Extent of burnout among teachers of vocational agriculture in Ohio. Journal of the American Association of Teacher Educators in Agriculture, 28(1), 26-33. doi:10.5032/jaatea.1987.01026

Olpin, M., \& Hesson, M. (2010). Stress managment for life: A research-based experiential approach (2nd ed.). Belmont, CA: Wadsworth, Cengage Learning.

Osborne, E. W., \& Dyer, J. E. (2000). Attitudes of Illinois agriscience students and their parents toward agriculture and agricultural education programs. Journal of Agricultural Education, 41(3), 50-59. doi: 10.5032/jae.2000.03050

Pate, M., Warnick, B., \& Meyers, T. (2012). Determining the critical skills beginning agriculture teachers need to successfully teach welding. Career and Technical Education Research, 37(2), 171-184.

Perry, D. K., Williams, R. L., \& Anderson, R. G. (2012). Safety conditions and practices in secondary agricultural mechanics programs. Journal of Agricultural Systems, Technology, and Management, 23, 45-55.

Peterson, K. D., Wahlquist, C., \& Bone, K. (2000). Student surveys for school teacher evaluation. Journal of Personnel Evaluation in Education, 14(2), 135-153.

Phipps, L.J. (1980). Handbook pi agricultural education in the public schools. Danville, IL:Interstate Printers and Publishers, Inc.

Phipps, L. J., Osborne, E. W., Dyer, J. E., \& Ball A. (2008). Handbook on agricultural education in public schools (6th ed.). Clifton, New York: Delmar. 
Rasty, J., Anderson, R. G., \& Paulsen, T. H. (2017). How the Quantity of Agricultural Mechanics Training Received at the Secondary Level Impact Teacher Perceived Importance of Agricultural Mechanics Skills. Journal of Agricultural Education, 58(1). 36-53

Reivich, K., \& Shatte, A. (2002). The resilience factor: 7 keys to finding your inner strength and overcoming life's hurdles. New York, NY: Broadway Books.

Sapolsky, R. M. (1994). Why zebras don't get ulcers. New York: WH Freeman.

Saucier, P. R., \& Krysher, S. (2014). Selected Factors Influencing Missouri School-Based Agricultural Educators to Instruct Agricultural Mechanics Curriculum. Journal of Agricultural Systems, Technology, and Management, 25, 1-11.

Saucier, P. R., \& McKim, B. R. (2011). Assessing the Learning Needs of Student Teachers in Texas regarding Management of the Agricultural Mechanics Laboratory: Implications for the Professional Development of Early Career Teachers in Agricultural Education. Journal of agricultural education, 52(4), 2443.

Saucier, P. R., \& McKim, B. R. (2014). Safety in the Agricultural Mechanics Laboratory: A Needs Assessment of Tennessee School-Based Agricultural Educators. Journal of Agricultural Systems, Technology, and Management, 25, 12-25.

Saucier, P. R., McKim, B. R., \& Tummons, J. D. (2012). A Delphi approach to the preparationof early-career agricultural educators in the curriculum area of agricultural mechanics: Fully qualified and highly motivated or status quo?. Journal of Agricultural Education, 53(1), 136-149.

Saucier, P. R., McKim, B. R., Terry, R., \& Schumacher, L. G. (2014). A performance competence-based needs assessment of Missouri school-based agricultural educators in agricultural mechanics laboratory management. Journal of Agricultural Systems, Technology, and Management, 25, 26-43.

Saucier, P. R., Terry, R., \& Schumacher, L. G. (2009). Laboratory management inservice needs of Missouri agricultural educators. Proceedings of the Southern Region Conference of the American Association for Agricultural Education, 176192. Retrieved from http://aaaeonline.org/uploads/allconferences/Proceedin gs_AAAESR_2009.pdf

Saucier, P. R., Vincent, S. K., \& Anderson, R. G. (2011). Agricultural mechanics laboratory safety: Professional development needs of Kentucky school-based agricultural educators. Paper presented at the 2011 American Association for Agricultural Education Conference. 
Saucier, R. P., Vincent, S. K., \& Anderson, R. G. (2014). Laboratory safety needs of Kentucky school-based agricultural mechanics teachers. Journal of Agricultural Education, 55(2), 184-200.

Schlautman, N. J., \& Silletto, T. A. (1992). Analysis of laboratory management competencies in Nebraska agricultural education programs. Journal of Agricultural Mechanics. 33(4). 2-8.

Schumacher, L. G., \& Johnson, D. M. (1990). Time series analysis of agricultural education student teachers' perceptions of agricultural mechanics lab management competencies. Journal of Agricultural Education, 31(4), 2-8.

Shinn, G. (1987). September - the time to improve your laboratory teaching. The Agricultural Education Magazine, 60(3), 16-17.

Shinn, G. C. (1998). Transforming Agricultural Mechanics Curriculum through Expert Opinion to Model Technologies in Food, Environmental, and Natural Resource Systems.

Shoulders, C. W., \& Myers, B. E. (2012). Teachers' Use of Agricultural Laboratories in Secondary Agricultural Education. Journal of Agricultural Education, 53(2), 124138.

Sorensen, T. J., \& McKim, A. J. (2014). Perceived Work-Life Balance Ability, Job Satisfaction, and Professional Commitment among Agriculture Teachers. Journal of Agricultural Education, 55(4), 116-132. doi: 10.5032/jae.2014.04116

Spielberger, C. D., \& Vagg, P. R. (1999). Job Stress Survey: Assessing perceived severity and frequency of occurrence of generic sources of stress in the workplace. Journal of Occupational Health Psychology, 4(3), 288-292.

Stone, R. T., McLaurin, E., Zhong, P., \& Watts, K. P. (2013). Full virtual reality vs. integrated virtual reality training in welding. Welding Journal, 92(6), 167S.

Stone, R. T., Watts, K. P., \& Zhong, P. (2011). Virtual reality integrated welder training. Welding Journal, 90(7), 136s.

Stone, R. T., Watts, K. P., Zhong, P., \& Wei, C. S. (2011). Physical and cognitive effects of virtual reality integrated training. Human factors, 53(5), 558-572.

Straquadine, G. S. (1990). Work, is it your drug of choice? The Agricultural Education Magazine, 62, 11-12.

Stringham, B., \& Swan, B. G. (2012). Model Tractor Teaching Tool. Journal of Agricultural Systems, Technology, and Management, 23, 1-12. 
Tait, M. (2008). Resilience as a contributor to novice teacher success, commitment, and retention. Teacher Education Quarterly, 35(4), 57-75.

Thieman, E. B., Henry, A. L., \& Kitchel, T. (2012). Resilient Agricultural Educators: Taking Stress to the Next Level. Journal of Agricultural Education, 53(1), 81-94.

Torres, R. M., Lambert, M. D., \& Tummons, J. D. (2012). The influence of time management practices on job stress among beginning secondary agriculture teachers. Journal of Agricultural Education, 53(1), 45-56. doi: 10.5032/jae.2012.01045

Torres, R. M., Lawver, R. G., \& Lambert, M. D. (2009). Job-related stress among secondary agricultural education teachers: A comparison study. Journal of Agricultural Education, 50(3), 100-111. doi: 10.5032/jae.2009.03100

Tummons, J. D., Langley, G. C., Reed, J. J. \& Paul, E. M. (2016). Concerns of female preservice teachers in teaching and supervising the Agricultural Mechanics Laboratory. Proceedings of the National AAAE Research Conference, Kansas City, $M O$.

Vandenberghe, R., \& Huberman, A. M. (1999). Understanding and preventing teacher burnout: A sourcebook of international research and practice. Cambridge, U.K.: Cambridge University Press.

Virnich, K., Wissing, K., Wirsching, M., Schaarschmidt, U., Bauer, J., Stamm, A., \& Mueller, U. (2006). Correlation between burnout syndrome and psychological and psychosomatic symptoms among teachers. International Archives of

Occupational and Environmental Health, 79(3), 199-204. doi: 10.1007/s00420005-0050-y

Walker, W. D., Garton, B. L., \& Kitchel, T. J. (2004). Job satisfaction and retention of secondary agriculture teachers. Journal of Agricultural Education, 45(2), 28-38. doi:10.5032/jae. 2004.02028

Wells, T., Perry, D. K., Anderson, R. G., Shultz, M. J., \& Paulsen, T. H. (2013). Does prior experience in secondary agricultural mechanics affect pre-service agricultural education teachers' intentions to enroll in post-secondary agricultural mechanics coursework. Journal of Agricultural Education, 54(4), 222-237.

Woodford, C. M., Lawrence, L. D., Bartrug, R., Center, A. M. V. A., \& Virginia, W. (1993). Hearing loss and hearing conservation practices in rural high school students. Journal of Agricultural Education, 34(4), 1-7. 


\section{Vita}

Jeff Reed was born in Mount Pleasant, Texas in June 1985. Jeff was an active member of the Winona FFA, where he earned the Lone Star FFA. Jeff graduated from Winona High School in 1985. Jeff served in the United States Marine Corps from August 2003-March 2009, where he earned the rank of Staff Sergeant. Jeff graduated from Texas A\&M University with a BS in Agricultural Education in 2011. Jeff completed his Masters of Education with Texas A\&M University in 2012, when he began teaching high school agriculture classes in Hillsboro, Texas. Jeff currently manages a row crop and cattle farm in Williamsville, Missouri with his wife Andrea. 